\title{
Advanced glycation and type 1 diabetes
}

Citation for published version (APA):

Nin, J. W. M. (2012). Advanced glycation and type 1 diabetes. [Doctoral Thesis, Maastricht University]. Maastricht University. https://doi.org/10.26481/dis.20120607jn

Document status and date:

Published: 01/01/2012

DOI:

10.26481/dis.20120607jn

Document Version:

Publisher's PDF, also known as Version of record

\section{Please check the document version of this publication:}

- A submitted manuscript is the version of the article upon submission and before peer-review. There can be important differences between the submitted version and the official published version of record.

People interested in the research are advised to contact the author for the final version of the publication, or visit the DOI to the publisher's website.

- The final author version and the galley proof are versions of the publication after peer review.

- The final published version features the final layout of the paper including the volume, issue and page numbers.

Link to publication

\footnotetext{
General rights rights.

- You may freely distribute the URL identifying the publication in the public portal. please follow below link for the End User Agreement:

www.umlib.nl/taverne-license

Take down policy

If you believe that this document breaches copyright please contact us at:

repository@maastrichtuniversity.nl

providing details and we will investigate your claim.
}

Copyright and moral rights for the publications made accessible in the public portal are retained by the authors and/or other copyright owners and it is a condition of accessing publications that users recognise and abide by the legal requirements associated with these

- Users may download and print one copy of any publication from the public portal for the purpose of private study or research.

- You may not further distribute the material or use it for any profit-making activity or commercial gain

If the publication is distributed under the terms of Article $25 \mathrm{fa}$ of the Dutch Copyright Act, indicated by the "Taverne" license above, 
Advanced glycation and type 1 diabetes 
(c) Johanna W.M. Nin, Maastricht 2012

Layout: Tiny Wouters

Cover: Johanna Nin

Production: GVO drukkers \& vormgevers B.V. | Ponsen \& Looijen

ISBN: 978-90-6464-557-0

Financial support by the Dutch Diabetes Research Foundation for the publication of this thesis is gratefully acknowledged. 


\section{Advanced glycation and type 1 diabetes}

\section{PROEFSCHRIFT}

ter verkrijging van de graad van doctor aan de Universiteit Maastricht, op gezag van de Rector Magnificus, Prof. mr. G.P.M.F. Mols, volgens het besluit van het College van Decanen, in het openbaar te verdedigen op donderdag 7 juni 2012 om 14:00 uur

door

Johanna W.M. Nin 


\section{Promotores}

Prof. dr. C.D.A. Stehouwer

Prof. dr. C.G. Schalkwijk

\section{Copromotores}

Dr. I. Ferreira

\section{Beoordelingscommissie}

Prof. dr. C.P. van Schayck (voorzitter)

Prof. dr. A. Bierhaus, University of Heidelberg, Heidelberg, Germany Prof. dr. W.A. Buurman

Prof. dr. J.M. Dekker, VU Medisch Centrum, Amsterdam, Nederland Prof. dr. N.C. Schaper 


\section{Contents}

$\begin{array}{lll}\text { Chapter } 1 & \text { General introduction } & 7\end{array}$

Chapter 2 Levels of soluble RAGE are cross-sectionally associated with 27 cardiovascular disease risk in type 1 diabetes and this association is partially mediated by endothelial and renal dysfunction and lowgrade inflammation: The EURODIAB Prospective Complications Study (PCS)

Chapter 3 Higher plasma SRAGE levels are associated with incident cardiovascular morbidity and mortality as well as all-cause mortality in type 1 diabetes: a 12-yr follow-up study

Chapter 4 Higher plasma levels of advanced glycation end products are associated with incident cardiovascular disease and all-cause mortality in type 1 diabetes: a 12-yr follow-up study

Chapter 5 Serum high-mobility group box-1 levels are positively associated with micro- and macroalbuminuria, but not with cardiovascular disease in type 1 diabetes: the EURODIAB Prospective Complications Study

Chapter 6 Higher plasma HMGB1 levels are associated with incident cardiovascular disease and all-cause mortality in type 1 diabetes: a 12-yr follow-up study

Chapter 7 Pulse pressure partially explains the higher incident cardiovascular 105 disease associated with low-grade inflammation and pentosidine in type 1 diabetes: a 12-yr follow-up study

Chapter 8 Summary and General discussion

Samenvatting

Dankwoord

Curriculum vitae

Abbreviations 



\section{Chapter 1}

General introduction 
Chapter 1 
Type 1 diabetes is a chronic disease, which commonly presents itself in childhood or in adolescence. Type 1 diabetes is characterised by hyperglycaemia and results from (auto-immune) destruction of insulin-producing beta cells clustered in the islets of Langerhans of the pancreas, resulting in mostly absolute insulin deficiency requiring daily insulin treatment. Symptoms caused by hyperglycaemia include polyuria, polydipsia, weight loss, vision changes, and fatigue (1). The incidence of childhood type 1 diabetes varies worldwide from $0.1 / 100,000$ per year in Zunyi, China to $36.8 / 100,000$ per year in Sardinia, Italy (2). In The Netherlands the incidence of type diabetes is estimated to be $13 / 100,000$ per year in children $\leq 14$ years of age (2). The incidence of type 1 diabetes seems to be increasing in all age groups, especially in younger children (3-6), with an overall annual increase of $\sim 3.9 \%$ estimated from 20 population-based registers in 17 European countries in the period 1989-2003 (5). The reasons for this increasing incidence are unknown, but probably involve environmental factors (7). Despite extensive research (8-11), type 1 diabetes cannot be prevented or cured with current available treatments, such as immunotherapy (12), stem cell therapy (10) or transplantation of islets of Langerhans (8).

Worldwide there are $\sim 22$ million patients with type 1 diabetes and this is predicted to double in the next 20-30 years $(1,13)$. In The Netherlands the current prevalence of type 1 diabetes is estimated to be $100,000(14,15)$. The burden of diabetes for patients as well as for the society is mainly caused by diabetes-related short- and long-term complications, illustrated by a 4-fold increase in the risk of cardiovascular disease in type 1 diabetes (16), and a $\sim$-fold and $\sim 17$-fold increase in risk for mortality from heart disease in men and women, respectively, who had type 1 diabetes and were younger than 40 years of age (17). In addition, diabetes-related microvascular complications (i.e. diabetic retinopathy and nephropathy) result in impaired vision and kidney function, which lead to higher morbidity in patients with type 1 diabetes. Diabetic retinopathy and diabetic nephropathy are present in $\sim 45 \%$ and $\sim 30 \%$, respectively, of the patients with type 1 diabetes after a duration of diabetes of $\sim 13$ years (18). Another late complication of diabetes is diabetic neuropathy, which is present in $\sim 42 \%$ of the patients with type 1 diabetes after a duration of $\geq 15$ years (19). Diabetic neuropathy can be divided into distal symmetric sensorimotor polyneuropathy, autonomic neuropathy, and focal mononeuropathy, of which distal symmetric sensorimotor polyneuropathy is the most common form. Furthermore, the need for insulin treatment also imposes on patients the risk of hypoglycaemia, which is an unpredictable and potentially dangerous side effect of insulin therapy. An observational study in six UK secondary care diabetes centres reported that the incidences of self-reported mild hypoglycaemic events that could be self-treated and severe hypoglycaemic events that needed help for recovery were 36 and 1.1 episodes per patient-year, respectively, in patients with type 1 diabetes and $<5$ years disease duration (20). The incidences of self-reported mild and severe hypoglycaemic events in patients with type 1 diabetes and $>15$ years disease duration were 29 and 3.2 episodes per patient-year, respectively (20). Besides these complications and the daily 
insulin injections, the burden of diabetes for patients is further increased by the need for continuous self-management to achieve self-directed behavioural changes to reduce their risk of short- and long-term complications. Because the prevalence of type 1 diabetes and the incidence op childhood type 1 diabetes are increasing, the health care costs related to anti-diabetic medication as well as treatment of the diabetes-associated complications are also increasing (21).

Cardiovascular diseases include four main clinical categories: coronary heart diseases, cerebrovascular disease, peripheral artery disease, and aortic atherosclerosis or aneurysm. Cardiovascular diseases result from arterial stiffening (i.e. arteriosclerosis) and atherothrombosis. Ageing is the dominant process altering arterial stiffness (22). Ageing-associated loss of elasticity in the arteries results from intrinsic structural alterations of the arterial wall (e.g. alteration of medial elastin) $(22,23)$. Arterial stiffening leads to an impaired cushioning function of the major arteries, which will increase pulse wave velocity and cause an early return of the pressure waves in late systole instead of early diastole $(22,24,25)$. Therefore, systolic blood pressure will increase, which will increase the cardiac afterload and oxygen demand. In addition, the decrease in diastolic blood pressure will impair coronary filling. Atherothrombosis is a focal arterial progressive disease starting with the formation of fatty streaks that may develop into atherosclerotic plaques $(26,27)$. Symptomatic complications occur when the lumen of the artery is occluded by the atherosclerotic plaque itself or by the thrombus formed when a plaque ruptures $(27,28)$.

Diabetic retinopathy can be classified into two groups: background/nonproliferative and proliferative retinopathy (29). Non-proliferative retinopathy is characterised by retinal vascular microaneurysms, blot haemorrhages, and cotton wool spots (29). This form of retinopathy can progress into more extensive disease with further pericyte loss, increase in retinal vascular permeability, and abnormal changes in retinal blood flow and vasculature, all of which contribute to retinal ischaemia (30). Neovascularisation in response to severe retinal ischaemia characterises proliferative retinopathy (30).

The development of diabetic nephropathy starts with hemodynamic alterations in the renal microcirculation, characterised by glomerular hyperperfusion and renal hypertrophy in the first years of the disease. Initially the glomerular filtration rate increases due to these changes, but will return to normal when the processes of glomerular basement membrane thickening, glomerular hypertrophy, and mesangial volume expansion set in (31). Diabetic nephropathy is characterised by albuminuria, which can be classified into micro- and macroalbuminuria. Microalbuminuria is defined as an albumin excretion of 30 to $300 \mathrm{mg} / \mathrm{d}$ in a 24-h urine collection, and macroalbuminuria is defined as an albumin loss of $>300 \mathrm{mg} / \mathrm{d}$ in a $24-\mathrm{h}$ urine collection (32). The early abnormalities in albumin excretion may be reversible, but once it progresses to overt macroalbuminuria, the changes are likely to be irreversible and glomerular filtration rate will steadily decrease and in 10 years $\sim 25 \%$ of these 
patients will reach end stage renal disease (33). However, reduced glomerular filtration rate can also be present in patients with persistent normoalbuminuria $(34,35)$, and rapid loss of glomerular filtration rate can occur in patients with normoor microalbuminuria $(36,37)$.

For the prevention and/or treatment of these diabetes-related complications, the underlying cellular and molecular mechanisms that could link hyperglycaemia to the development of micro- and macrovascular complications in patients with type 1 diabetes need to be better elucidated (26). This thesis focuses on the potential roles of advanced glycation endproducts (AGEs) and their receptor (RAGE), high-mobility group box-1 (HMGB1), endothelial and renal dysfunction, chronic low-grade inflammation, and accelerated arterial stiffening.

\section{Advanced glycation endproducts (AGEs)}

Non-enzymatic glycation is a chemical post-translational modification of proteins, lipids and nucleic acids and is a major cause of spontaneous damage to cellular and extracellular components in physiological systems. Although glycation is a naturally occurring process, increased glycation and the resulting formation of AGEs occur under physiological circumstances with ageing (38) and is implicated in many diseases such as diabetes. The non-enzymatically reaction known as the Maillard reaction results in irreversible AGEs via the formation of reversible Schiff bases and Amadori products $(38,39)$, as illustrated in Figure 1.1 . The early steps of this glycation process are (glucose) concentration dependent which is, thus, enhanced in diabetes $(38,39)$. The formation of AGEs is also enhanced in conditions of elevated oxidative stress and inflammation (39). The reversible nature of the early glycation products, Schiff bases and Amadori products, prevents accumulation of these products. However, these early glycation products can undergo a slow process of further rearrangements to form irreversible AGEs (Figure 1.1), which comprise a heterogeneous group with different characteristics (38-40).

Serum AGEs were found to be higher in patients with type 1 diabetes compared with controls $(41,42)$. Several studies so far have reported positive associations between various circulating AGEs and micro- (42-44) and macrovascular complications $(45,46)$, or surrogates thereof $(47)$, in patients with type 1 diabetes, but most of these were limited by their cross-sectional study design (42-46). The few prospective studies investigating AGEs, or markers thereof, in patients with type 1 diabetes have reported skin autofluorescence (48), as a potential marker of tissue AGEs levels, and AGEmodified LDL in immune complexes (47) to be positively associated with cardiac mortality (48) and progression of carotid intima-media thickness (47), respectively. However, so far, no prospective studies have investigated the associations between plasma AGEs and incident cardiovascular complications in patients with type 1 diabetes. 


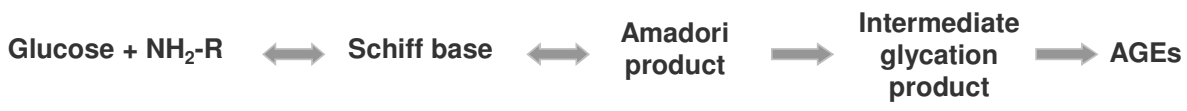<smiles>[R]NCC(=O)C(=O)C(O)C(O)CO</smiles>

AGEs

Ne-(carboxyethyl)lysine<smiles>CC(NCCCCCC(=O)O)C(=O)O</smiles>

$\mathrm{N} \varepsilon$-(carboxymethyl)lysine

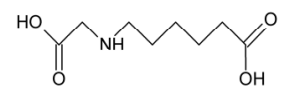

Pentosidine

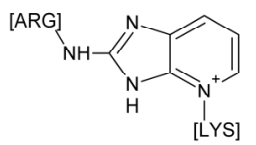

Figure 1.1 Formation of AGEs by the Maillard reaction. Reducing sugars, such as glucose, react nonenzymatically with amino groups in proteins, lipids, and nucleic acids through a series of reactions forming Schiff bases and Amadori products to produce AGEs. Structures of the wellcharacterised AGEs, CEL, CML, and pentosidine, are given.

AGEs affect cells in three general ways: 1) cellular functions can be altered when intracellular proteins are modified to AGEs, 2) modification of extracellular matrix proteins to AGEs resulting in abnormal interactions between these proteins, and 3) circulating AGEs can bind to AGE receptors, which could induce receptor-mediated production of reactive oxygen species and activate transcription factor nuclear factor$\mathrm{KB}(\mathrm{NF}-\mathrm{KB}$ ), thereby leading to deleterious changes in cellular processes (39) (Figure 1.2). Several $A G E$ receptors have been identified, including macrophage scavenger receptors type I and II (49), oligosaccharyltransferase-48 (50), 80K-H phosphoprotein (50), galectin-3 (51), CD36 (52), LOX-170 (53), and RAGE (54). So far the AGE receptor that has been best-characterised and most frequently studied is RAGE.

\section{Receptor for advanced glycation endproducts (RAGE)}

RAGE $(55 \mathrm{kD})$ is a multi-ligand member of the immunoglobulin superfamily of cell surface molecules and under physiological conditions it is mainly expressed in the 
lungs, though its expression occurs in multiple tissues (56). The cell types that express RAGE include endothelial, monocytes/macrophages, T-lymphocytes, neuronal and glomerular epithelial cells $(56,57)$. RAGE consists of three specific domains including an extracellular, transmembrane, and an intracellular cytoplasmic domain. The extracellular domain has a V-type immunoglobulin domain, in which the ligand binding site is located, and two C-type domains (C1 and C2) (58,59). However, the $\mathrm{V}$-domain may not act independently in ligand binding, but needs to integrate with the C1-domain into one unit (60). In addition, RAGE does not act as a monomeric receptor, but rather oligomerises to acquire high affinity in binding ligands (61).

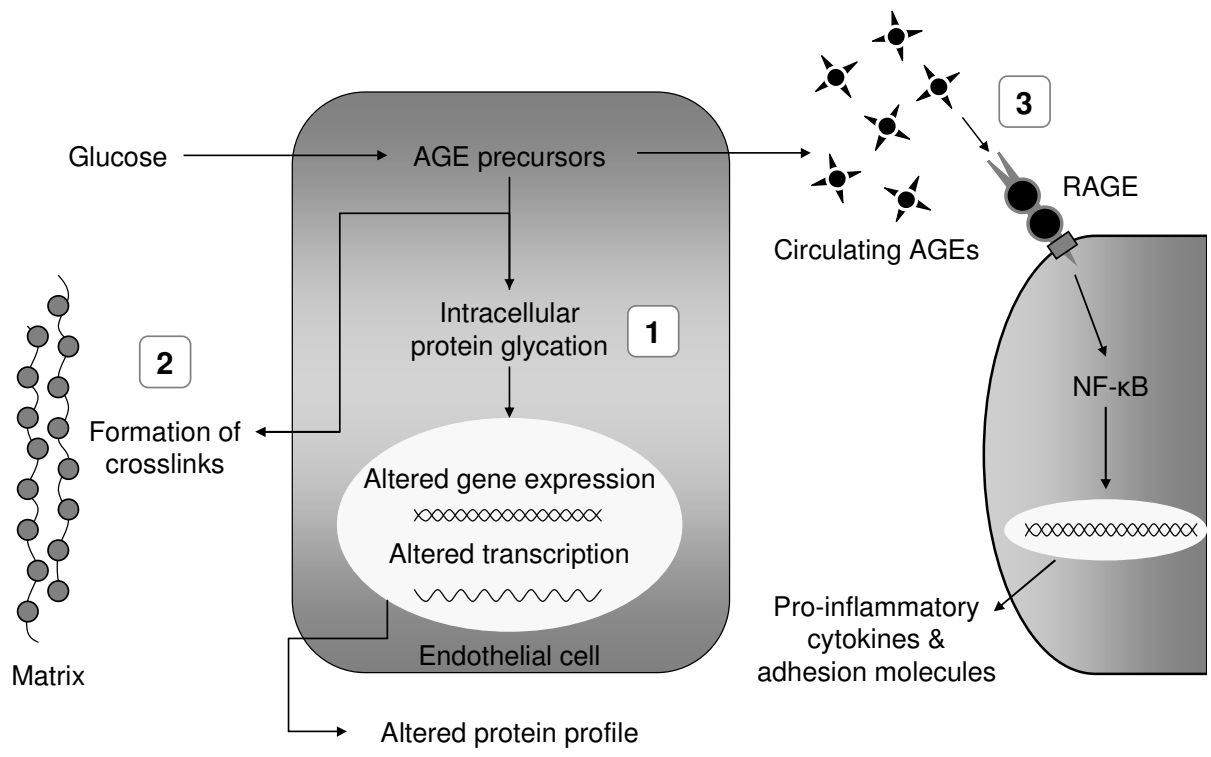

Figure 1.2 Mechanisms by which AGEs and its precursors exert unfavourable effects. Covalent modification of intracellular proteins by AGE precursors alters several cellular functions (1). Modification of extracellular matrix proteins causes abnormal interactions with other matrix proteins and with integrins (2). Modification of plasma proteins by AGE precursors creates ligands that bind to AGE receptors, inducing changes in gene expression (3). (Figure adapted from Brownlee et al. Nature 2001) (55).

Various downstream cellular signalling pathways have been identified, including p21ras, extracellular signal-regulated kinase (ERK) 1/2, p38 and SAPK/JNK MAP kinases, rho GTPases, phosphoinositol-3 kinase, and the JAK/STAT pathway $(40,62)$, while the proximal signalling proteins, which actually bind to the cytoplasmic domain of RAGE, still need to be identified (62). The diverse RAGE-induced signalling pathways could imply that these may be ligand-specific. 
Binding of AGEs to RAGE activates diverse cellular processes, including tubular epithelial-myofibroblast transdifferentiation (63) and glomerular sclerosis (57) in diabetic nephropathy, increases in generation of pro-inflammatory cytokines and expression of adhesion molecules $(64,65)$, migration of mononuclear phagocytes (66), increases in vascular hyperpermeability to macromolecules (67), and increases in cytosolic reactive oxygen species production and mitochondrial oxidase activity (68).

These RAGE-associated cellular processes could contribute to endothelial and renal dysfunction, low-grade inflammation and arterial stiffening $(57,58,64,65)$, all of which may explain, at least in part, the increased cardiovascular morbidity and mortality in diabetes. Recent studies $(62,69,70)$ have suggested a potential role of RAGE in the development of vascular disease in diabetes mellitus. Indeed, at the molecular level, RAGE has been shown to be upregulated in atherosclerotic lesions in diabetes (69).

In addition to the membrane-bound form, soluble forms of RAGE can be detected in plasma. These soluble forms result from alternative splicing (71) or from proteolytical cleavage of the membrane-bound RAGE (72) (Figure 1.3). The functional role of these soluble forms of RAGE in the circulation remains unclear, but they may reflect RAGE expression.

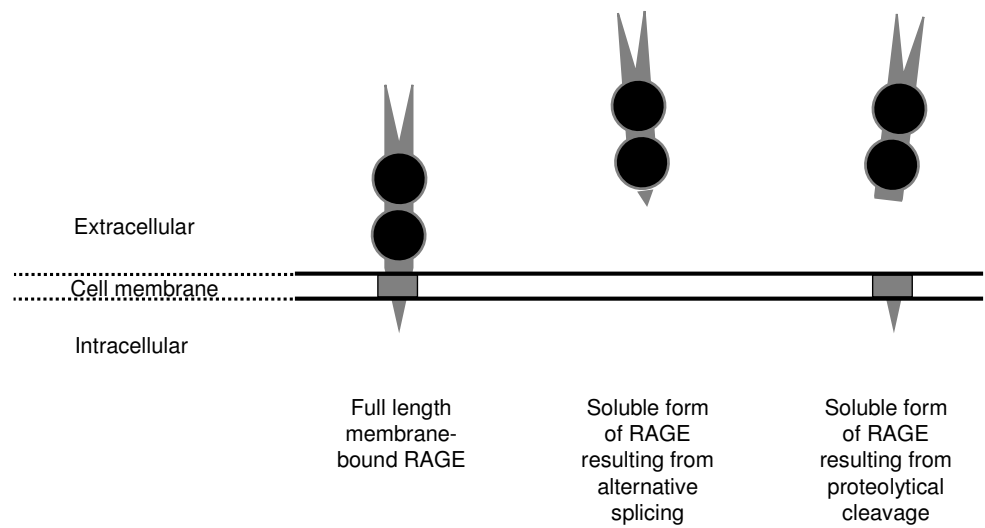

Figure 1.3 Different forms of RAGE. In addition to the membrane-bound form, soluble forms of RAGE can be detected in plasma. These soluble forms result from alternative splicing or from proteolytical cleavage of the membrane-bound RAGE. 


\section{High-mobility group box 1 (HMGB1)}

Besides AGEs, RAGE can also be activated by other ligands, which include amyloid- $\beta$ peptide (73), amyloid A (74), members of the S100/calgranulin family (75), and HMGB1 (76). HMGB1 is a multifunctional nuclear DNA-binding protein that facilitates gene transcription (77). Extracellular HMGB1 released from necrotic cells (78) as well as from immune cells upon inflammatory stimuli (79) functions as a pro-inflammatory cytokine (80), which elicits pro-inflammatory responses from macrophages and endothelial cells (81). Extracellular effects of HMGB1 are mediated by its binding to RAGE, but also, at least in part, by its binding to the receptors of the toll-like receptors family (82).

HMGB1-induced production of adhesion molecules and inflammatory cytokines may contribute to the increased risk of vascular complications in diabetes, which is supported by the findings that HMGB1 expression is higher in the cytoplasm of renal tissue of diabetic rats compared with control rats (83), and that kidney HMGB1 levels were associated with the presence and severity of diabetic nephropathy in rats (84). Three cross-sectional studies have investigated the associations between HMGB1 and cardiovascular outcomes in humans. These have reported higher levels of HMGB1 in patients with stable or unstable angina pectoris (85), with type 2 diabetes and coronary artery disease (86), and with heart failure (87) as compared with controls. In addition, one of these studies has also shown that individuals with heart failure at study entry who died during the follow-up of two years had higher levels of HMGB1 at baseline compared with the survivors (87). So far, no study has investigated the potential association of HMGB1 with vascular complications in patients with type 1 diabetes.

\section{Potential mediating mechanisms through which AGE-RAGE axis could lead to increased risk of vascular complications}

\section{Endothelial dysfunction}

The endothelium is the inner layer of blood vessels and it plays an important role in the regulation of vascular tone and permeability as well as inflammatory processes in the vessel wall (88). Endothelial dysfunction is involved in the development of atherothrombosis and its progression (89). Risk factors for atherothrombotic disease may induce endothelial activation and subsequently endothelial dysfunction, characterised by an imbalance between vasodilators and vasoconstrictors, elevated expression of adhesion molecules, increased permeability, decreased anticoagulant activity, and altered extracellular matrix synthesis (89). Circulating adhesion molecules (e.g. soluble intercellular adhesion molecule, soluble vascular cell adhesion molecule, 
and soluble E-selectine) and other endothelium-derived factors (e.g. von Willebrand factor) may reflect the degree of endothelial activation/dysfunction (89).

Compared to controls, it has been reported that patients with type 1 diabetes have higher levels of circulating adhesion molecules $(90,91)$, and other endotheliumderived factors (91). In addition, it has been shown that markers of endothelial dysfunction are positively associated with the presence of micro- and macrovascular complications (92,93), progression of carotid intima-media thickness (92), and incident coronary artery disease (94) in patients with type 1 diabetes. However, in a prospective study after adjustment for conventional cardiovascular risk factors no association could be found between endothelial dysfunction markers and incident cardiovascular morbidity and mortality (95).

\section{Low-grade inflammation}

Atherosclerosis is thought to be an inflammatory disease and involves immune responses in every phase of the disease (96). Accumulation of immune cells and lipid droplets, and the formation of foam cells belong to the early stages in the development of atherosclerotic lesions (96). In general, pro-inflammatory cytokines produced by the immune cells will activate macrophages and endothelial cells, increase production of other inflammatory cytokines, elevate expression of adhesion molecules, prompt the tendency for thrombus formation, and inhibit collagen production (97).

Markers of low-grade inflammation (e.g. c-reactive protein and interleukin-6) have been reported to be higher in patients with type 1 diabetes than in controls without type 1 diabetes $(91,98,99)$. In addition, various markers of low-grade inflammation (i.e. c-reactive protein, tumour necrosis factor- $\alpha$, interleukin-6, and secreted phospholipase A2) have been positively associated with higher prevalence of micro$(100,101)$ and macrovascular complications (102), carotid intima-media thickness (103), as well as incident fatal and non-fatal CVD (95) in type 1 diabetes. In contrast, it has also been reported that c-reactive protein was not associated with nephropathy and carotid intima-media thickness in a large cohort among patients with type 1 diabetes (92).

\section{Accelerated arterial ageing (arterial stiffening)}

Arterial stiffness leads to an increase in systolic blood pressure, because hearts ejecting into a stiffer arterial bed must generate higher end-systolic pressures for the same net stroke volume. This leads to increased arterial pressure and volume during systole, causing a reduced arterial volume at the onset of diastole, which in turn causes an enhanced fall in diastolic blood pressure $(22,104)$. Systolic blood pressure increases with age, while diastolic blood pressure decreases, in particular, from the $5^{\text {th }}$ decade onwards (22). Therefore, pulse pressure (calculated by systolic minus diastolic blood pressure) increases with age and is a marker of arterial stiffness $(22,25)$. 
However, in type 1 diabetes the increases in pulse pressure with ageing occurs 10-15 years earlier (105), which illustrates the process of accelerated arterial ageing in these patients. Importantly, higher pulse pressure is associated with increased risk of incident CVD in type 1 diabetes $(18,106)$.

\section{Renal dysfunction}

Renal dysfunction can be evaluated by a decrease in glomerular filtration rate and/or by the presence of albuminuria reflecting increased glomerular permeability. Patients with severe chronic kidney disease are more likely to die of cardiovascular disease than of kidney failure $(107,108)$. The highly increased incidence of CVD was first demonstrated in patients who need dialysis treatment. However, the adverse association between renal dysfunction and CVD is not limited to the dialysis population, but applies across various degrees (including the mildest degrees) of kidney dysfunction (107). Mechanisms through which renal dysfunction could lead to increased risk of CVD include activation of the renin-angiotensin aldosterone system, oxidative stress, elevated asymmetric dimethyl arginine (ADMA), increased circulating pro-inflammatory cytokines, and dyslipidaemia (107).

However, whether renal dysfunction is causally linked to cardiovascular disease remains to be elucidated (109). Alternatively, renal function may be a risk marker of cardiovascular disease, or renal dysfunction and cardiovascular disease may be caused by a common risk factor or pathophysiological mechanisms (e.g. endothelial dysfunction) (109).

\section{Aim of this thesis}

The increasing prevalence of type 1 diabetes and its related vascular complications pose a tremendous burden for patients and our society. However, the pathophysiological mechanisms underlying the development of these vascular complications still need to be better elucidated. Several potential cellular and molecular mechanisms have been proposed that could explain the link between diabetes and the development of vascular complications. These could constitute new targets in the prevention and/or treatment of vascular complications in these patients.

We have investigated these issues (Figure 1.4.) in two cohort studies; a crosssectional nested case-control study (EURODIAB) (110), and a prospective study (Steno Diabetes Center) (111), which will be described in detail in the specific chapters. Briefly, the cross-sectional case-control study $(n=543)$ is a follow-up of the EURODIAB IDDM complications study, of which baseline investigations were performed between 1989 and 1991 on 3,250 patients with diabetes mellitus type 1 . The patients were recruited from 31 centres in 16 European countries. These patients were invited for a 
follow-up examination on average 7-9 years after the baseline examinations. Of the 3,250 included patients, $1,880(57.8 \%)$ returned for re-examination. At follow-up, a cross-sectional nested case-control study of markers of inflammation and endothelial dysfunction and their associations with vascular complications was performed. Cases were selected as those with greatest vascular complication burden as possible and controls were selected as those who were completely free of any complications (i.e. with no evidence of CVD, albuminuria, and retinopathy). In the prospective cohort study, 199 patients with type 1 diabetes and nephropathy and 192 with normoalbuminuria were recruited from the outpatient clinic at the Steno Diabetes Center in 1993. All patients were followed to the last visit at Steno Diabetes Center, until 1 September 2006 or until death $(n=82)$ or emigration $(n=3)$. The primary study outcome was a combined end-point of fatal and non-fatal CVD and the study's secondary end-point was all-cause mortality.

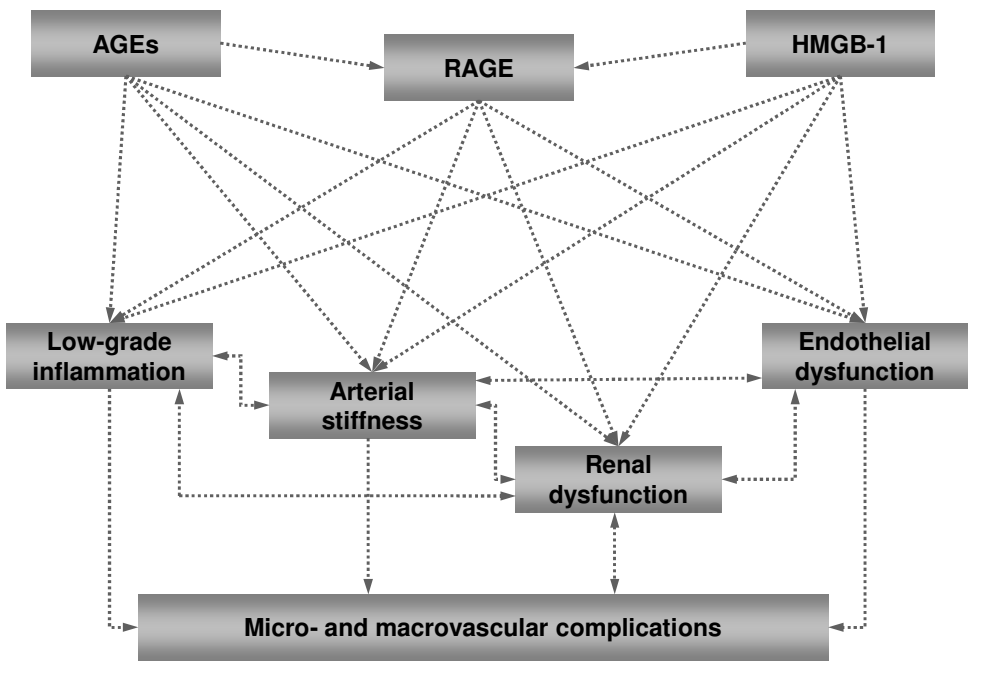

Figure 1.4 Potential pathophysiological mechanisms that could explain the link between diabetes and the development of vascular complications as hypothesised in the present thesis.

One of the proposed pathways that could link diabetes with the increased risk for vascular complications involves the AGE-RAGE axis. Circulating soluble RAGE may be a marker that reflects the AGE-RAGE axis and we have, therefore, investigated the associations between soluble RAGE (Chapters 2-3) and AGEs (Chapter 4) on the one hand and prevalence (Chapter 2) as well as incidence (Chapters 3-4) of cardiovascular complications in patients with type 1 diabetes. We have also investigated the 
associations between HMGB-1, a pro-inflammatory cytokine but also a ligand of RAGE, and cardiovascular complications (Chapters 5-6).

In addition, we have examined whether endothelial and renal dysfunction, lowgrade inflammation, and arterial stiffness could explain, in part, the potential associations between SRAGE, AGEs as well as HMGB-1 and cardiovascular complications in type 1 diabetes (Chapters 2-6).

Furthermore, patients with type 1 diabetes show signs of accelerated arterial ageing, which has been related to increased risk of cardiovascular disease in these patients. However, the role of arterial stiffness and its relation to other potential mechanisms (i.e. low-grade inflammation and cross-linking AGEs) that are related to increased risk of cardiovascular disease remain to be clarified. We have, therefore, investigated whether low-grade inflammation, pentosidine (a cross-linking AGE), and arterial stiffness were related to each other, and with incident cardiovascular disease in patients with type 1 diabetes (Chapter 7).

Finally, in Chapter 8 the present findings, limitations and implications will be discussed. 


\section{References}

1. Diabetes Mellitus fact sheet 312. World Health Organization: January 2011

2. Karvonen M, Viik-Kajander M, Moltchanova E, Libman I, LaPorte R, Tuomilehto J. Incidence of childhood type 1 diabetes worldwide. Diabetes Mondiale (DiaMond) Project Group. Diabetes Care 2000;23:1516-1526

3. Gale EA. The rise of childhood type 1 diabetes in the 20th century. Diabetes 51:3353-3361, 2002

4. Harjutsalo V, Sjoberg L, Tuomilehto J. Time trends in the incidence of type 1 diabetes in Finnish children: a cohort study. Lancet 2008;371:1777-1782

5. Patterson CC, Dahlquist GG, Gyurus E, Green A, Soltesz G. Incidence trends for childhood type 1 diabetes in Europe during 1989-2003 and predicted new cases 2005-20: a multicentre prospective registration study. Lancet 2009;373:2027-2033

6. van Wouwe JP, Mattiazzo GF, el Mokadem N, Reeser HM, Hirasing RA. [The incidence and initial symptoms of diabetes mellitus type 1 in 0-14-year-olds in the Netherlands, 1996-1999]. Ned Tijdschr Geneeskd 2004;148:1824-1829

7. Myers M, Zimmet P. Halting the accelerating epidemic of type 1 diabetes. Lancet 2008;371:1730-1731

8. de Kort H, de Koning EJ, Rabelink TJ, Bruijn JA, Bajema IM: Islet transplantation in type 1 diabetes. BMJ 2011;342:426-432

9. Eisenbarth GS. Update in type 1 diabetes. J Clin Endocrinol Metab 2007;92:2403-2407

10. McCall MD, Toso C, Baetge EE, Shapiro AM. Are stem cells a cure for diabetes? Clin Sci (Lond) 2010;118:87-97

11. Zhang L, Eisenbarth GS. Prediction and prevention of Type 1 diabetes mellitus. J Diabetes 2011;3: 48-57

12. Phillips B, Trucco M, Giannoukakis N. Current state of type 1 diabetes immunotherapy: incremental advances, huge leaps, or more of the same? Clin Dev Immunol Clin Dev Immunol. 2011;2011:432016

13. Wild S, Roglic G, Green A, Sicree R, King H. Global prevalence of diabetes: estimates for the year 2000 and projections for 2030. Diabetes Care 2004;27:1047-1053

14. Rijksinstituut voor Volksgezondheid en Milieu (RIVM). Diabetes in Nederland: Omvang, risicofactoren en gevolgen, nu en in de toekomst., 2007

15. Baan CA, Poos MJJC. Rijksinstituut voor Volksgezondheid en Milieu. Hoe vaak komt diabetes mellitus voor en hoeveel mensen sterven eraan? Volksgezondheid Toekomst Verkenning, Nationaal Kompas Volksgezondheid, 2011

16. Soedamah-Muthu SS, Fuller JH, Mulnier HE, Raleigh VS, Lawrenson RA, Colhoun HM. High risk of cardiovascular disease in patients with type 1 diabetes in the U.K.: a cohort study using the general practice research database. Diabetes Care 2006;29:798-804

17. Laing SP, Swerdlow AJ, Slater SD, Burden AC, Morris A, Waugh NR, Gatling W, Bingley PJ, Patterson CC. Mortality from heart disease in a cohort of 23,000 patients with insulin-treated diabetes. Diabetologia 2003;46:760-765

18. Schram MT, Chaturvedi N, Fuller JH, Stehouwer CD. Pulse pressure is associated with age and cardiovascular disease in type 1 diabetes: the Eurodiab Prospective Complications Study. J Hypertens 2003;21:2035-2044

19. Tesfaye S, Stevens LK, Stephenson JM, Fuller JH, Plater M, Ionescu-Tirgoviste C, Nuber A, Pozza G, Ward JD. Prevalence of diabetic peripheral neuropathy and its relation to glycaemic control and potential risk factors: the EURODIAB IDDM Complications Study. Diabetologia 1996;39:1377-1384

20. UK Hypoglycaemia Study Group. Risk of hypoglycaemia in types 1 and 2 diabetes: effects of treatment modalities and their duration. Diabetologia 2007;50:1140-1147

21. Passa P. Diabetes trends in Europe. Diabetes Metab Res Rev 2002;18 Suppl 3:S3-8

22. Safar ME, Levy BI, Struijker-Boudier H. Current perspectives on arterial stiffness and pulse pressure in hypertension and cardiovascular diseases. Circulation 2003;107:2864-2869

23. Avolio A, Jones D, Tafazzoli-Shadpour M. Quantification of alterations in structure and function of elastin in the arterial media. Hypertension 1998;32:170-175

24. Dart AM, Kingwell BA. Pulse pressure-a review of mechanisms and clinical relevance. J Am Coll Cardiol 2001;37:975-984 
25. Stehouwer CD, Henry RM, Ferreira I. Arterial stiffness in diabetes and the metabolic syndrome: a pathway to cardiovascular disease. Diabetologia 2008;51:527-539

26. Libby P, Nathan DM, Abraham K, Brunzell JD, Fradkin JE, Haffner SM, Hsueh W, Rewers M, Roberts BT, Savage PJ, Skarlatos S, Wassef M, Rabadan-Diehl C. Report of the National Heart, Lung, and Blood Institute-National Institute of Diabetes and Digestive and Kidney Diseases Working Group on Cardiovascular Complications of Type 1 Diabetes Mellitus. Circulation 2005;111:3489-3493

27. Beckman JA, Creager MA, Libby P. Diabetes and atherosclerosis: epidemiology, pathophysiology, and management. JAMA 2002;287:2570-2581

28. Boyle PJ. Diabetes mellitus and macrovascular disease: mechanisms and mediators. Am J Med 2007;120:S12-17

29. Watkins PJ. Retinopathy. BMJ 2003;326:924-926

30. Frank RN. Diabetic retinopathy. N Engl J Med 2004;350:48-58

31. Cooper ME. Pathogenesis, prevention, and treatment of diabetic nephropathy. Lancet 1998;352: 213-219

32. Eknoyan G, Hostetter T, Bakris GL, Hebert L, Levey AS, Parving HH, Steffes MW, Toto R. Proteinuria and other markers of chronic kidney disease: a position statement of the national kidney foundation (NKF) and the national institute of diabetes and digestive and kidney diseases (NIDDK). Am J Kidney Dis 42:617-622, 2003

33. Astrup AS, Tarnow L, Rossing P, Pietraszek L, Riis Hansen $\mathrm{P}$, Parving $\mathrm{HH}$. Improved prognosis in type 1 diabetic patients with nephropathy: a prospective follow-up study. Kidney Int 2005;68:1250-1257

34. Caramori ML, Fioretto $\mathrm{P}$, Mauer $\mathrm{M}$. Low glomerular filtration rate in normoalbuminuric type 1 diabetic patients: an indicator of more advanced glomerular lesions. Diabetes 2003;52:1036-1040

35. Molitch ME, Steffes M, Sun W, Rutledge B, Cleary P, de Boer IH, Zinman B, Lachin J. Development and progression of renal insufficiency with and without albuminuria in adults with type 1 diabetes in the diabetes control and complications trial and the epidemiology of diabetes interventions and complications study. Diabetes Care 2010;33:1536-1543

36. Perkins BA, Ficociello LH, Roshan B, Warram JH, Krolewski AS. In patients with type 1 diabetes and new-onset microalbuminuria the development of advanced chronic kidney disease may not require progression to proteinuria. Kidney Int 2010;77:57-64

37. Perkins BA, Ficociello LH, Ostrander BE, Silva KH, Weinberg J, Warram JH, Krolewski AS. Microalbuminuria and the risk for early progressive renal function decline in type 1 diabetes. J Am Soc Nephrol 2007;18:1353-1361

38. Brownlee M, Cerami A, Vlassara H. Advanced glycosylation end products in tissue and the biochemical basis of diabetic complications. N Engl J Med 1988;318:1315-1321

39. Goldin A, Beckman JA, Schmidt AM, Creager MA. Advanced glycation end products: sparking the development of diabetic vascular injury. Circulation 2006;114:597-605

40. Wautier JL, Schmidt AM. Protein glycation: a firm link to endothelial cell dysfunction. Circ Res 2004;95:233-238

41. Berg TJ, Dahl-Jorgensen K, Torjesen PA, Hanssen KF. Increased serum levels of advanced glycation end products (AGEs) in children and adolescents with IDDM. Diabetes Care 1997;20:1006-1008

42. Chiarelli F, Catino M, Tumini S, Cipollone F, Mezzetti A, Vanelli M, Verrotti A. Advanced glycation end products in adolescents and young adults with diabetic angiopathy. Pediatr Nephrol 2000;14:841-846

43. Fosmark DS, Berg JP, Jensen AB, Sandvik L, Agardh E, Agardh CD, Hanssen KF. Increased retinopathy occurrence in type 1 diabetes patients with increased serum levels of the advanced glycation endproduct hydroimidazolone. Acta Ophthalmol 2009;87:498-500

44. Miura J, Yamagishi S, Uchigata Y, Takeuchi M, Yamamoto H, Makita Z, Iwamoto Y. Serum levels of non-carboxymethyllysine advanced glycation endproducts are correlated to severity of microvascular complications in patients with Type 1 diabetes. J Diabetes Complications 2003;17:16-21

45. Berg TJ, Snorgaard O, Faber J, Torjesen PA, Hildebrandt P, Mehlsen J, Hanssen KF. Serum levels of advanced glycation end products are associated with left ventricular diastolic function in patients with type 1 diabetes. Diabetes Care 1999;22:1186-1190

46. Steine K, Larsen JR, Stugaard M, Berg TJ, Brekke M, Dahl-Jorgensen K. LV systolic impairment in patients with asymptomatic coronary heart disease and type 1 diabetes is related to coronary atherosclerosis, glycaemic control and advanced glycation endproducts. Eur J Heart Fail 2007;9: 1044-1050 
47. Lopes-Virella MF, Hunt KJ, Baker NL, Lachin J, Nathan DM, Virella G. Levels of oxidized LDL and advanced glycation end products-modified LDL in circulating immune complexes are strongly associated with increased levels of carotid intima-media thickness and its progression in type 1 diabetes. Diabetes 2011;60:582-589

48. Meerwaldt R, Lutgers HL, Links TP, Graaff R, Baynes JW, Gans RO, Smit AJ. Skin autofluorescence is a strong predictor of cardiac mortality in diabetes. Diabetes Care 2007;30:107-112

49. Araki N, Higashi T, Mori T, Shibayama R, Kawabe Y, Kodama T, Takahashi K, Shichiri M, Horiuchi S. Macrophage scavenger receptor mediates the endocytic uptake and degradation of advanced glycation end products of the Maillard reaction. Eur J Biochem 1995;230:408-415

50. Li YM, Mitsuhashi T, Wojciechowicz D, Shimizu N, Li J, Stitt A, He C, Banerjee D, Vlassara H: Molecular identity and cellular distribution of advanced glycation endproduct receptors: relationship of p60 to OST-48 and p90 to 80K-H membrane proteins. Proc Natl Acad Sci U S A 1996;93:11047-11052

51. Vlassara H, Li YM, Imani F, Wojciechowicz D, Yang Z, Liu FT, Cerami A. Identification of galectin-3 as a high-affinity binding protein for advanced glycation end products (AGE): a new member of the AGEreceptor complex. Mol Med 1995;1:634-646

52. Ohgami N, Nagai R, Ikemoto M, Arai H, Kuniyasu A, Horiuchi S, Nakayama H. Cd36, a member of the class $\mathrm{b}$ scavenger receptor family, as a receptor for advanced glycation end products. J Biol Chem 2001;276:3195-3202

53. Jono T, Miyazaki A, Nagai R, Sawamura T, Kitamura T, Horiuchi S. Lectin-like oxidized low density lipoprotein receptor-1 (LOX-1) serves as an endothelial receptor for advanced glycation end products (AGE). FEBS Lett 2002;511:170-174

54. Schmidt AM, Vianna M, Gerlach M, Brett J, Ryan J, Kao J, Esposito C, Hegarty H, Hurley W, Clauss M, et al.: Isolation and characterization of two binding proteins for advanced glycosylation end products from bovine lung which are present on the endothelial cell surface. J Biol Chem 1992;267:1498714997

55. Brownlee M: Biochemistry and molecular cell biology of diabetic complications. Nature 2001;414: 813-820

56. Brett J, Schmidt AM, Yan SD, Zou YS, Weidman E, Pinsky D, Nowygrod R, Neeper M, Przysiecki C, Shaw $A$, et al.. Survey of the distribution of a newly characterized receptor for advanced glycation end products in tissues. Am J Pathol 1993;143:1699-1712

57. Wendt TM, Tanji N, Guo J, Kislinger TR, Qu W, Lu Y, Bucciarelli LG, Rong LL, Moser B, Markowitz GS, Stein G, Bierhaus A, Liliensiek B, Arnold B, Nawroth PP, Stern DM, D'Agati VD, Schmidt AM. RAGE drives the development of glomerulosclerosis and implicates podocyte activation in the pathogenesis of diabetic nephropathy. Am J Pathol 2003;162:1123-1137

58. Kislinger T, Fu C, Huber B, Qu W, Taguchi A, Du Yan S, Hofmann M, Yan SF, Pischetsrieder M, Stern D, Schmidt AM. N(epsilon)-(carboxymethyl)lysine adducts of proteins are ligands for receptor for advanced glycation end products that activate cell signaling pathways and modulate gene expression. J Biol Chem 1999;274:31740-31749

59. Hudson BI, Carter AM, Harja E, Kalea AZ, Arriero M, Yang H, Grant PJ, Schmidt AM: Identification, classification, and expression of RAGE gene splice variants. Faseb J 2008;22:1572-1580

60. Dattilo BM, Fritz G, Leclerc E, Kooi CW, Heizmann CW, Chazin WJ: The extracellular region of the receptor for advanced glycation end products is composed of two independent structural units. Biochemistry 2007;46:6957-6970

61. Xie J, Reverdatto S, Frolov A, Hoffmann R, Burz DS, Shekhtman A: Structural basis for pattern recognition by the receptor for advanced glycation end products (RAGE). J Biol Chem 2008;283: 27255-27269

62. Kalea AZ, Schmidt AM, Hudson BI. RAGE: a novel biological and genetic marker for vascular disease. Clin Sci (Lond) 116:621-637, 2009

63. Li JH, Wang W, Huang XR, Oldfield M, Schmidt AM, Cooper ME, Lan HY. Advanced glycation end products induce tubular epithelial-myofibroblast transition through the RAGE-ERK1/2 MAP kinase signaling pathway. Am J Pathol 2004;164:1389-1397

64. Basta G, Lazzerini G, Massaro M, Simoncini T, Tanganelli P, Fu C, Kislinger T, Stern DM, Schmidt AM, De Caterina R. Advanced glycation end products activate endothelium through signal-transduction receptor RAGE: a mechanism for amplification of inflammatory responses. Circulation 2002;105: 816-822 
65. Harja E, Bu DX, Hudson BI, Chang JS, Shen X, Hallam K, Kalea AZ, Lu Y, Rosario RH, Oruganti S, Nikolla Z, Belov D, Lalla E, Ramasamy R, Yan SF, Schmidt AM. Vascular and inflammatory stresses mediate atherosclerosis via RAGE and its ligands in apoE-/- mice. J Clin Invest 2008;118:183-194

66. Schmidt AM, Yan SD, Brett J, Mora R, Nowygrod R, Stern D. Regulation of human mononuclear phagocyte migration by cell surface-binding proteins for advanced glycation end products. J Clin Invest 1993;91:2155-2168

67. Wautier JL, Zoukourian C, Chappey O, Wautier MP, Guillausseau PJ, Cao R, Hori O, Stern D, Schmidt AM. Receptor-mediated endothelial cell dysfunction in diabetic vasculopathy. Soluble receptor for advanced glycation end products blocks hyperpermeability in diabetic rats. J Clin Invest 1996;97: 238-243

68. Coughlan MT, Thorburn DR, Penfold SA, Laskowski A, Harcourt BE, Sourris KC, Tan AL, Fukami K, Thallas-Bonke V, Nawroth PP, Brownlee M, Bierhaus A, Cooper ME, Forbes JM. RAGE-induced cytosolic ROS promote mitochondrial superoxide generation in diabetes. J Am Soc Nephrol 2009;20:742-752

69. Cipollone F, lezzi A, Fazia M, Zucchelli M, Pini B, Cuccurullo C, De Cesare D, De Blasis G, Muraro R, Bei R, Chiarelli F, Schmidt AM, Cuccurullo F, Mezzetti A. The receptor RAGE as a progression factor amplifying arachidonate-dependent inflammatory and proteolytic response in human atherosclerotic plaques: role of glycemic control. Circulation 2003;108:1070-1077

70. Shoji T, Koyama H, Morioka T, Tanaka S, Kizu A, Motoyama K, Mori K, Fukumoto S, Shioi A, Shimogaito $\mathrm{N}$, Takeuchi M, Yamamoto Y, Yonekura H, Yamamoto H, Nishizawa Y. Receptor for advanced glycation end products is involved in impaired angiogenic response in diabetes. Diabetes 2006;55:2245-2255

71. Yonekura H, Yamamoto Y, Sakurai S, Petrova RG, Abedin MJ, Li H, Yasui K, Takeuchi M, Makita Z, Takasawa S, Okamoto H, Watanabe T, Yamamoto H. Novel splice variants of the receptor for advanced glycation end-products expressed in human vascular endothelial cells and pericytes, and their putative roles in diabetes-induced vascular injury. Biochem J 2003;370:1097-1109

72. Raucci A, Cugusi S, Antonelli A, Barabino SM, Monti L, Bierhaus A, Reiss K, Saftig P, Bianchi ME. A soluble form of the receptor for advanced glycation endproducts (RAGE) is produced by proteolytic cleavage of the membrane-bound form by the sheddase a disintegrin and metalloprotease 10 (ADAM10). Faseb J 2008;22:3716-3727

73. Du Yan S, Zhu H, Fu J, Yan SF, Roher A, Tourtellotte WW, Rajavashisth T, Chen X, Godman GC, Stern D, Schmidt AM. Amyloid-beta peptide-receptor for advanced glycation endproduct interaction elicits neuronal expression of macrophage-colony stimulating factor: a proinflammatory pathway in Alzheimer disease. Proc Natl Acad Sci U S A 1997;94:5296-5301

74. Yan SD, Zhu H, Zhu A, Golabek A, Du H, Roher A, Yu J, Soto C, Schmidt AM, Stern D, Kindy M. Receptor-dependent cell stress and amyloid accumulation in systemic amyloidosis. Nat Med 2000;6:643-651

75. Hofmann MA, Drury S, Fu C, Qu W, Taguchi A, Lu Y, Avila C, Kambham N, Bierhaus A, Nawroth P, Neurath MF, Slattery T, Beach D, McClary J, Nagashima M, Morser J, Stern D, Schmidt AM. RAGE mediates a novel proinflammatory axis: a central cell surface receptor for $\mathrm{S100/ \text {calgranulin }}$ polypeptides. Cell 1999;97:889-901

76. Hori O, Brett J, Slattery T, Cao R, Zhang J, Chen JX, Nagashima M, Lundh ER, Vijay S, Nitecki D, et al.. The receptor for advanced glycation end products (RAGE) is a cellular binding site for amphoterin. Mediation of neurite outgrowth and co-expression of rage and amphoterin in the developing nervous system. J Biol Chem 1995;270:25752-25761

77. Bianchi ME, Agresti A. HMG proteins: dynamic players in gene regulation and differentiation. Curr Opin Genet Dev 2005;15:496-506

78. Scaffidi P, Misteli T, Bianchi ME. Release of chromatin protein HMGB1 by necrotic cells triggers inflammation. Nature 2002;418:191-195

79. Rendon-Mitchell B, Ochani M, Li J, Han J, Wang H, Yang H, Susarla S, Czura C, Mitchell RA, Chen G, Sama AE, Tracey KJ, Wang $\mathrm{H}$. IFN-gamma induces high mobility group box 1 protein release partly through a TNF-dependent mechanism. J Immunol 2003;170:3890-3897

80. Li J, Kokkola R, Tabibzadeh S, Yang R, Ochani M, Qiang X, Harris HE, Czura CJ, Wang H, Ulloa L, Wang H, Warren HS, Moldawer LL, Fink MP, Andersson U, Tracey KJ, Yang H. Structural basis for the proinflammatory cytokine activity of high mobility group box 1. Mol Med 2003;9:37-45 
81. Fiuza C, Bustin M, Talwar S, Tropea M, Gerstenberger E, Shelhamer JH, Suffredini AF. Inflammationpromoting activity of HMGB1 on human microvascular endothelial cells. Blood 2003;101:2652-2660

82. van Zoelen MA, Yang H, Florquin S, Meijers JC, Akira S, Arnold B, Nawroth PP, Bierhaus A, Tracey KJ, van der Poll T. Role of toll-like receptors 2 and 4, and the receptor for advanced glycation end products in high-mobility group box 1-induced inflammation in vivo. Shock 2009;31:280-284

83. Kim J, Sohn E, Kim CS, Jo K, Kim JS. The role of high-mobility group box-1 protein in the development of diabetic nephropathy. Am J Nephrol 2011;33:524-529

84. Li F, Yang N, Zhang L, Tan H, Huang B, Liang Y, Chen M, Yu X. Increased expression of toll-like receptor 2 in rat diabetic nephropathy. Am J Nephrol 2010;32:179-186

85. Hu X, Jiang H, Bai Q, Zhou X, Xu C, Lu Z, Cui B, Wen H. Increased serum HMGB1 is related to the severity of coronary artery stenosis. Clin Chim Acta 2009;406:139-142

86. Yan XX, Lu L, Peng WH, Wang LJ, Zhang Q, Zhang RY, Chen QJ, Shen WF. Increased serum HMGB1 level is associated with coronary artery disease in nondiabetic and type 2 diabetic patients. Atherosclerosis 2009;205:544-548

87. Wang L, Lu L, Zhang FR, Chen QJ, De Caterina R, Shen WF. Increased serum high-mobility group box-1 and cleaved receptor for advanced glycation endproducts levels and decreased endogenous secretory receptor for advanced glycation endproducts levels in diabetic and non-diabetic patients with heart failure. Eur J Heart Fail 2011;13:440-449

88. Aird WC: Phenotypic heterogeneity of the endothelium: I. Structure, function, and mechanisms. Circ Res 2007;100:158-173

89. Schalkwijk CG, Stehouwer CD. Vascular complications in diabetes mellitus: the role of endothelial dysfunction. Clin Sci (Lond) 2005;109:143-159

90. Sibal L, Agarwal SC, Schwedhelm E, Luneburg N, Boger RH, Home PD. A study of endothelial function and circulating asymmetric dimethylarginine levels in people with Type 1 diabetes without macrovascular disease or microalbuminuria. Cardiovasc Diabetol 2009;8:27

91. Targher G, Bertolini L, Zoppini G, Zenari L, Falezza G. Increased plasma markers of inflammation and endothelial dysfunction and their association with microvascular complications in Type 1 diabetic patients without clinically manifest macroangiopathy. Diabet Med 2005;22:999-1004

92. Lopes-Virella MF, Carter RE, Gilbert GE, Klein RL, Jaffa M, Jenkins AJ, Lyons TJ, Garvey WT, Virella G. Risk factors related to inflammation and endothelial dysfunction in the DCCT/EDIC cohort and their relationship with nephropathy and macrovascular complications. Diabetes Care 2008;31:2006-2012

93. Soedamah-Muthu SS, Chaturvedi N, Schalkwijk CG, Stehouwer CD, Ebeling P, Fuller JH. Soluble vascular cell adhesion molecule-1 and soluble E-selectin are associated with micro- and macrovascular complications in Type 1 diabetic patients. J Diabetes Complications 2006;20:188-195

94. Costacou T, Lopes-Virella MF, Zgibor JC, Virella G, Otvos J, Walsh M, Orchard TJ. Markers of endothelial dysfunction in the prediction of coronary artery disease in type 1 diabetes. The Pittsburgh Epidemiology of Diabetes Complications Study. J Diabetes Complications 2005;19:183-193

95. Astrup AS, Tarnow L, Pietraszek L, Schalkwijk CG, Stehouwer CD, Parving HH, Rossing P. Markers of endothelial dysfunction and inflammation in type 1 diabetic patients with or without diabetic nephropathy followed for 10 years: association with mortality and decline of glomerular filtration rate. Diabetes Care 2008;31:1170-1176

96. Hansson GK, Libby P. The immune response in atherosclerosis: a double-edged sword. Nat Rev Immunol 2006;6:508-519

97. Tedgui A, Mallat Z. Cytokines in atherosclerosis: pathogenic and regulatory pathways. Physiol Rev 2006;86:515-581

98. Babar GS, Zidan H, Widlansky ME, Das E, Hoffmann RG, Daoud M, Alemzadeh R. Impaired endothelial function in preadolescent children with type 1 diabetes. Diabetes Care 2011;34:681-685

99. Snell-Bergeon JK, West NA, Mayer-Davis EJ, Liese AD, Marcovina SM, D'Agostino RB, Jr., Hamman RF, Dabelea D. Inflammatory markers are increased in youth with type 1 diabetes: the SEARCH CaseControl study. J Clin Endocrinol Metab 2010;95:2868-2876

100. Devaraj S, Cheung AT, Jialal I, Griffen SC, Nguyen D, Glaser N, Aoki T. Evidence of increased inflammation and microcirculatory abnormalities in patients with type 1 diabetes and their role in microvascular complications. Diabetes 2007;56:2790-2796

101. Saraheimo M, Teppo AM, Forsblom C, Fagerudd J, Groop PH. Diabetic nephropathy is associated with low-grade inflammation in Type 1 diabetic patients. Diabetologia 2003;46:1402-1407 
102. Schram MT, Chaturvedi N, Schalkwijk CG, Fuller JH, Stehouwer CD. Markers of inflammation are crosssectionally associated with microvascular complications and cardiovascular disease in type 1 diabetesthe EURODIAB Prospective Complications Study. Diabetologia 2005;48:370-378

103. Hayaishi-Okano R, Yamasaki Y, Katakami N, Ohtoshi K, Gorogawa S, Kuroda A, Matsuhisa M, Kosugi K, Nishikawa N, Kajimoto Y, Hori M. Elevated C-reactive protein associates with early-stage carotid atherosclerosis in young subjects with type 1 diabetes. Diabetes Care 2002;25:1432-1438

104. Laurent S, Cockcroft J, Van Bortel L, Boutouyrie P, Giannattasio C, Hayoz D, Pannier B, Vlachopoulos C, Wilkinson I, Struijker-Boudier H. Expert consensus document on arterial stiffness: methodological issues and clinical applications. Eur Heart J 2006;27:2588-2605

105. Ronnback M, Fagerudd J, Forsblom C, Pettersson-Fernholm K, Reunanen A, Groop PH. Altered agerelated blood pressure pattern in type 1 diabetes. Circulation 2004;110:1076-1082

106. Gordin D, Waden J, Forsblom C, Thorn L, Rosengard-Barlund M, Tolonen N, Saraheimo M, Harjutsalo $\mathrm{V}$, Groop PH. Pulse pressure predicts incident cardiovascular disease but not diabetic nephropathy in patients with type 1 diabetes (The FinnDiane Study). Diabetes Care 34:886-891, 2011

107. Schiffrin EL, Lipman ML, Mann JF. Chronic kidney disease: effects on the cardiovascular system. Circulation 2007; 116:85-97

108. Tonelli M, Wiebe N, Culleton B, House A, Rabbat C, Fok M, McAlister F, Garg AX. Chronic kidney disease and mortality risk: a systematic review. J Am Soc Nephrol 2006;17:2034-2047

109. Stehouwer CD, Smulders YM. Microalbuminuria and risk for cardiovascular disease: Analysis of potential mechanisms. J Am Soc Nephrol 2006;17:2106-2111

110. The EURODIAB Study Group. Microvascular and acute complications in IDDM patients: the EURODIAB IDDM Complications Study. Diabetologia 1994;37:278-285

111. Tarnow L, Cambien F, Rossing P, Nielsen FS, Hansen BV, Lecerf L, Poirier O, Danilov S, Boelskifte S, Borch-Johnsen K. Insertion/deletion polymorphism in the angiotensin-I-converting enzyme gene is associated with coronary heart disease in IDDM patients with diabetic nephropathy. Diabetologia 1995;38:798-803 


\section{Chapter 2}

Soluble RAGE levels are cross-sectionally associated with cardiovascular disease in type

1 diabetes and this association is partially mediated by endothelial and renal dysfunction and low-grade inflammation: The EURODIAB Prospective Complications Study

JWM Nin, I Ferreira, CG Schalkwijk, MH Prins, N Chaturvedi, JH Fuller, CDA Stehouwer, and the EURODIAB Prospective Complications Study Group

Diabetologia 2009;52:705-714 


\section{Abstract}

\section{Background and objective}

Serum soluble receptor for advanced glycation endproducts (sRAGE) may reflect the activity of the AGERAGE axis, which has been proposed as a potential mechanism linking hyperglycaemia to vascular complications in diabetes. We have therefore investigated 1) whether SRAGE is associated with greater prevalence of cardiovascular disease (CVD) and microvascular complications in type 1 diabetic patients; and 2 ) the extent to which any such associations are explained by markers of endothelial and renal dysfunction and inflammation.

\section{Methods}

The study included 477 subjects (234 women; mean age $42 \pm 10 \mathrm{yrs}$ ) from the EURODIAB Prospective Complications Study. We used linear regression analyses to investigate the differences in sRAGE levels between subjects with vs. without vascular complications. All analyses were adjusted for age, sex, HbA1c, duration of diabetes and other risk factors.

Results

Subjects with CVD ( $n=116)$ had higher levels of SRAGE than those without CVD or any microvascular complications $(n=178)$ : $\beta=0.15$ (95\% Cl: $0.04 ; 0.27)$. Further adjustments for markers of endothelial $[\beta=0.13$ $(0.02 ; 0.24)]$ and renal dysfunction $[\beta=0.10(-0.01 ; 0.20)]$ and inflammation $[\beta=0.12(0.01 ; 0.23)]$ attenuated these differences; altogether these variables explained about $50 \%$ of the association between sRAGE and prevalent CVD. Soluble RAGE levels tended to be higher in the presence and across the levels of severity of albuminuria ( $p$-trend=0.087) and retinopathy ( $p$-trend=0.057); adjustments for endothelial and renal dysfunction and inflammation also attenuated these differences.

\section{Conclusions}

SRAGE is associated with greater prevalence of CVD in type 1 diabetic subjects, and these associations may be partly explained by endothelial and renal dysfunction and low-grade inflammation. 


\section{Introduction}

The increased cardiovascular disease risk in patients with diabetes mellitus (DM) cannot be fully explained by traditional cardiovascular risk factors (1-3). Therefore, other factors and mechanisms potentially involved need to be explored. At the molecular level, one pathway through which hyperglycaemia may lead to vascular complications is the formation of advanced glycation endproducts (AGEs). An important mechanism through which AGEs induce vascular disease is by binding to their specific receptors $(4,5)$.

Several different receptors for AGEs have been identified, one of which is termed RAGE. Different cell types including human endothelial cells express RAGE (6). In addition to cell-bound RAGE, soluble forms of RAGE appear in plasma $(6,7)$, as different splice variants of RAGE (esRAGE) leaking the transmembrane and cytosolic domain $(6,8)$, and as a proteolytically cleaved form of RAGE (sRAGE), which is most probably shed into the circulation by the sheddase a disintegrin and metalloprotease 10 (9). The functional role of these soluble forms of RAGE in the circulation remains unclear, but they may reflect the activity of the AGE-RAGE axis. The ligation of RAGE activates the endothelial cell and triggers multiple signalling cascades $(10,11)$, resulting in activation and translocation of nuclear transcription factors and transcription of the target genes, including adhesion molecules $(11,12)$ and proinflammatory cytokines (13). The activation of RAGE may also lead to nephropathy (14). We have therefore hypothesised that the activation of the AGE-RAGE axis may lead to vascular complications in diabetes through increases in endothelial and renal dysfunction and low-grade inflammation.

Evidence so far with regard to the association between soluble forms of RAGE and vascular disease is contradictory, with several studies showing positive (15-18) but also inverse associations (19-22). Soluble forms of RAGE levels have also been shown to be either increased $(16,23)$ or decreased $(19)$ in diabetic patients. The fact that these studies have investigated either esRAGE (18-20) or sRAGE (15-18,21-23) may explain the discrepancies. Indeed, in the only study in which both soluble forms of RAGE were examined, SRAGE, but not esRAGE, was associated with albuminuria in subjects with type 2 diabetes (18). In addition, the extent to which mechanisms such as endothelial and renal dysfunction and low-grade inflammation, which are intertwined and related to macro- and microvascular complications in diabetes (24-26), underlie the association between SRAGE and vascular complications (if any) has never been investigated.

In view of these considerations, we have investigated, first, whether sRAGE levels are associated with a greater prevalence of macro- and microvascular complications in patients with type 1 diabetes; and second, the extent to which any such associations are explained (i.e. are mediated) by markers of endothelial and renal dysfunction and low-grade inflammation. 


\section{Methods}

\section{Subjects and study design}

We used data from the EURODIAB Prospective Complications Study, which is a followup of the EURODIAB IDDM complications study that has been described in detail elsewhere (27-29). Briefly, baseline investigations were performed between 1989 and 1991 on 3,250 patients with diabetes mellitus type 1, defined as a clinical diagnosis made before the age of 36 years, and needing continuous insulin therapy within 1 year of diagnosis. The patients, aged between 15 and 60 years, were recruited from 31 centres in 16 European countries. Sample selection was stratified by sex, age group and duration of diabetes, to ensure sufficient representation in all categories. All patients gave informed consent and the study was approved by the local Ethics Committees (29). These patients were invited for a follow-up examination on average 7-9 years after the baseline examinations. Of the 3,250 included patients, 1,880 (57.8\%) returned for re-examination. At follow-up, a cross-sectional nested casecontrol study of markers of inflammation and endothelial dysfunction and their associations with complications was performed in a subset of patients $(n=543)$. The present study includes 477 of these subjects in whom complete data on serum levels of sRAGE, endothelial and renal dysfunction markers, inflammatory markers and other covariates were available.

\section{Main determinant}

Plasma levels of sRAGE were measured using a commercially available enzyme-linked immunosorbent assay kit (Quantikine: R\&D systems, Minneapolis, USA) according to the manufacturer's protocol. Briefly, a monoclonal antibody generated against the $\mathrm{N}$-terminal extracellular domain of human RAGE was used to capture sRAGE from plasma. Captured sRAGE was detected with a polyclonal antihuman sRAGE antibody. After washing, plates were incubated with streptavidin horseradish peroxidase, developed with appropriate substrate, and OD450 was determined using an enzymelinked immunosorbent assay plate reader. Measurements were performed in duplicate and the intra-assay and inter-assay coefficients of variation were $2.9 \%$ and $11.5 \%$, respectively.

\section{Main outcomes}

\section{Macrovascular disease}

Cardiovascular disease was defined as a positive medical history of a cardiovascular event, including myocardial infarction, angina, coronary artery bypass graft and/or stroke, and/or ischaemic changes on a centrally Minnesota coded ECG (30). 


\section{Microvascular disease}

Albumin excretion rates were measured from duplicate 24-h urine collections (28) and micro- and macroalbuminuria were defined as an albumin excretion rate between 20 and 200, and above $200 \mu \mathrm{g} / \mathrm{min}$, respectively. We also estimated subjects' glomerular filtration rate (eGFR) with the Cockcroft-Gault formula (31). Retinopathy was assessed from retinal photographs according to the EURODIAB protocol; non-proliferative retinopathy was defined as the presence of one or more microaneurysms, haemorrhages, and/or hard exudates. Proliferative retinopathy was defined as any new vessels, fibrous proliferations, pre-retinal haemorrhage, vitreous haemorrhage, or photocoagulation scars (32).

\section{Other risk factors}

Blood pressure was recorded twice with a random zero sphygmomanometer (Hawskley, Lancing, UK). Hypertension was defined as systolic pressure $\geq 140 \mathrm{mmHg}$, diastolic pressure $\geq 90 \mathrm{mmHg}$ and/or use of antihypertensive drugs. Smoking habits were ascertained by questionnaire and subjects were categorised into categories: 'non-', 'moderate', and 'heavy smokers', according to their levels of pack years smoked (none, and below or above the sex-specific median, respectively). Weight and height were measured with indoor clothing without shoes and body mass index (BMI) was calculated. Blood samples were taken, fasting if possible, for measurement of lipids and glycaemic control. Cholesterol and triglyceride levels were measured by enzymatic colorimetric tests (33), and HDL cholesterol was measured directly (34). LDL cholesterol was calculated from Friedewald's formula (35). Glycated haemoglobin $\left(\mathrm{HbA}_{1 \mathrm{c}}\right)$ was measured by a latex enhanced turbidimetric immunoassay (Roche Products, Welwyn Garden City, UK). The reference range for this assay was $4.2-6.2 \%$.

\section{Potential Mediators}

\section{Markers of endothelial dysfunction}

Soluble vascular cell adhesion molecule-1 (sVCAM-1) and soluble E-selectin (sEselectin) were measured in duplicate by sandwich enzyme immunoassays (R\&D Systems, Oxon, U.K.). The mean of the duplicates is presented. The intra- and interassay coefficients of variation for sVCAM-1 were $4.0 \%$ and $9.1 \%$, respectively, and for sE-selectin, $2.1 \%$ and $3.1 \%$, respectively.

\section{Inflammatory markers}

Plasma levels of C-reactive protein (CRP) were measured with a highly sensitive inhouse ELISA (25) and plasma levels of interleukin-6 (IL-6) and tumour necrosis factor- $\alpha$ (TNF- $\alpha$ ) were measured using commercially available ELISA kits (R\&D Systems, Oxon, 
U.K.) (25). Intra- and inter-assay coefficients of variation were 3.9 and $8.7 \%, 4.5$ and $9.0 \%, 7.3$ and $8.5 \%$, respectively.

\section{Advanced glycation endproducts}

Pentosidine levels were determined in unhydrolysed urine (36). Urinary excretion of pentosidine was normalised for urine concentration by expressing it as $\mathrm{nmol}$ pentosidine/mmol urinary creatinine. Protein-bound $\mathrm{N}^{\varepsilon}$-(carboxymethyl)lysine $(\mathrm{CML})$ and $\mathrm{N}^{\varepsilon}$-(carboxyethyl)lysine (CEL) were determined in plasma as previously described (37) with an inter-assay coefficient of variation of $6.0 \%$. CML and CEL were normalised for lysine concentration.

\section{Statistical analyses}

All analyses were performed with the Statistical Package for Social Sciences (SPSS) version $\mathbf{1 5 . 0}$ for Windows (SPSS Inc, Chicago, Illinois, USA). Variables with a skewed distribution (i.e. triglycerides, CRP, IL-6, TNF $\alpha$ and pentosidine) were log transformed prior to further analyses. Comparisons of characteristics between subjects with vs. without vascular complications were performed with Student's t- or Chi-Square tests, as appropriate. Cases were all those subjects with cardiovascular disease or retinopathy or micro- or macroalbuminuria $(n=299)$; controls were all those who had no evidence of cardiovascular disease, nor retinopathy, and were normoalbuminuric $(n=178)$.

Linear regression analyses were used to examine whether SRAGE levels differed between subjects with vs. without CVD, and similarly, between those with and without microvascular complications. In the analyses comparing individuals with vs. without CVD, we excluded those in whom CVD was absent but who did have any of the other vascular complications (183 out of 299 individuals). The same control group ( $n=178$ ) was used in the analyses comparing subjects with vs. without albuminuria and subjects with vs. without retinopathy. These analyses were first adjusted for age, sex, $\mathrm{HbA1C}$ and duration of DM, and then further adjusted for other cardiovascular risk factors (i.e. BMI, triglycerides, HDL, LDL, systolic blood pressure and smoking). Linear regression analyses were also used to examine the extent to which sRAGE levels were associated with endothelial dysfunction (comprised in an averaged Z-score of sVCAM-1 and sE-selectin), inflammation (comprised in an averaged Z-score of CRP, IL-6 and TNF $\alpha$ ) and eGFR. Results of these analyses are expressed in standardised regression coefficients ( $95 \%$ confidence interval) to allow the comparison of the strength of the association between SRAGEs and each of these variables/scores. Finally, successive adjustments for these variables were performed in order to investigate the extent to which these variables explained (i.e. attenuated) the differences in SRAGE levels between subjects with and without complications.

Because we measured the markers of the potential mediators only once, the associations observed will tend to be diluted. This is the reason why we combined the 
markers per mechanism (i.e. inflammation and endothelial dysfunction) to yield an inflammatory and an endothelial dysfunction marker Z-score. We thereby assumed that each marker contributes equally to the activity of the mechanism to which it belongs.

\section{Results}

Table 2.1 shows the characteristics of the patients with vascular complications (cases) vs. those without (controls).

Table 2.1 Clinical characteristics of the study population.

\begin{tabular}{|c|c|c|c|}
\hline & \multicolumn{3}{|c|}{ All $(n=477)$} \\
\hline & $\begin{array}{c}\text { Vascular } \\
\text { complications } \\
(n=299)\end{array}$ & $\begin{array}{l}\text { No vascular } \\
\text { complications } \\
(n=178)\end{array}$ & p-value \\
\hline Age (years) & $41.7(10.4)$ & $35.9(8.1)$ & $<0.001$ \\
\hline Gender $(m / f, \%)$ & $54 / 46$ & $46 / 54$ & 0.072 \\
\hline $\mathrm{BMI}\left(\mathrm{kg} / \mathrm{m}^{2}\right)$ & $24.9(3.5)$ & $23.7(2.6)$ & $<0.001$ \\
\hline $\mathrm{HbA1c}(\%)$ & $9.0(1.6)$ & $7.8(1.3)$ & $<0.001$ \\
\hline Duration of Diabetes (years) & $25.2(9.1)$ & $15.3(7.0)$ & $<0.001$ \\
\hline LDL Cholesterol (mmol/l) & $3.25(1.09)$ & $2.87(0.90)$ & $<0.001$ \\
\hline HDL Cholesterol (mmol/l) & $1.59(0.42)$ & $1.69(0.45)$ & 0.022 \\
\hline Triglyceride (mmol/l) & $1.14[0.85-1.58]$ & 0.85 [0.66-1.09] & $<0.001$ \\
\hline Smoking (Non/Moderate/Heavy smokers) (\%) & $39 / 27 / 34$ & $51 / 31 / 18$ & $<0.001$ \\
\hline Diastolic blood pressure (mmHg) & $75(12)$ & $73(11)$ & 0.048 \\
\hline Systolic blood pressure (mmHg) & $127(21)$ & $114(14)$ & $<0.001$ \\
\hline Serum Creatinine $(\mu \mathrm{mol} / \mathrm{l})$ & $76[68-90]$ & $71[64-78]$ & $<0.001$ \\
\hline eGFR (ml/min) & $113.9(17.4)$ & $96.9(27.5)$ & $<0.001$ \\
\hline Cardiovascular disease (\%) & 38.8 & - & - \\
\hline Albuminuria (Normo-/Micro-/Macro-) (\%) & $38.5 / 24.1 / 37.5$ & - & - \\
\hline Retinopathy (No/Background/Proliferative) (\%) & 11.7/41.1/47.2 & - & - \\
\hline $\mathrm{CRP}(\mathrm{mg} / \mathrm{l})$ & $1.30[0.46-2.80]$ & $0.71[0.35-1.82]$ & $<0.001$ \\
\hline IL-6 (pg/ml) & $2.13[1.35-3.94)]$ & 1.55 [1.05-2.49] & $<0.001$ \\
\hline TNF- $\alpha(p g / m l)$ & $3.17[2.40-4.41]$ & $2.23[1.68-2.85]$ & $<0.001$ \\
\hline sE-selectin (ng/ml) & $36(17)$ & $31(11)$ & $<0.001$ \\
\hline sVCAM-1(ng/ml) & $437(147)$ & $379(104)$ & $<0.001$ \\
\hline CEL/Lysine $\left(\mu \mathrm{mol} \mathrm{I}^{-1} \mathrm{mmol}^{-1}\right)$ & $0.030(0.012)$ & $0.031(0.011)$ & 0.896 \\
\hline $\mathrm{CML} /$ Lysine $\left(\mu \mathrm{mol} \mathrm{I}^{-1} \mathrm{mmol}^{-1}\right)$ & $0.058(0.020)$ & $0.055(0.015)$ & 0.097 \\
\hline Pentosidine ( $\mathrm{nmol} / \mathrm{l}$ per mmol urinary creatinine) & $0.46[0.33-0.67]$ & $0.43[0.32-0.56]$ & 0.003 \\
\hline
\end{tabular}

Data are means (standard deviation), median [inter-quartile range], or percentages, as appropriate.

BMI, body mass index; HbA1c, glycated hemoglobin; LDL, low-density lipoprotein; HDL, high-density lipoprotein; eGFR, estimated glomerular filtration rate by Cockcroft-Gault formula; CRP, $C$ reactive protein; IL-6, interleukin-6; TNF- $\alpha$, tumor necrosis factor- $\alpha$; sE-selectin, soluble E-selectin; sVCAM-1, soluble vascular cell adhesion molecule-1; CEL, $\mathrm{N}^{\varepsilon}$-(carboxyethyl)lysine; CML, $\mathrm{N}^{\varepsilon}$-(carboxymethyl)lysine; sRAGE, soluble receptor for advanced glycation end-products. 


\section{Associations between SRAGE and cardiovascular and microvascular disease}

Subjects with CVD had higher levels of sRAGE than those without CVD: $\beta=0.16 \mathrm{ng} / \mathrm{ml}$ (95\% Cl: 0.05; 0.26) (Table 2.2, model 1; Figure 2.1). Adjustments for other risk factors did not change this difference (model 2 ).

Soluble RAGE levels were also increased across the levels of severity of albuminuria: $[\beta=0.04(-0.08 ; 0.16)$ and $\beta=0.13(0.01 ; 0.25)$ in subjects with micro- and macroalbuminuria vs. normoalbuminuria, respectively ( $p$-trend $=0.031)$ ] and similarly across the levels of severity of retinopathy $[\beta=0.06(-0.04 ; 0.15)$ and $\beta=0.12(0.01 ; 0.22)$ in those with non-proliferative and proliferative vs. without retinopathy, respectively (p-trend=0.037)] (Table 2.2; model 1; Figure 2.1). These differences were not markedly attenuated after further adjustments for other risk factors but were not longer statistically significant (model 2).

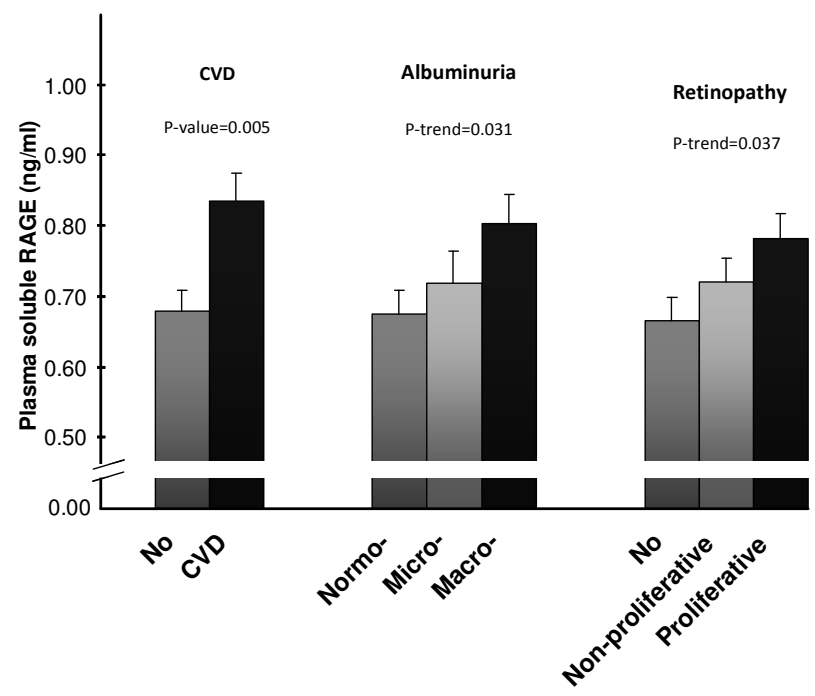

Figure 2.1 SRAGE levels according to the presence of cardiovascular disease and the presence and severity of albuminuria and retinopathy. Bars are means adjusted for age, sex, duration of $\mathrm{DM}$ and $\mathrm{HbA1c}$; error bars indicate SEs of the means.

Association between SRAGE and markers of endothelial and renal dysfunction, lowgrade inflammation and advanced glycation endproducts

Soluble RAGE was positively and significantly associated with endothelial dysfunction, low-grade inflammation and AGEs scores, and even more strongly so with levels of eGFR (Table 2.3; model 1). Adjustments for other cardiovascular risk factors did not materially change these associations (model 2). 


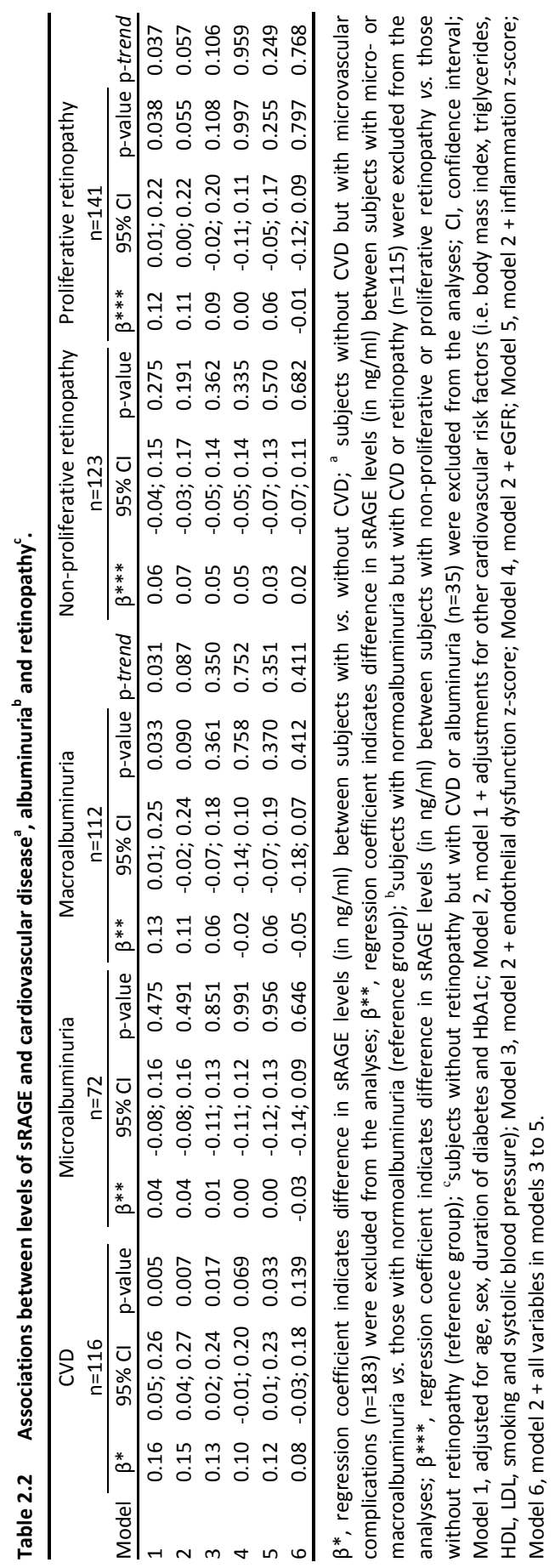


Table 2.3 Associations between levels of SRAGE levels and markers of endothelial and renal dysfunction, low-grade inflammation and advanced glycation endproducts.

\begin{tabular}{lcccc}
\hline Dependent Variables & Model & $\beta$ & $95 \% \mathrm{Cl}$ & $\mathrm{p}$-value \\
\hline Endothelial dysfunction z-score & 1 & 0.18 & $0.12 ; 0.24$ & $<0.001$ \\
Estimated glomerular filtration rate & 2 & 0.17 & $0.11 ; 0.23$ & $<0.001$ \\
& 1 & -0.32 & $-0.39 ;-0.25$ & $<0.001$ \\
Inflammation z-score & 2 & -0.28 & $-0.35 ;-0.21$ & $<0.001$ \\
& 3 & -0.28 & $-0.34 ;-0.21$ & $<0.001$ \\
Advanced glycation endproducts z-score & 1 & 0.15 & $0.09 ; 0.21$ & $<0.001$ \\
& 2 & 0.14 & $0.09 ; 0.20$ & $<0.001$ \\
& 1 & 0.21 & $0.15 ; 0.27$ & $<0.001$ \\
\hline
\end{tabular}

$\beta$, standardised regression coefficient: indicates increase (in SDs) of the dependent variable per 1 SD increase in SRAGE levels; $\mathrm{Cl}$ : confidence interval. Model 1, adjusted for age, sex, duration of diabetes and HbA1c; Model 2, model 1 + adjustments for other cardiovascular risk factors (i.e. body mass index, triglycerides HDL, LDL, smoking and systolic blood pressure); Model 3, model $2+$ adjustment for the presence of vascular complications.

Mediating effects of endothelial and renal dysfunction and low-grade inflammation in the associations between SRAGE and cardiovascular and microvascular complications

The differences in SRAGE between subjects with vs. without CVD were attenuated after adjustments for markers of endothelial dysfunction and low-grade inflammation and more strongly so after adjustments for eGFR (Table 2.2, models 3 to 5 vs. model 2 ). These variables explained about $13 \%, 20 \%$ and $33 \%$ of the association between SRAGE levels and the prevalence of CVD, respectively. All together, these potential mediators explained about $50 \%$ (change of $\beta$ from 0.15 in model 2 to 0.08 in model 6 ) of the differences in SRAGE between subjects with vs. without CVD. Endothelial dysfunction, low-grade inflammation and particularly eGFR also attenuated the differences in SRAGE levels across the levels of severity of albuminuria and retinopathy (Table 2.2, models 3 to 6 ).

\section{Additional analyses}

In the analyses above (Table 2.2, models 4), we have considered eGFR (a marker of kidney dysfunction) as a potential mediator in the relationship between SRAGE and vascular complications. However, kidney dysfunction could also be a confounder in the association between SRAGE levels and vascular complications, and our analyses cannot distinguish between these possibilities. Finally, eGFR could also be a risk marker of vascular complications. When analysed as such, we observed that subjects with CVD had lower eGFR than those without CVD $[\beta=-5.33 \mathrm{ml} / \mathrm{min}(95 \% \mathrm{Cl}:-10.49$; -0.16), after adjustments for other cardiovascular risk factors and SRAGE levels]. However, the inverse associations reported between SRAGE and eGFR (Table 2.3, models 1 and 2), were not attenuated when further adjusted for the presence of 
vascular disease (Table 2.3, model 3), which argues against eGFR being a risk marker of vascular disease.

We found significant effect modification by sex in the association between SRAGE and CVD ( $p$-values sex-interaction $=0.008$ ), indicating that the association between SRAGE and CVD was stronger in men $[\beta=0.25 \mathrm{ng} / \mathrm{ml}(0.08 ; 0.43)]$ than in women $[\beta=0.07 \mathrm{ng} / \mathrm{ml}(-0.07 ; 0.20)]$. However, in both sexes the direction of the association was the same and the number of cases and controls did not differ markedly between the two sexes: 55:81 and 61:97 in men and women, respectively.

\section{Discussion}

The main finding of this study is that SRAGE levels are positively associated with cardiovascular disease in type 1 diabetes. This association was independent of other 'traditional' cardiovascular risk factors, but could be partially explained by endothelial and renal dysfunction and low-grade inflammation. Although sRAGE has been investigated in several studies, findings have been scattered. This is the first study that has investigated the associations between SRAGE and macro- and microvascular complications, and has also addressed potential mechanisms that could explain the observed associations.

The observed positive association between SRAGE and CVD reported herein is in line with some $(16,17)$ but not all $(19,22)$ previous studies. The reasons for these contradictory findings are not clear but may be explained by the fact that different variants of soluble RAGE were measured and investigated across studies. Human endothelial cells express at least three RAGE variants (6). The first one is the fulllength RAGE, the second, the amino-terminally truncated variant with still an unknown function, and the third, the carbonyl-terminally truncated soluble form. This naturally occurring form of soluble RAGE, as well as artificially produced SRAGE, can potentially bind to an AGE ligand thereby acting as a decoy, preventing AGE-RAGE interaction and activation (6). This could thus explain any inverse association observed between SRAGE and vascular complications. However, although SRAGE has been an interesting subject of investigation under this suspected decoy function, it is very unlikely that sRAGE can act as such (i.e. by capturing and eliminating AGEs) because the sRAGE concentrations found in plasma are approximately 1000 times lower than needed for efficient binding and elimination of AGEs (18). Although circulating RAGE can be measured, different pools of soluble forms of RAGE are detected by different assays, namely the total pool of SRAGE by the Quantikine SRAGE ELISA kit (R\&D systems, Minneapolis, USA) (15-18,21-23) or specifically esRAGE by the B-Bridge International esRAGE ELISA kit (Daiichi Fine Chemicals, Takaoka, Japan) (18-20). The conflicting findings from the studies so far may thus be due to differences in measured variants of soluble RAGE, each of which might have a different function. Recently, new splice variants have been discovered (8) and further studies are 
necessary to establish which variants of sRAGE are measured by these assays. The differences in the study population (i.e. diabetes vs. no diabetes or differences in ethnicity) might also contribute to the discrepancies in previous studies.

SRAGE levels were also positively associated with microvascular complications, although these were not independent of other risk factors in the present study. Positive associations between sRAGE levels and albuminuria have been reported previously, although these were not fully adjusted for conventional risk factors (i.e. dyslipidaemia, smoking and/or blood pressure) $(15,18)$. In contradiction, subjects with diabetic retinopathy were characterised by lower levels of soluble RAGE compared to individuals without retinopathy, but again these differences did not account for confounding and selection bias may have influenced the association (20).

We, as others, have found positive associations between sRAGE and markers of endothelial dysfunction and low-grade inflammation (38). The current view is that the activation of RAGE, a 55-kDa protein and member of the immunoglobulin superfamily of cell surface receptors, through ligand binding activates the endothelial cell and triggers multiple signalling cascades $(10,11)$. This results in activation and translocation of nuclear transcription factors and transcription of the target genes, including VCAM-1 (11), E-selectin (12), and proinflammatory cytokines (13). AGEs are positive regulators of the cellular RAGE expression (39), and an increased formation of AGEs enhanced the expression and secretion of the soluble forms of RAGE $(40,41)$. In addition, the association between SRAGE and AGEs observed in this study supports the view that SRAGE could be a reflection of RAGE, and that activation of the AGERAGE axis can lead to increased endothelial dysfunction and low-grade inflammation, and subsequently to an increased risk of cardiovascular complications in type 1 diabetes.

We have shown that SRAGE is positively and independently associated with renal dysfunction, defined as eGFR. This is in line with a previous study, which has shown that the activation of the AGE-RAGE axis could lead to glomerulosclerosis and glomerular hyperpermeability through the upregulation of vascular endothelial growth factor and/or transforming growth factor- $\beta$ (14). We have also shown that renal dysfunction mediated the associations between sRAGE levels on the one hand and CVD or microvascular complications on the other. Although there is some evidence to support the assumption of renal dysfunction being a mediator in the causal pathway between SRAGE levels (as a reflection of the activity of the AGE-RAGE axis) and vascular complications, we cannot neglect the possibility of renal dysfunction being a confounder in these associations.

It is unclear why the relationship between SRAGE levels and CVD observed in the present study was stronger in men than in women. SRAGE levels did not differ between the two sexes. In this study cohort, associations between sialic acid and fibrinogen and coronary heart disease have also been found in men only (42). These findings suggest that different pathophysiological mechanisms may be involved in the two sexes with regard to CVD in type 1 diabetes. 
There are limitations to our study. First, we cannot establish whether the associations are causal due to the cross-sectional design of the study, and our findings are limited to type 1 diabetic patients. However, no longitudinal data of this type exist in large groups of type 1 diabetes at the time, and therefore this cross-sectional study may serve as a reasonable starting point to further explore these associations. Second, although we minimised the influence of confounding in the associations observed by adjustments for many possible confounders, interference by factors we did not measure cannot be ruled out. Third, the levels of the mediators investigated were only measured once, which might have diluted the associations we found. However, we combined different markers of the potential mediators in Z-scores to yield more robust scores.

In conclusion, in this study of patients with type 1 diabetes, SRAGE was found to be significantly associated with CVD and this was independent of other cardiovascular risk factors. Endothelial and renal dysfunction and low-grade inflammation explained about $50 \%$ of this association, suggesting that sRAGE levels as a reflection of RAGE lead to greater prevalence of CVD through increased endothelial and renal dysfunction and low-grade inflammation. Nevertheless, the precise role of SRAGE in the pathophysiology of diabetes mellitus and vascular complications need to be explored further in prospective studies. 


\section{References}

1. Soedamah-Muthu SS, Fuller JH, Mulnier HE, Raleigh VS, Lawrenson RA, Colhoun HM. High risk of cardiovascular disease in patients with type 1 diabetes in the U.K.: a cohort study using the general practice research database. Diabetes Care 2006;29:798-804

2. Laing SP, Swerdlow AJ, Slater SD, Burden AC, Morris A, Waugh NR, Gatling W, Bingley PJ, Patterson CC. Mortality from heart disease in a cohort of 23,000 patients with insulin-treated diabetes. Diabetologia 2003;46:760-765

3. Barrett-Connor EL, Cohn BA, Wingard DL, Edelstein SL. Why is diabetes mellitus a stronger risk factor for fatal ischemic heart disease in women than in men? The Rancho Bernardo Study. JAMA 1991; 265:627-631

4. Brownlee M. Biochemistry and molecular cell biology of diabetic complications. Nature 2001;414: 813-820

5. Goldin A, Beckman JA, Schmidt AM, Creager MA. Advanced glycation end products: sparking the development of diabetic vascular injury. Circulation 2006;114:597-605

6. Yonekura H, Yamamoto Y, Sakurai S, Petrova RG, Abedin MJ, Li H, Yasui K, Takeuchi M, Makita Z, Takasawa S, Okamoto $H$, Watanabe T, Yamamoto $H$. Novel splice variants of the receptor for advanced glycation end-products expressed in human vascular endothelial cells and pericytes, and their putative roles in diabetes-induced vascular injury. Biochem J 2003;370:1097-1109

7. Schlueter C, Hauke S, Flohr AM, Rogalla P, Bullerdiek J. Tissue-specific expression patterns of the RAGE receptor and its soluble forms--a result of regulated alternative splicing? Biochim Biophys Acta 2003;1630:1-6

8. Hudson BI, Carter AM, Harja E, Kalea AZ, Arriero M, Yang H, Grant PJ, Schmidt AM. Identification, classification, and expression of RAGE gene splice variants. Faseb J 2008;22:1572-1580

9. Raucci A, Cugusi S, Antonelli A, Barabino SM, Monti L, Bierhaus A, Reiss K, Saftig P, Bianchi ME. A soluble form of the receptor for advanced glycation endproducts (RAGE) is produced by proteolytic cleavage of the membrane-bound form by the sheddase a disintegrin and metalloprotease 10 (ADAM10). Faseb J 2008;22:3716-3727

10. Kislinger T, Fu C, Huber B, Qu W, Taguchi A, Du Yan S, Hofmann M, Yan SF, Pischetsrieder M, Stern D, Schmidt AM. N(epsilon)-(carboxymethyl)lysine adducts of proteins are ligands for receptor for advanced glycation end products that activate cell signaling pathways and modulate gene expression. J Biol Chem 1999;274:31740-31749

11. Harja E, Bu DX, Hudson BI, Chang JS, Shen X, Hallam K, Kalea AZ, Lu Y, Rosario RH, Oruganti S, Nikolla Z, Belov D, Lalla E, Ramasamy R, Yan SF, Schmidt AM. Vascular and inflammatory stresses mediate atherosclerosis via RAGE and its ligands in apoE-/- mice. J Clin Invest 2008;118:183-194

12. Basta G, Lazzerini G, Massaro M, Simoncini T, Tanganelli P, Fu C, Kislinger T, Stern DM, Schmidt AM, De Caterina R. Advanced glycation end products activate endothelium through signal-transduction receptor RAGE: a mechanism for amplification of inflammatory responses. Circulation 2002;105: 816-822

13. Hofmann MA, Drury S, Fu C, Qu W, Taguchi A, Lu Y, Avila C, Kambham N, Bierhaus A, Nawroth P, Neurath MF, Slattery T, Beach D, McClary J, Nagashima M, Morser J, Stern D, Schmidt AM. RAGE mediates a novel proinflammatory axis: a central cell surface receptor for S100/calgranulin polypeptides. Cell 1999;97:889-901

14. Wendt TM, Tanji N, Guo J, Kislinger TR, Qu W, Lu Y, Bucciarelli LG, Rong LL, Moser B, Markowitz GS, Stein G, Bierhaus A, Liliensiek B, Arnold B, Nawroth PP, Stern DM, D'Agati VD, Schmidt AM. RAGE drives the development of glomerulosclerosis and implicates podocyte activation in the pathogenesis of diabetic nephropathy. Am J Pathol 2003;162:1123-1137

15. Tan KC, Shiu SW, Chow WS, Leng L, Bucala R, Betteridge DJ. Association between serum levels of soluble receptor for advanced glycation end products and circulating advanced glycation end products in type 2 diabetes. Diabetologia 2006;49:2756-2762

16. Nakamura K, Yamagishi S, Adachi H, Kurita-Nakamura Y, Matsui T, Yoshida T, Sato A, Imaizumi T. Elevation of soluble form of receptor for advanced glycation end products (sRAGE) in diabetic subjects with coronary artery disease. Diabetes Metab Res Rev 2007;23:368-371 
17. Koyama Y, Takeishi Y, Niizeki T, Suzuki S, Kitahara T, Sasaki T, Kubota I. Soluble Receptor for advanced glycation end products (RAGE) is a prognostic factor for heart failure. J Card Fail 2008;14:133-139

18. Humpert PM, Djuric Z, Kopf S, Rudofsky G, Morcos M, Nawroth PP, Bierhaus A. Soluble RAGE but not endogenous secretory RAGE is associated with albuminuria in patients with type 2 diabetes. Cardiovasc Diabetol 2007;6:9

19. Koyama H, Shoji T, Fukumoto S, Shinohara K, Shoji T, Emoto M, Mori K, Tahara H, Ishimura E, Kakiya R, Tabata T, Yamamoto $H$, Nishizawa Y. Low circulating endogenous secretory receptor for AGEs predicts cardiovascular mortality in patients with end-stage renal disease. Arterioscler Thromb Vasc Biol 2007; 27:147-153

20. Katakami N, Matsuhisa M, Kaneto H, Matsuoka TA, Sakamoto K, Nakatani Y, Ohtoshi K, HayaishiOkano R, Kosugi K, Hori M, Yamasaki Y. Decreased endogenous secretory advanced glycation end product receptor in type 1 diabetic patients: its possible association with diabetic vascular complications. Diabetes Care 2005;28:2716-2721

21. Geroldi D, Falcone C, Emanuele E, D'Angelo A, Calcagnino M, Buzzi MP, Scioli GA, Fogari R. Decreased plasma levels of soluble receptor for advanced glycation end-products in patients with essential hypertension. J Hypertens 2005;23:1725-1729

22. Falcone C, Emanuele E, D'Angelo A, Buzzi MP, Belvito C, Cuccia M, Geroldi D. Plasma levels of soluble receptor for advanced glycation end products and coronary artery disease in nondiabetic men. Arterioscler Thromb Vasc Biol 2005;25:1032-1037

23. Challier $M$, Jacqueminet $S$, Benabdesselam $O$, Grimaldi $A$, Beaudeux JL. Increased serum concentrations of soluble receptor for advanced glycation endproducts in patients with type 1 diabetes. Clin Chem 2005;51:1749-1750

24. Schram MT, Chaturvedi N, Schalkwijk CG, Fuller JH, Stehouwer CD. Markers of inflammation are crosssectionally associated with microvascular complications and cardiovascular disease in type 1 diabetes-the EURODIAB Prospective Complications Study. Diabetologia 2005;48:370-378

25. Schram MT, Chaturvedi N, Schalkwijk C, Giorgino F, Ebeling P, Fuller JH, Stehouwer CD. Vascular risk factors and markers of endothelial function as determinants of inflammatory markers in type 1 diabetes: the EURODIAB Prospective Complications Study. Diabetes Care 2003;26:2165-2173

26. Schiffrin EL, Lipman ML, Mann JF. Chronic kidney disease: effects on the cardiovascular system. Circulation 2007; 116:85-97

27. Chaturvedi N, Sjoelie AK, Porta M, Aldington SJ, Fuller JH, Songini M, Kohner EM. Markers of insulin resistance are strong risk factors for retinopathy incidence in type 1 diabetes. Diabetes Care 2001; 24:284-289

28. Chaturvedi N, Bandinelli S, Mangili R, Penno G, Rottiers RE, Fuller JH. Microalbuminuria in type 1 diabetes: rates, risk factors and glycemic threshold. Kidney Int 2001;60:219-227

29. Stephenson J, Fuller J. Microvascular and acute complications in IDDM patients: the EURODIAB IDDM Complications Study. Diabetologia 1994;37:278-285

30. Koivisto VA, Stevens LK, Mattock M, Ebeling P, Muggeo M, Stephenson J, Idzior-Walus B. Cardiovascular disease and its risk factors in IDDM in Europe. EURODIAB IDDM Complications Study Group. Diabetes Care 1996;19:689-697

31. Cockcroft DW, Gault MH. Prediction of creatinine clearance from serum creatinine. Nephron 1976; 16:31-41

32. Aldington SJ, Kohner EM, Meuer S, Klein R, Sjolie AK. Methodology for retinal photography and assessment of diabetic retinopathy: the EURODIAB IDDM complications study. Diabetologia 1995;38:437-444

33. Fossati P, Prencipe L. Serum triglycerides determined colorimetrically with an enzyme that produces hydrogen peroxide. Clin Chem 1982;28:2077-2080

34. Sugiuchi H, Uji Y, Okabe H, Irie T, Uekama K, Kayahara N, Miyauchi K. Direct measurement of highdensity lipoprotein cholesterol in serum with polyethylene glycol-modified enzymes and sulfated alpha-cyclodextrin. Clin Chem 1995;41:717-723

35. Friedewald WT, Levy RI, Fredrickson DS. Estimation of the concentration of low-density lipoprotein cholesterol in plasma, without use of the preparative ultracentrifuge. Clin Chem 1972;18:499-502 
36. Smulders RA, Stehouwer CD, Schalkwijk CG, Donker AJ, van Hinsbergh VW, TeKoppele JM. Distinct associations of $\mathrm{HbA} 1 \mathrm{c}$ and the urinary excretion of pentosidine, an advanced glycosylation endproduct, with markers of endothelial function in insulin-dependent diabetes mellitus. Thromb Haemost 1998;80:52-57

37. Lieuw-A-Fa ML, van Hinsbergh VW, Teerlink T, Barto R, Twisk J, Stehouwer CD, Schalkwijk CG. Increased levels of $\mathrm{N}$ (epsilon)-(carboxymethyl)lysine and $\mathrm{N}$ (epsilon)-(carboxyethyl)lysine in type 1 diabetic patients with impaired renal function: correlation with markers of endothelial dysfunction. Nephrol Dial Transplant 2004;19:631-636

38. Nakamura K, Yamagishi S, Adachi H, Kurita-Nakamura Y, Matsui T, Yoshida T, Imaizumi T. Serum levels of SRAGE, the soluble form of receptor for advanced glycation end products, are associated with inflammatory markers in patients with type 2 diabetes. Mol Med 2007;13:185-189

39. Tanaka N, Yonekura H, Yamagishi S, Fujimori H, Yamamoto Y, Yamamoto H. The receptor for advanced glycation end products is induced by the glycation products themselves and tumor necrosis factor-alpha through nuclear factor-kappa B, and by 17 beta-estradiol through Sp-1 in human vascular endothelial cells. J Biol Chem 2000;275:25781-25790

40. Miura J, Yamamoto Y, Osawa M, Watanabe T, Yonekura H, Uchigata Y, Yamamoto H, Iwamoto Y. Endogenous secretory receptor for advanced glycation endproducts levels are correlated with serum pentosidine and CML in patients with type 1 diabetes. Arterioscler Thromb Vasc Biol 2007;27:253-254

41. Yamagishi S, Adachi H, Nakamura K, Matsui T, Jinnouchi $Y$, Takenaka K, Takeuchi M, Enomoto M, Furuki K, Hino A, Shigeto $Y$, Imaizumi T. Positive association between serum levels of advanced glycation end products and the soluble form of receptor for advanced glycation end products in nondiabetic subjects. Metabolism 2006;55:1227-1231

42. Soedamah-Muthu SS, Chaturvedi N, Pickup JC, Fuller JH. Relationship between plasma sialic acid and fibrinogen concentration and incident micro- and macrovascular complications in type 1 diabetes. The EURODIAB Prospective Complications Study (PCS). Diabetologia 2008;51:493-501 


\section{Chapter}

Higher plasma soluble receptor for advanced glycation endproducts (sRAGE) levels are associated with incident cardiovascular disease and all-cause mortality in type 1 diabetes:

a 12-yr follow-up study

Johanna W Nin*, Anders Jorsal*, Isabel Ferreira, Casper G Schalkwijk, Martin H Prins, Hans-Henrik Parving, Lise Tarnow, Peter Rossing, Coen D Stehouwer

*Equal contribution

Diabetes 2010 59:2027-2032 


\section{Abstract}

\section{Background and objective}

To investigate the associations of plasma levels of soluble receptor for advanced glycation endproducts (sRAGE) with incident cardiovascular disease (CVD) and all-cause mortality in type 1 diabetes, and the extent to which any such associations could be explained by endothelial and renal dysfunction, low-grade inflammation, arterial stiffness and advanced glycation endproducts (AGEs).

\section{Methods}

We prospectively followed 169 individuals with diabetic nephropathy and 170 individuals with persistent normoalbuminuria who were free of CVD at study entry and in whom levels of sRAGE and other biomarkers were measured at baseline. The median follow-up duration was 12.3 (7.6-12.5) years.

Results

The incidence of fatal and non-fatal CVD and of all-cause mortality increased with higher baseline levels of Ln-sRAGE independently of other CVD risk factors: hazard ratio $(\mathrm{HR})=1.90(95 \% \mathrm{Cl}=1.13$ to 3.21$)$ and $\mathrm{HR}=2.12$ (1.26 to 3.57) per 1 unit increase in Ln-sRAGE, respectively. Adjustments for estimated glomerular filtration rate $\left(e G F R_{M D R D}\right)$, but not or to a smaller extent for markers of endothelial dysfunction, low-grade inflammation, arterial stiffness and AGEs, attenuated these associations to HR=1.59 (0.91 to 2.77) for fatal and non-fatal CVD events, and to $H R=1.90$ (1.09 to 3.31) for all-cause mortality. In addition, in patients with nephropathy the rate of decline of GFR was $1.38 \mathrm{ml} / \mathrm{min} / 1.73 \mathrm{~m}^{2}$ per year greater per 1 unit increase of Ln-sRAGE at baseline $(p=0.036)$.

\section{Conclusions}

Higher levels of SRAGE are associated with incident fatal and non-fatal CVD, and all-cause mortality in individuals with type 1 diabetes. sRAGE-associated renal dysfunction may partially explain this association. 


\section{Introduction}

Recent studies have suggested a potential role of the receptor for advanced glycation endproducts (RAGE) in the development of vascular disease in individuals with diabetes mellitus (1). At the molecular level, RAGE is upregulated in atherosclerotic lesions in diabetes (2). RAGE-induced production of adhesion molecules (3-5) and inflammatory cytokines (4) could contribute to endothelial $(4,5)$ and renal dysfunction (6), low-grade inflammation $(4,5)$ and arterial stiffening, all of which may partially explain the increased CVD in diabetes.

We have recently shown, in a large cross-sectional study of type 1 diabetes (EURODIAB), that plasma levels of sRAGE were positively associated with macro- and microvascular complications, and also with endothelial and renal dysfunction, and low-grade inflammation as pathophysiological mechanisms that explained, in part, the associations of sRAGE with vascular complications (7). Whether sRAGE is associated with incident fatal and non-fatal CVD as well as all-cause mortality in individuals with type 1 diabetes has never been investigated. In addition, the extent to which any such associations could be explained by markers of endothelial and renal dysfunction, lowgrade inflammation, arterial stiffness and AGEs, is also not known. We hereby address these questions in a 12-yr prospective follow-up study.

\section{Methods}

\section{Study population and design}

In 1993, 199 of all 242 albuminuric patients older than 18 years attending the outpatient clinic at Steno Diabetes Centre agreed to participate and were enrolled in a prospective observational study. Diabetic nephropathy was diagnosed according to the following criteria: persistent macroalbuminuria ( $>300 \mathrm{mg} / 24 \mathrm{~h}$ ) in at least two out of three previous consecutive 24-h urine collections, presence of retinopathy, and absence of other kidney or urinary tract disease. In addition, 192 patients with persistent normoalbuminuria [i.e. urinary albumin excretion rate (UAE) $<30 \mathrm{mg} / 24 \mathrm{~h}$ ] and matched for age, sex, and duration of diabetes were also enrolled as controls (8). The present study refers to 339 of the original 391 patients included in the cohort; details on inclusion/exclusion criteria and study main outcomes are depicted in a flow chart (Figure 3.1). The study was approved by the local ethics committee, in accordance with the Helsinki Declaration, and all patients gave their informed written consent. 


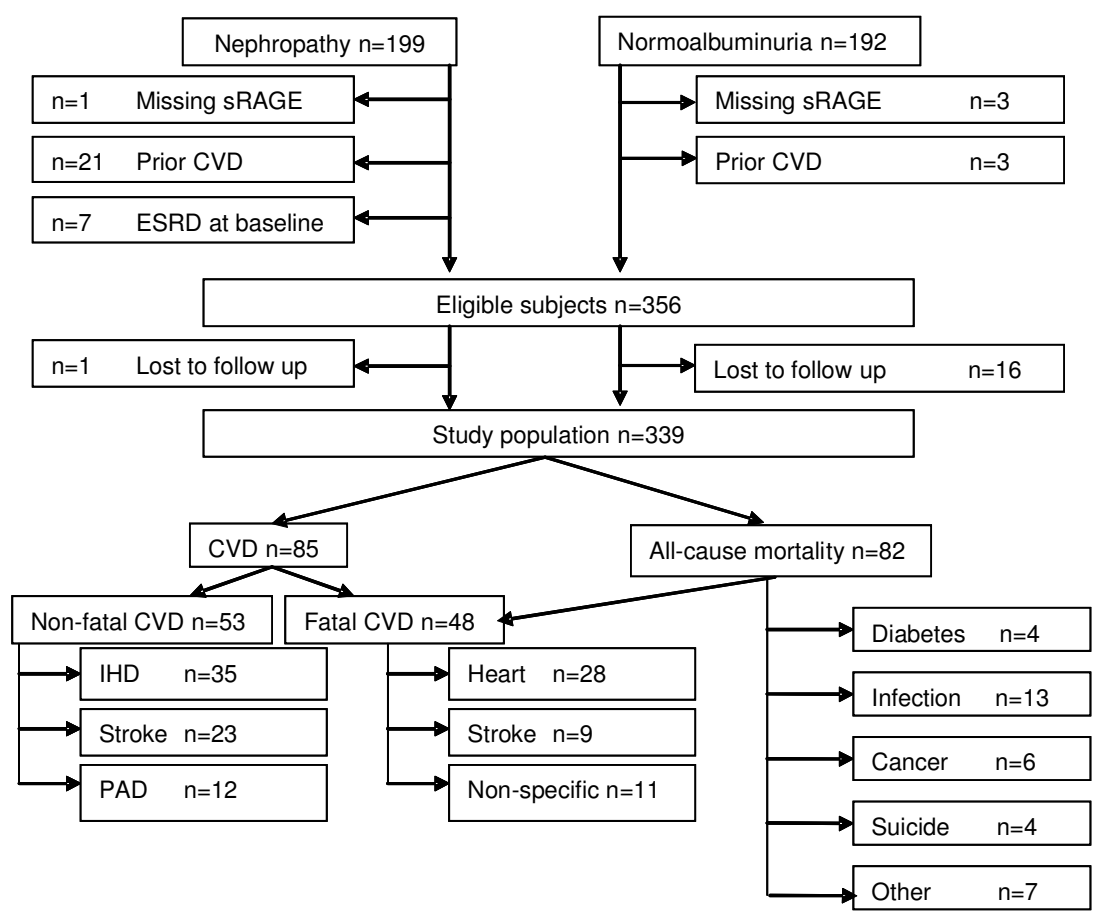

Figure 3.1 Flow chart study population.

Note: some patients had a non-fatal and a fatal cardiovascular event, and some patients both suffered a stroke and had ischaemic heart disease (IHD), or peripheral arterial disease (PAD). Time to the event that occurred first was used in the analyses.

\section{Baseline investigations}

\section{SRAGES}

Plasma levels of sRAGE were measured using a commercially available ELISA kit (Quantikine; R\&D systems, Minneapolis, MN, USA) according to the manufacturer's protocol. Briefly, a monoclonal antibody generated against the $\mathrm{N}$-terminal extracellular domain of human RAGE was used to capture SRAGE from plasma. Captured SRAGE was detected with a polyclonal anti-human SRAGE antibody. After washing, plates were incubated with streptavidin-horseradish peroxidase, developed with appropriate substrate, and OD450 was determined using an enzyme-linked immunosorbent assay plate reader. Measurements were performed in duplicate and the intra- and inter-assay CV values were $2 \%$ and $17.5 \%$, respectively. 


\section{Other baseline measurements}

Measurements of other biomarkers and risk factors have been described in detail elsewhere (8,9). All investigations were performed in the morning after an overnight fast. No antihypertensive medication was ever prescribed in $24 \%$ of patients with nephropathy and $88 \%$ of the normoalbuminuric patients. All of the remaining patients were asked to stop their antihypertensive and diuretic treatment 8 days before the examination, but $15 \%$ of the 339 patients ( $27 \%$ in the nephropathy group) considered in our analyses did not comply with this recommendation. Arterial blood pressure was measured twice with an appropriate cuff size following at least $10 \mathrm{~min}$ rest in the supine position. Mean arterial pressure was calculated as [systolic blood pressure + $(2 *$ diastolic blood pressure)]/3. Pulse pressure was calculated by subtracting the diastolic from the systolic blood pressure, and used as a marker of arterial stiffness (21). Urinary albumin excretion was measured by an enzyme immunoassay from 24-h urine collections. Serum creatinine concentration was assessed by a kinetic Jaffé method. In all patients glomerular filtration rate (eGFR) was estimated according to the short Modification of Diet in Renal Disease equation (MDRD) $=186 *$ [serum creatinine $(\mathrm{mg} / \mathrm{dl})]-1.154 *$ [age] $-0.203 *$ [0.742 if patient is female]. Patients were interviewed using the WHO cardiovascular questionnaire. Individuals were categorised into three groups according to their smoking status as never, former or current smokers.

High-sensitivity C-reactive protein and secreted phospholipase A2 were determined by ELISAs as described previously (9). Commercially available ELISA kits were used for measurements of plasma soluble vascular cell adhesion molecule-1, soluble intercellular adhesion molecule-1 and interleukin-6 (Quantikine High Sensitivity; R\&D Systems, Oxon, U.K.). The intra- and inter-assay CVs of these immunoassays were $<8 \%$. Protein-bound pentosidine levels were determined in plasma by a single step reversed phase based high-performance liquid chromatography separation with fluorescent detection. Protein-bound $\mathrm{N} \varepsilon$ (carboxymethyl)lysine (CML) and $\mathrm{N} \varepsilon$-(carboxyethyl)lysine (CEL) were determined in plasma by stable-isotope dilution tandem mass spectrometry. The intra- and interassay CVs were $2.7 \%$ and $2.8 \%$ for pentosidine, $3.5 \%$ and $3.6 \%$ for $\mathrm{CML}$, and $7.3 \%$ and $2.0 \%$ for $\mathrm{CEL}$, respectively. The laboratory analyses of these biomarkers were done on frozen $\left(-80^{\circ} \mathrm{C}\right)$ samples.

\section{Follow-up and study end-points}

All patients were followed up to the last visit at Steno Diabetes Center, until 1 September 2006 or until death $(n=82)$ or emigration $(n=3)$. All patients were traced through the national register during autumn 2006. If a patient had died before 1 September 2006, the date of death was recorded and the primary cause of death was obtained from the death certificate, which was reviewed by two independent observers. Additional available information from necropsy reports was also included. 
All deaths were classified as cardiovascular unless an unequivocal non-cardiovascular cause was established. In all patients alive at the end of follow-up non-fatal CVD were retrieved from their patient files at Steno Diabetes Center or other hospital records. The primary end-point was a combination of fatal and non-fatal CVD (i.e. myocardial infarction, percutaneous coronary intervention, coronary bypass grafting, amputation due to ischaemia, vascular surgery for peripheral atherosclerotic disease and stroke), and the secondary end-point was all-cause mortality.

\section{Statistical analyses}

All analyses were performed with SPSS version 15.0 for Windows (SPSS, Chicago, IL, USA).

Variables with a skewed distribution were $\log _{e}$ transformed prior to further analyses. Comparisons of baseline characteristics between groups were performed with Student's $t$ or $\chi^{2}$ tests, as appropriate. The associations between Ln-sRAGE and study end-points were investigated with Cox proportional hazards regression models adjusted, first, for sex, age, duration of diabetes, case-control status and HbA1c, second, for other traditional cardiovascular risk factors, and third, for the use of reninangiotensin-aldosterone system inhibitors and/or other antihypertensive treatment or whether subjects did or did not withheld their medication prior to baseline examinations. Further adjustments for markers of renal dysfunction, [i.e. estimated glomerular filtration rate (eGFR $\mathrm{MDRD}_{\text {) }}$ or $\mathrm{Ln}-\mathrm{UAE}$ ], low-grade inflammation [average of the $z$ scores of Ln-interleukin-6, Ln-C-reactive protein, soluble intracellular adhesion molecule-1 (sICAM-1) and Ln-secreted phospholipase-A2], endothelial dysfunction (average of the $z$ scores of soluble vascular cell adhesion molecule-1 and sICAM-1), and arterial stiffness (i.e. pulse pressure), were added into this model to ascertain the extent these could explain (i.e. attenuate the strength of) the association between LnsRAGE and study end-points. The cross-sectional associations between Ln-sRAGE and markers of these pathophysiological mechanisms and AGEs (average of the $z$ scores of Ln-pentosidine, $\quad N^{\varepsilon}$-(carboxymethyl)lysine and $N^{\varepsilon}$-(carboxyethyl)lysine), were examined with the use of linear regression analyses.

Finally, we investigated whether the associations listed above differed between patients with normoalbuminuria vs. nephropathy by adding interaction terms between Ln-sRAGE and case-control status to our models; whenever the p-value of such interactions were $<0.1$, results were presented for the two groups separately.

\section{Results}

During the course of follow-up [median: 12.3 years (inter-quartile range 7.6-12.5)], 82 individuals (24.2\%) died; 85 (25.1\%) suffered a fatal $(n=48)$ and/or non-fatal $(n=53)$ CVD event. Individuals with incident CVD events or who had died at follow-up had, at 
baseline, higher levels of Ln-sRAGE and a more adverse atherosclerotic risk (Table 3.1).

After adjustments for age, sex, case-control status, $\mathrm{HbA1c}$ and duration of diabetes, the incidence of fatal and non-fatal CVD increased with a HR of $2.00(95 \% \mathrm{Cl}$ : 1.19-3.36), and the incidence of all-cause mortality increased with a HR of 2.44 (1.46-4.07), per unit increase in baseline levels of Ln-sRAGE (Table 3.2, model 1, Figure $3.2 A$ and $B$, respectively). The associations between Ln-SRAGE and study end-points were attenuated, but remained significant after adjustments for other CVD risk factors and the use of medication: $H R=1.90$ (1.13-3.21) for fatal and non-fatal CVD events, and $\mathrm{HR}=2.12$ (1.26-3.57) for all-cause mortality (Table 3.2, models 2-3).

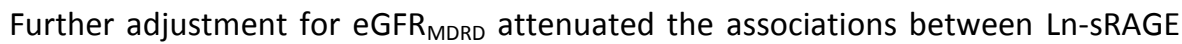
and incident fatal and non-fatal CVD as well as all-cause mortality by $28 \%$ and $14 \%$, respectively (Table 3.2, model 4). Adjustments for Ln-UAE, pulse pressure and AGEs attenuated these associations to a smaller extent, whereas adjustments for markers of endothelial dysfunction and low-grade inflammation did not (Table 3.2, models 5-9), despite the adverse associations between Ln-sRAGE and these variables (Table 3.3).

The adverse associations between Ln-sRAGE on the one hand, and baseline levels of eGFR $\mathrm{MDRD}_{\mathrm{M}}$, inflammation, endothelial dysfunction and AGEs on the other were stronger in individuals with nephropathy than in those with normoalbuminuria, however (Table 3.3).
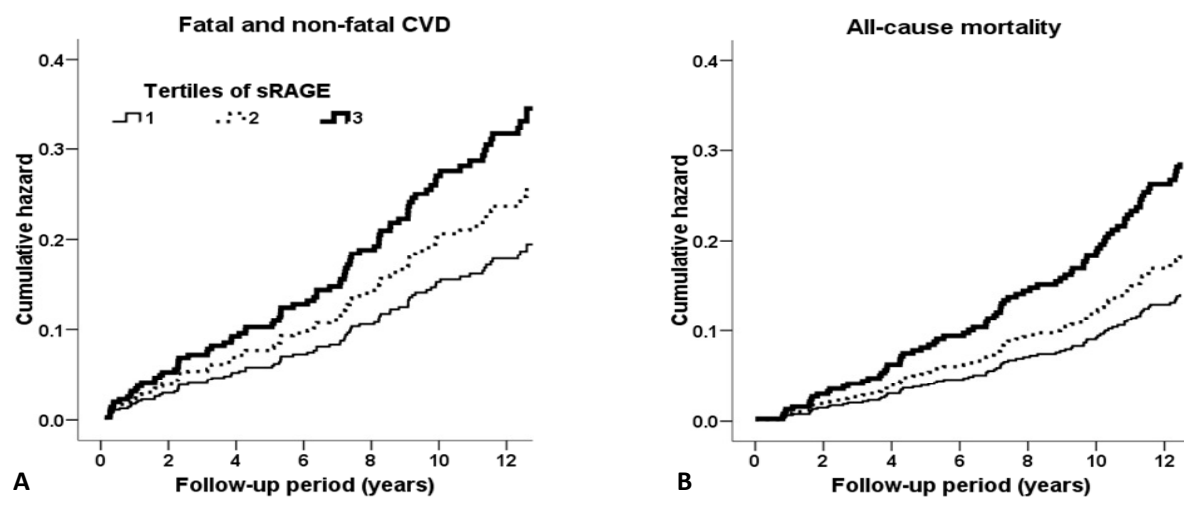

Figure 3.2 Cumulative hazard for fatal and non-fatal CVD (A) as well as all-cause mortality (B) across tertiles of plasma SRAGE. Data are adjusted for age, sex, case-control status, duration of diabetes and HbA1c. Compared with patients in the lowest tertile of sRAGE, those in the middle and highest tertiles had increased risk for non-fatal and fatal CVD [HR=1.33 $(95 \% \mathrm{Cl}$ 0.76 to 2.31 ) and 1.78 (1.03 to 3.06), respectively, $p$ for trend=0.038] and all-cause mortality [HR=1.31 ( $95 \% \mathrm{Cl} 0.73$ to 2.38 ) and 2.04 (1.17 to 3.55$)$, respectively, $\mathrm{p}$ for trend $=0.010$ ]. 


\section{Additional analyses}

In all individuals, decline in eGFR $\mathrm{MDRD}_{\text {per year }}\left(\triangle \mathrm{e} G F \mathrm{R}_{\mathrm{MDRD}}\right.$ ) was estimated using the last eGFR $\mathrm{R}_{\mathrm{MDD}}$ measure at follow-up. During the course of follow-up, and in patients with diabetic nephropathy only, GFR was also measured yearly after a single injection of $3.7 \mathrm{MBq} 51 \mathrm{Cr}$-EDTA (GFR $\mathrm{EDTA}_{\mathrm{A}}$ ) by determination of radioactivity in venous blood samples taken 180, 200, 220 and 240 minutes after the injection. With the use of these data we estimated a more valid and precise rate of decline in kidney function $\left(\triangle G_{F R} R_{\text {EDTA }}\right)$ over time in those patients with at least 3 follow-up measurements.

In order to clarify further the role of eGFR in the associations between Ln-sRAGE and incident fatal and non-fatal cardiovascular disease, we also investigated the extent to which Ln-sRAGE levels at baseline were associated with changes in (e)GFR and the extent to which any such associations could explain the sRAGE-related increase risks.

eGFR $\mathrm{MDRD}_{\mathrm{M}}$ decreased over the course of follow-up [median decline of: $-2.07 \mathrm{ml} / \mathrm{min} / 1.73 \mathrm{~m}^{2}$ per year (inter-quartile range -2.90 to -1.19 )]. After

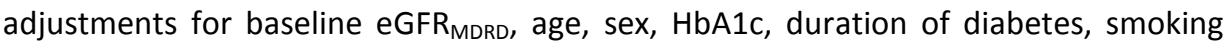
status, MAP, total cholesterol and use of RAAS inhibitors or other antihypertensive treatment, higher levels of Ln-sRAGE at baseline were associated with an accelerated decline in eGFR $\mathrm{MDRD}\left[\beta=-0.34 \mathrm{ml} / \mathrm{min} / 1.73 \mathrm{~m}^{2}\right.$ per year, $(95 \% \mathrm{Cl}:-0.90$ to 0.21$)$, $p=0.227]$. However, this association was present in individuals with nephropathy $[\beta=-$ $0.71 \mathrm{ml} / \mathrm{min} / 1.73 \mathrm{~m}^{2}$ per year $(-1.70$ to 0.29$\left.)\right]$, but not in those with normoalbuminuria $[\beta=0.23$ ( -0.32 to 0.77$)]$.

In patients with nephropathy we had data on $\triangle G F R_{E D T A}$ on 165 out of the 169 patients in this group: median decline of $-2.99 \mathrm{ml} / \mathrm{min} / 1.73 \mathrm{~m}^{2}$ per year (inter-quartile range: -5.15 to -1.60$)$. In these patients, and after adjustments for age, sex, HbA1c, duration of diabetes, MAP, smoking status, total cholesterol and use of RAAS inhibitors or other antihypertensive treatment, the rate of decline in $\triangle G F R_{E D T A}$ was $1.38 \mathrm{ml} / \mathrm{min} / 1.73 \mathrm{~m}^{2}$ per year $(p=0.036)$ greater per each unit increase in Ln-sRAGE levels at baseline. This raises the possibility that sRAGE-associated impaired renal clearance could explain, at least in part, the positive association between Ln-sRAGE and incident fatal and non-fatal cardiovascular disease. In addition, in these patients, the associations between Ln-SRAGE and incident fatal and non-fatal CVD events as well as all-cause mortality (Table 3.4, models $4 a$ and $5 a$ ) were further attenuated when adjusted for $\Delta(e)$ GFR (either as estimated by MDRD or EDTA, but more strongly so by the latter). 


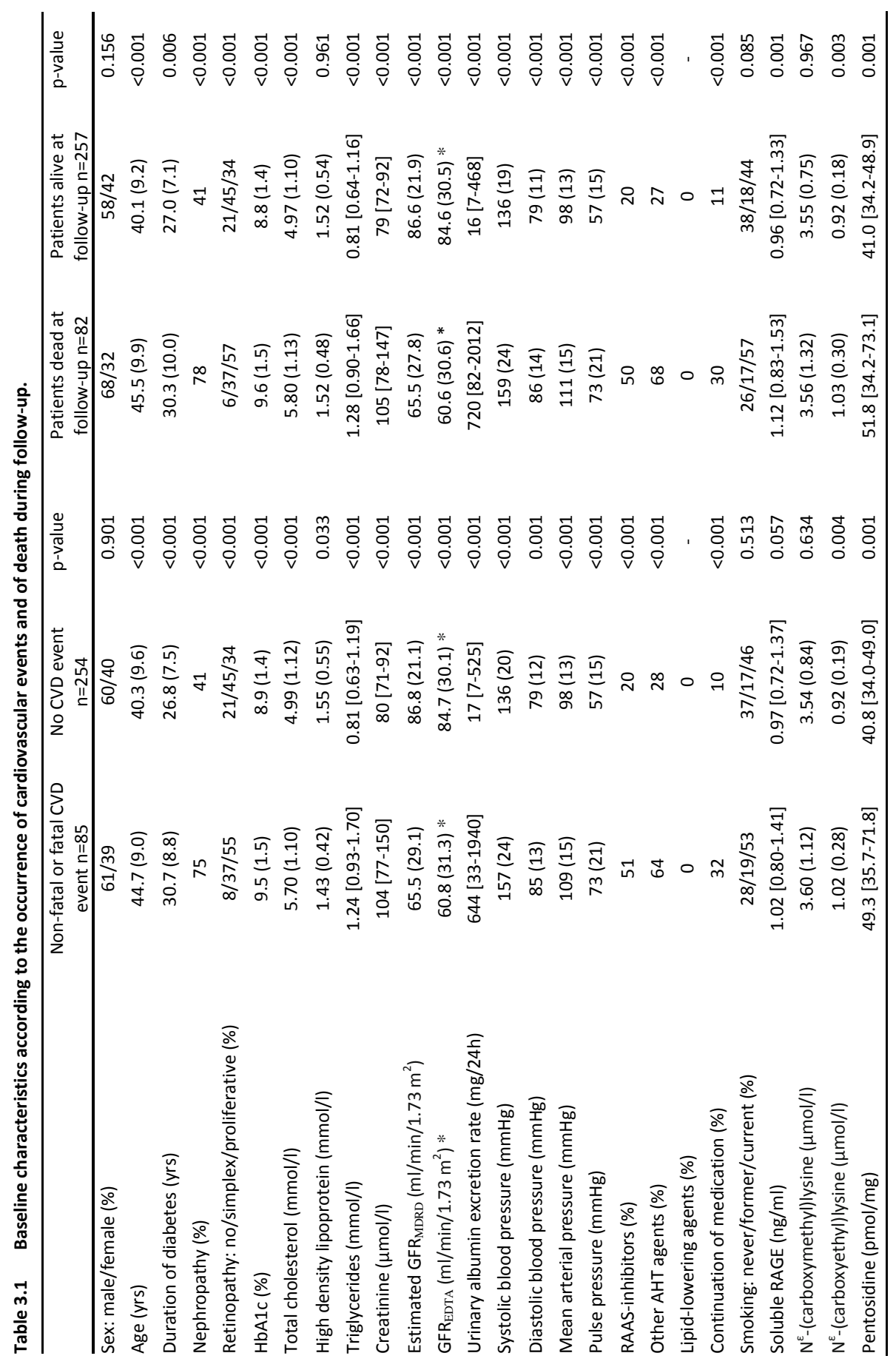



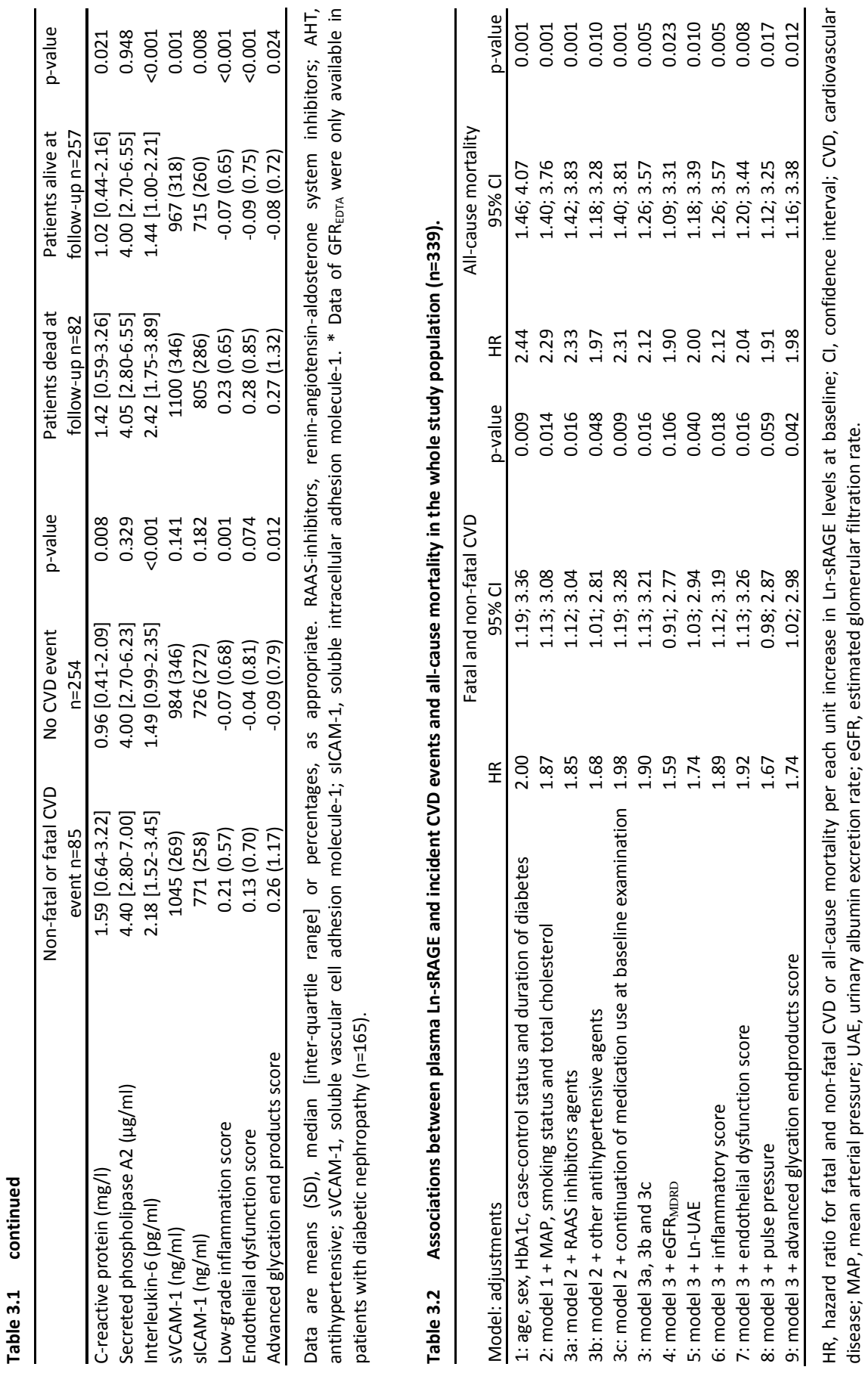


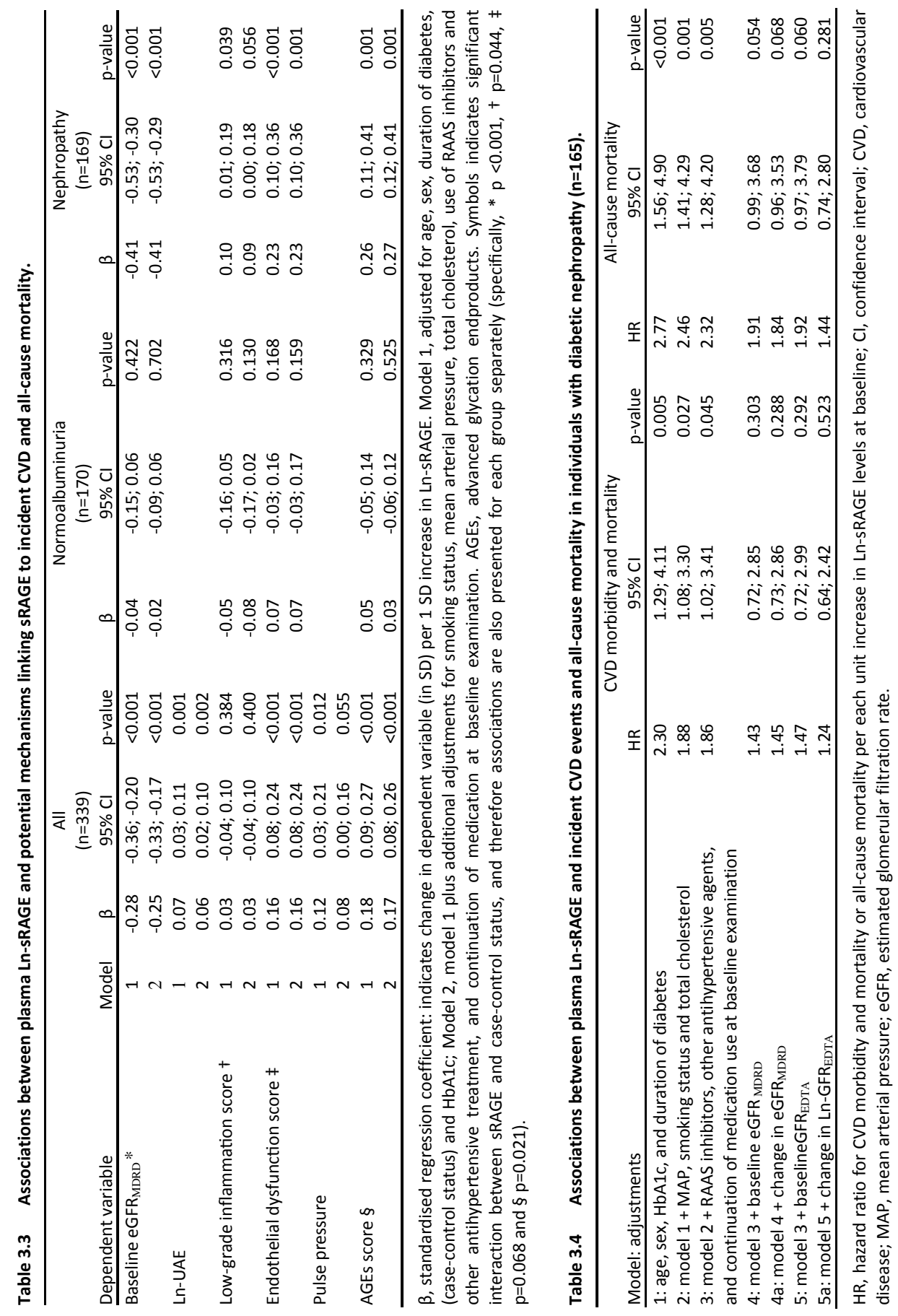




\section{Discussion}

The main findings of this study were two-fold. First, in patients with type 1 diabetes, higher levels of plasma SRAGE are associated with incident fatal and non-fatal CVD as well as all-cause mortality, independently of other 'traditional' cardiovascular risk factors. Second, these associations could be partially explained by SRAGE-associated impairment in renal clearance, particularly in patients with nephropathy. Our findings are in agreement with studies that have examined the associations of SRAGE with CVD, but these were limited by cross-sectional designs $(7,10-12)$. This is the first prospective study that has investigated the associations between plasma SRAGE and incident fatal and non-fatal CVD as well as all-cause mortality in a large sample of individuals with type 1 diabetes, and has also addressed potential mechanisms that could explain the associations observed.

We hypothesised SRAGE to act as a putative marker of RAGE expression. The adverse associations found between SRAGE and CVD but also between SRAGE and markers of renal and endothelial dysfunction, low-grade inflammation, pulse pressure and AGEs reported herein, which are in agreement with others (7,10-15), supported this hypothesis. However, sRAGE reflects the total pool of soluble RAGE in plasma, and thus consists of different variants. These can result from alternative splicing (e.g. endogenous secretory RAGE, esRAGE) (16) or from proteolytical cleavage of the membrane-bound RAGE (17). The exact functions of SRAGE in plasma are unknown but these may differ across different variants. Indeed, several studies have reported inverse and thus 'protective' associations between esRAGE, and (surrogate markers of) CVD (11,18-23). We have measured the total pool of plasma SRAGE only and therefore cannot discern whether the different variants of sRAGE have specific and potentially opposite associations with study outcomes. In addition, the extent to which levels of (e)sRAGE in plasma reflect local concentrations and have the same effects as in tissues need to be further clarified.

The associations of SRAGE with CVD and all-cause mortality were attenuated when further adjusted for baseline eGFR, the former association being no longer statistically significant. However, this adjustment explained only $28 \%$ of the increased CVD risk associated with higher sRAGE. In addition, independent associations of both SRAGE and creatinine with CVD have been reported in individuals with diabetes (10). Furthermore, we found that sRAGE contributed to an accelerated decline in GFR, as estimated by eGFR $R_{M D R D}$ or by GFR $_{\text {EDTA }}$ in subjects with diabetic nephropathy. This is in line with a recent study in which sRAGE was inversely associated with changes in eGFR in the course of 1-yr of follow-up in a large population of elderly women (24). These findings support the hypothesis of renal dysfunction being one of the intermediate factors linking sRAGE (as a reflection of RAGE expression) to vascular complications. However, we cannot discard the alternative (or concomitant) possibility, i.e. that baseline sRAGE levels may have been elevated as a consequence of impaired renal clearance. Indeed, our data also support this possibility; specifically, the association 
between higher baseline eGFR (per $10 \mathrm{ml} / \mathrm{min}$ per $1.73 \mathrm{~m}^{2}$ ) and incident CVD [HR=0.89 (95\% Cl 0.78-1.00)] was attenuated by $\sim 24 \%$ when further adjusted for Ln-sRAGE: to $H R=0.92$ (95\% $\mathrm{Cl} 0.81-1.04)$. These observations reflect the interrelationships between SRAGE and eGFR at baseline, the exact directions of which we cannot fully unravel in the present study. Nevertheless, and altogether, these observations support the view that higher sRAGE, due to, but also to a great extent independent of, impaired GFR are positively associated with CVD and all-cause mortality. Further studies with repeated data on both sRAGE and GFR are needed to disentangle the temporal order of these associations.

There are limitations to our study. Samples for analyses of SRAGE and other biomarkers were taken at baseline only, which impedes evaluation of the impact of changes in these variables on study outcomes. In addition, the relatively high interassay CV in the measurement of plasma SRAGE, and the potential misclassification of non-specific mortality as CVD-related mortality may have introduced non-differential biases, in which case the estimates reported herein may have been underestimated. However, we cannot discard the possibility that possible underreporting of non-fatal CVD introduced some differential bias affecting our results. Finally, although our findings did not suggest strong mediating effects of endothelial dysfunction, lowgrade inflammation, arterial stiffness and AGEs in the associations between SRAGE and study outcomes, we cannot fully exclude their potential mediating role due to the use of a selection of markers representing these processes.

In conclusion, higher plasma SRAGE levels, as a reflection of RAGE expression, are associated with incident fatal and non-fatal CVD as well as all-cause mortality in type 1 diabetes, and this may partially be explained by sRAGE-associated renal dysfunction in patients with nephropathy. 


\section{References}

1. Kalea AZ, Schmidt AM, Hudson BI. RAGE: a novel biological and genetic marker for vascular disease. Clin Sci (Lond) 2009;116:621-637

2. Cipollone F, lezzi A, Fazia M, Zucchelli M, Pini B, Cuccurullo C, De Cesare D, De Blasis G, Muraro R, Bei $R$, Chiarelli F, Schmidt AM, Cuccurullo F, Mezzetti A. The receptor RAGE as a progression factor amplifying arachidonate-dependent inflammatory and proteolytic response in human atherosclerotic plaques: role of glycemic control. Circulation 2003;108:1070-1077

3. Kislinger T, Fu C, Huber B, Qu W, Taguchi A, Du Yan S, Hofmann M, Yan SF, Pischetsrieder M, Stern D, Schmidt AM. N(epsilon)-(carboxymethyl)lysine adducts of proteins are ligands for receptor for advanced glycation end products that activate cell signaling pathways and modulate gene expression. J Biol Chem 1999;274:31740-31749

4. Harja E, Bu DX, Hudson BI, Chang JS, Shen X, Hallam K, Kalea AZ, Lu Y, Rosario RH, Oruganti S, Nikolla Z, Belov D, Lalla E, Ramasamy R, Yan SF, Schmidt AM. Vascular and inflammatory stresses mediate atherosclerosis via RAGE and its ligands in apoE-/- mice. J Clin Invest 2008;118:183-194

5. Basta G, Lazzerini G, Massaro M, Simoncini T, Tanganelli P, Fu C, Kislinger T, Stern DM, Schmidt AM, De Caterina R. Advanced glycation end products activate endothelium through signal-transduction receptor RAGE: a mechanism for amplification of inflammatory responses. Circulation 2002;105: 816-822

6. Wendt TM, Tanji N, Guo J, Kislinger TR, Qu W, Lu Y, Bucciarelli LG, Rong LL, Moser B, Markowitz GS, Stein G, Bierhaus A, Liliensiek B, Arnold B, Nawroth PP, Stern DM, D'Agati VD, Schmidt AM. RAGE drives the development of glomerulosclerosis and implicates podocyte activation in the pathogenesis of diabetic nephropathy. Am J Pathol 2003;162:1123-1137

7. Nin JW, Ferreira I, Schalkwijk CG, Prins MH, Chaturvedi N, Fuller JH, Stehouwer CD. Levels of soluble receptor for AGE are cross-sectionally associated with cardiovascular disease in type 1 diabetes, and this association is partially mediated by endothelial and renal dysfunction and by low-grade inflammation: the EURODIAB Prospective Complications Study. Diabetologia 2009;52:705-714

8. Astrup AS, Tarnow L, Rossing P, Pietraszek L, Riis Hansen P, Parving HH. Improved prognosis in type 1 diabetic patients with nephropathy: a prospective follow-up study. Kidney Int 2005;68:1250-1257

9. Astrup AS, Tarnow L, Pietraszek L, Schalkwijk CG, Stehouwer CD, Parving HH, Rossing P. Markers of endothelial dysfunction and inflammation in type 1 diabetic patients with or without diabetic nephropathy followed for 10 years: association with mortality and decline of glomerular filtration rate. Diabetes Care 2008;31:1170-1176

10. Nakamura K, Yamagishi S, Adachi H, Kurita-Nakamura Y, Matsui T, Yoshida T, Sato A, Imaizumi T. Elevation of soluble form of receptor for advanced glycation end products (sRAGE) in diabetic subjects with coronary artery disease. Diabetes Metab Res Rev 2007;23:368-371

11. Yan XX, Lu L, Peng WH, Wang LJ, Zhang Q, Zhang RY, Chen QJ, Shen WF. Increased serum HMGB1 level is associated with coronary artery disease in nondiabetic and type 2 diabetic patients. Atherosclerosis 2009;205:544-548

12. Humpert PM, Djuric Z, Kopf S, Rudofsky G, Morcos M, Nawroth PP, Bierhaus A. Soluble RAGE but not endogenous secretory RAGE is associated with albuminuria in patients with type 2 diabetes. Cardiovasc Diabetol 2007;6:9

13. Tan KC, Shiu SW, Chow WS, Leng L, Bucala R, Betteridge DJ. Association between serum levels of soluble receptor for advanced glycation end products and circulating advanced glycation end products in type 2 diabetes. Diabetologia 2006;49:2756-2762

14. Nakamura K, Yamagishi S, Adachi H, Matsui T, Kurita-Nakamura Y, Takeuchi M, Inoue H, Imaizumi T. Serum levels of soluble form of receptor for advanced glycation end products (SRAGE) are positively associated with circulating AGEs and soluble form of VCAM-1 in patients with type 2 diabetes. Microvasc Res 2008;76:52-56

15. Nakamura K, Yamagishi S, Adachi H, Kurita-Nakamura Y, Matsui T, Yoshida T, Imaizumi T. Serum levels of SRAGE, the soluble form of receptor for advanced glycation end products, are associated with inflammatory markers in patients with type 2 diabetes. Mol Med 2007;13:185-189 
16. Yonekura H, Yamamoto Y, Sakurai S, Petrova RG, Abedin MJ, Li H, Yasui K, Takeuchi M, Makita Z, Takasawa S, Okamoto $H$, Watanabe T, Yamamoto $H$. Novel splice variants of the receptor for advanced glycation end-products expressed in human vascular endothelial cells and pericytes, and their putative roles in diabetes-induced vascular injury. Biochem J 2003;370:1097-1109

17. Raucci A, Cugusi S, Antonelli A, Barabino SM, Monti L, Bierhaus A, Reiss K, Saftig P, Bianchi ME. A soluble form of the receptor for advanced glycation endproducts (RAGE) is produced by proteolytic cleavage of the membrane-bound form by the sheddase a disintegrin and metalloprotease 10 (ADAM10). Faseb J 2008;22:3716-3727

18. Peng WH, Lu L, Hu J, Yan XX, Zhang Q, Zhang RY, Chen QJ, Shen WF. Decreased serum esRAGE level is associated with angiographically determined coronary plaque progression in diabetic patients. Clin Biochem 2009;42:1252-1259

19. Lu L, Pu LJ, Zhang Q, Wang L, Kang S, Zhang RY, Chen QJ, Wang JG, De Caterina R, Shen WF. Increased glycated albumin and decreased esRAGE levels are related to angiographic severity and extent of coronary artery disease in patients with type 2 diabetes. Atherosclerosis 2009;206:540-545

20. Koyama H, Shoji T, Yokoyama H, Motoyama K, Mori K, Fukumoto S, Emoto M, Shoji T, Tamei H, Matsuki H, Sakurai S, Yamamoto Y, Yonekura H, Watanabe T, Yamamoto H, Nishizawa Y. Plasma level of endogenous secretory RAGE is associated with components of the metabolic syndrome and atherosclerosis. Arterioscler Thromb Vasc Biol 2005;25:2587-2593

21. Katakami N, Matsuhisa M, Kaneto H, Matsuoka TA, Sakamoto K, Yasuda T, Yamasaki Y. Endogenous secretory RAGE but not soluble RAGE is associated with carotid atherosclerosis in type 1 diabetes patients. Diab Vasc Dis Res 2008;5:190-197

22. Katakami N, Matsuhisa M, Kaneto H, Matsuoka TA, Sakamoto K, Yasuda T, Umayahara Y, Kosugi K, Yamasaki Y. Serum endogenous secretory RAGE level is an independent risk factor for the progression of carotid atherosclerosis in type 1 diabetes. Atherosclerosis 2009;204:288-292

23. Katakami N, Matsuhisa M, Kaneto H, Matsuoka TA, Sakamoto K, Nakatani Y, Ohtoshi K, HayaishiOkano R, Kosugi K, Hori M, Yamasaki Y. Decreased endogenous secretory advanced glycation end product receptor in type 1 diabetic patients: its possible association with diabetic vascular complications. Diabetes Care 2005;28:2716-2721

24. Semba RD, Ferrucci L, Fink JC, Sun K, Beck J, Dalal M, Guralnik JM, Fried LP. Advanced Glycation End Products and Their Circulating Receptors and Level of Kidney Function in Older Community-Dwelling Women. Am J Kidney Dis 2009;53:51-58 


\section{Chapter 4}

Higher plasma levels of advanced glycation end products are associated with incident cardiovascular disease and all-cause mortality in type 1 diabetes: a 12-yr follow-up study

Johanna W Nin*, Anders Jorsal*, Isabel Ferreira, Casper G Schalkwijk, Martin H Prins, Hans-Henrik Parving, Lise Tarnow, Peter Rossing, Coen D Stehouwer

*Equal contribution

Diabetes Care 2011;34:442-447 


\section{Abstract}

\section{Background and objective}

To investigate the associations of plasma levels of advanced glycation end products (AGEs) with incident cardiovascular disease (CVD) and all-cause mortality in type 1 diabetes, and the extent to which any such associations could be explained by endothelial and renal dysfunction, low-grade inflammation and arterial stiffness.

\section{Methods}

We prospectively followed 169 individuals with diabetic nephropathy and 170 individuals with persistent normoalbuminuria who were free of CVD at study entry and in whom levels of $\mathrm{N} \varepsilon$-(carboxymethyl)lysine, $\mathrm{N} \varepsilon$-(carboxyethyl)lysine, pentosidine and other biomarkers were measured at baseline. The median followup duration was 12.3 (inter-quartile range: 7.6-12.5) years.

Results

During the course of follow-up, 82 individuals (24.2\%) died; $85(25.1 \%)$ suffered a fatal $(n=48)$ and/or nonfatal ( $n=53$ ) CVD event. The incidence of fatal and non-fatal CVD, and of all-cause mortality increased with higher baseline levels of AGEs independently of traditional CVD risk factors: hazard ratio $(H R)=1.30$ $(95 \% \mathrm{Cl}=1.03$ to 1.66$)$ and $\mathrm{HR}=1.27$ (1.00 to 1.62$)$, respectively. These associations were not attenuated after further adjustments for markers of renal or endothelial dysfunction, low-grade inflammation or arterial stiffness.

\section{Conclusions}

Higher levels of AGEs are associated with incident fatal and non-fatal CVD as well as all-cause mortality in individuals with type 1 diabetes, independently of other risk factors and of several potential AGEs-related pathophysiological mechanisms. AGEs may thus explain, in part, the increased cardiovascular disease and mortality attributable to type 1 diabetes, and constitute a specific target for treatment in these patients. 


\section{Introduction}

Diabetes is characterised by hyperglycaemia and associated with increased cardiovascular disease (CVD) risk (1). Advanced glycation end products (AGEs) may link hyperglycaemia to the development of vascular complications in diabetes (2). AGEs affect cells in three general ways: 1 ) cellular functions can be altered when intracellular proteins are modified by AGEs, 2) modification of extracellular matrix proteins results in abnormal interactions betweens these proteins, and 3) circulating AGEs can bind to AGE receptors, which could induce receptor-mediated production of reactive oxygen species and activate transcription factor NF-kB, thereby leading to deleterious changes in cellular processes (2).

Several studies so far have examined the associations between various plasma AGEs and microvascular and macrovascular complications in subjects with (3-12) or without (6-8,13-15) diabetes, most of which were confined to specific study populations (i.e. in elderly, patients with end stage renal failure, patients with heart failure or women only) $(6,7,13,14)$ and/or had a cross-sectional design $(3,5,10-12)$. Among the few prospective studies, most have reported positive associations between plasma AGEs and (CVD) mortality in patients with $(8,9)$ or without $(6,7,14,15)$ type 2 diabetes. However, so far, no prospective studies have investigated the associations between plasma AGEs and incident cardiovascular complications in patients with type 1 diabetes. In addition, the mechanisms through which AGEs could lead to the development of cardiovascular disease in these individuals are unclear. Endothelial (2) and renal dysfunction (16), low-grade inflammation $(2,14)$ and arterial stiffness (2) could constitute such mechanisms.

In view of these considerations, we have investigated, in a 12-yr prospective follow-up study; first, whether plasma levels of $\mathrm{N}^{\varepsilon}$-(carboxyethyl)lysine (CEL), $\mathrm{N}^{\varepsilon}$-(carboxymethyl)lysine $(\mathrm{CML})$ and pentosidine were associated with incident fatal and non-fatal CVD as well as all-cause mortality in individuals with type 1 diabetes; and second, the extent to which any such associations were explained (i.e. mediated) by markers of endothelial and renal dysfunction, low-grade inflammation, and arterial stiffness.

\section{Methods}

\section{Study population and design}

In 1993, 199 patients with type 1 diabetes and diabetic nephropathy defined according to clinical criteria [i.e. persistent macroalbuminuria ( $>300 \mathrm{mg} / 24 \mathrm{~h}$ ) in at least two out of three previous consecutive 24-h urine collections, in the presence of diabetic retinopathy and the absence of other kidney or urinary tract disease] and 192 with persistent normoalbuminuria (i.e. urinary excretion rate $<30 \mathrm{mg} / 24 \mathrm{~h}$ ) were 
recruited from the outpatient clinic at Steno Diabetes Center for a prospective observational follow-up study. Details of the inclusion criteria and selection procedures have been described elsewhere (17). The study was approved by the local ethics committee, in accordance with the Helsinki Declaration, and all patients gave their informed written consent.

\section{Baseline investigations}

\section{Biomarkers}

Analyses of the biomarkers were done on frozen $\left(-80^{\circ} \mathrm{C}\right)$ samples and were performed at a central laboratory by C.G.S.

The AGEs CML, CEL and pentosidine were measured as decribed $(18,19)$ with minor modifications. Briefly, (to measure CEL, CML and pentosidine) $50 \mu$ plasma was mixed with $100 \mu \mathrm{l}$ water in a $10 \mathrm{ml}$ glass tube with a Teflon-lined screw-cap. To prevent formation of AGEs from early glycation products during sample preparation, plasma samples were reduced by $500 \mu$ sodium borohydride borate buffer $(200 \mathrm{mM}$, $\mathrm{pH}$ 9.2) before precipitation. This mixture was allowed to stand for $2 \mathrm{~h}$ at room temperature. Proteins were then precipitated by addition of $2 \mathrm{ml} 20 \%$ trichloroacetic acid and centrifuged for $10 \mathrm{~min}\left(4^{\circ} \mathrm{C}\right)$ at $4500 \times \mathrm{g}$. The supernatant was carefully removed by aspiration with a Pasteur pipette. The protein pellet was washed once by adding $2 \mathrm{ml} 5 \%$ trichloroacetic acid followed by centrifugation and removal of the supernatant. The samples were hydrolyzed by adding $1000 \mu \mathrm{l} 6 \mathrm{~N} \mathrm{HCl}$ and incubated for $18 \mathrm{~h}$ at $110^{\circ} \mathrm{C}$.

After hydrolysis, $100 \mu \mathrm{l}$ of these samples were evaporated to dryness at $80^{\circ} \mathrm{C}$ under a stream of nitrogen gas and reconstituted in $200 \mu \mathrm{l} 0.5 \mathrm{mM}$ tridecafluoroheptanoic acid for the CEL and CML measurements. Five microliters of this solution was injected on the ultra-performance liquid chromatography tandem mass spectrometry. Liquid chromatography was performed at $30^{\circ} \mathrm{C}$ using an Acquity UPLC BEH C18, $1.7 \mu \mathrm{m}, 2.1 \times 100 \mathrm{~mm}$ column (Waters, Milford, MA) and the Micromass Quattro Premier XE Tandem Mass Spectrometer (Waters, Milford, MA) was used in the multiple reaction monitoring mode in the ESI-positive mode. The intra- and inter-assay CVs were $7.3 \%$ and $2.0 \%$ for CEL, and $3.5 \%$ and $3.6 \%$ for CML, respectively.

For the pentosidine measurement $900 \mu \mathrm{l}$ of the hydrolysed samples were evaporated to dryness at $80^{\circ} \mathrm{C}$ under a stream of nitrogen gas and reconstituted in $200 \mu \mathrm{l} 25 \mathrm{mM}$ citric acid/l. This solution was centrifuged for $10 \mathrm{~min}\left(4^{\circ} \mathrm{C}\right)$ at $4500 \times \mathrm{g}$ and ten microliters of this solution was injected on the high-performance liquid chromatography system. Detection was carried out using a Jasco type 821-FP spectrofluorometer (Jasco Benelux, Maarssen, The Netherlands) set at an excitation and emission wavelength of 325 and $385 \mathrm{~nm}$, respectively. The intra- and inter-assay CVs were $2.7 \%$ and $2.8 \%$ for pentosidine, respectively. 
High-sensitivity C-reactive protein (hsCRP) and secreted phospholipase A2 (sPLA2) were determined by enzyme-linked immunosorbent assays (ELISA) as described previously (20). Commercially available ELISA kits were used for measurements of plasma soluble vascular cell adhesion molecule-1 (sVCAM-1), soluble intercellular adhesion molecule-1 (sICAM-1) and interleukin-6 (IL-6) (Quantikine High Sensitivity; R\&D Systems, Oxon, U.K.). The intra- and inter-assay CVs of these immunoassays were $<8 \%$.

\section{Other baseline assessments}

All investigations were performed in the morning after an overnight fast. No antihypertensive medication was ever prescribed in $24 \%$ of patients with nephropathy and $88 \%$ of the normoalbuminuric patients. All of the remaining patients were asked to stop their antihypertensive and diuretic treatment 8 days before the examination. Arterial blood pressure was measured twice with an appropriate cuff size following at least 10 minutes rest in the supine position. Mean arterial pressure (MAP) was calculated as [systolic blood pressure $+(2 *$ diastolic blood pressure $)] / 3$. Pulse pressure was calculated by subtracting the diastolic from the systolic blood pressure, and used as a marker of arterial stiffness (21). Body mass index (BMI) was calculated by dividing weight by height squared. Urinary albumin excretion (UAE) was measured by an enzyme immunoassay from 24-h urine collections. Serum creatinine concentration was assessed by a kinetic Jaffé method. In all patients glomerular filtration rate (eGFR) was estimated according to the short Modification of Diet in Renal Disease equation $(\mathrm{MDRD})=186 *$ serum creatinine $(\mathrm{mg} / \mathrm{dl})]^{-1.154} *$ [age $]^{-0.203} *[0.742$ if patient is female]. Patients were interviewed using the WHO cardiovascular questionnaire. Individuals were categorised into three groups according to their smoking status as never, former or current smokers.

\section{Follow-up and study end-points}

All patients were followed up to the last visit at Steno Diabetes Center, until 1 September 2006 or until death $(n=82)$ or emigration $(n=3)$. All patients were traced through the national register during autumn 2006. If a patient had died before 1 September 2006, the date of death was recorded and information on the primary cause of death was obtained from the death certificate, which was reviewed by two independent observers. Additional available information from necropsy reports was also included. All deaths were classified as cardiovascular unless an unequivocal noncardiovascular cause was established. In all patients alive at the end of follow-up nonfatal cardiovascular events were retrieved from their patient files from Steno Diabetes Center and/or other hospital records. The primary study outcome was a combined end-point of fatal and non-fatal cardiovascular disease (i.e. myocardial infarction, percutaneous coronary intervention, coronary bypass grafting, amputation due to 
ischaemia, vascular surgery for peripheral atherosclerotic disease and stroke), and the secondary outcome was all-cause mortality.

\section{Statistical analyses}

All analyses were performed with the Statistical Package for Social Sciences (SPSS) version 15.0 for Windows (SPSS, Chicago, IL, USA).

Variables with a skewed distribution, i.e. triglycerides, CRP, IL-6, SPLA2, UAE and pentosidine, were $\log _{e}$ transformed prior to further analyses. Comparisons of baseline characteristics between groups were performed with Student's $t$ or $\chi^{2}$ tests, as appropriate. To investigate the association between CEL, CML, Ln-pentosidine and an AGEs score (calculated by averaging the $z$ scores of CEL, CML and Ln-pentosidine) on the one hand and incident CVD as well as all-cause mortality on the other, we used Cox proportional hazards regression models. These analyses were adjusted, first, for sex, age, duration of diabetes, case-control status and $\mathrm{HbA1c}$; second, for other cardiovascular risk factors (i.e. BMI, smoking status, total cholesterol and MAP); and third, for the use of renin-angiotensin-aldosterone system (RAAS) inhibitors and/or other antihypertensive treatment. This model was then further adjusted for markers of renal dysfunction, (i.e. eGFR $\mathrm{MDRD}_{\mathrm{M}}$ and $\mathrm{Ln}-\mathrm{UAE}$ ), low-grade inflammation (expressed as a total score computed by averaging the $z$ scores of Ln-IL-6, Ln-CRP, sICAM-1 and Ln-sPLA2), endothelial dysfunction (expressed as a total score computed by averaging the $z$ scores of SVCAM-1 and sICAM-1), and arterial stiffness (i.e. pulse pressure); these markers were entered one at a time to ascertain the extent to which any such marker could attenuate (i.e. explain) the strength of the association between the AGEs and study end-points, which were given as hazard ratios (HR) with $95 \%$ confidence intervals (Cls).

We used linear regression analyses to investigate the cross-sectional associations between CEL, CML, Ln-pentosidine and AGEs score on the one hand and markers of renal dysfunction, low-grade inflammation, endothelial dysfunction, and arterial stiffness on the other. Results of these analyses are expressed in standardised regression coefficients to allow comparison of the strength of the association between the AGEs and each of these variables.

Finally, we investigated whether the associations listed above differed between patients with normoalbuminuria and those with nephropathy by adding interaction terms to our models, the significance of which was judged on the basis of a p-value $<0.1$ for the interaction term. We found no such interactions and therefore all results are presented for the two groups combined. 


\section{Results}

Of the 391 patients included in this study, we excluded 17 (1 with nephropathy and 16 with normoalbuminuria) in whom follow-up data were not obtained, 4 with missing data on baseline biomarkers levels (1 patient with nephropathy and 3 patients with normoalbuminuria), 7 with end stage renal failure and 24 with prior CVD at baseline (21 patients with nephropathy and 3 with normoalbuminuria). Results reported herein thus refer to 339 patients (170 with persistent normoalbuminuria and 169 with nephropathy at baseline).

During the course of follow-up [median: 12.3 years (inter-quartile range 7.6-12.5)], 82 individuals (24.2\%) died; 85 (25.1\%) suffered a fatal $(n=48)$ and/or non-fatal $(n=53)$ CVD event. Individuals with incident CVD events or who had died at follow-up had, at baseline, higher levels of AGEs and a more adverse atherosclerotic risk profile as illustrated by the more unfavorable levels of traditional risk factors, markers of endothelial dysfunction, low-grade inflammation and pulse pressure (Table 4.1).

After adjustments for age, sex, duration of diabetes, HbA1c, case-control status, other risk factors and the use of medication, the incidence of fatal and non-fatal CVD increased with a HR of 1.30 (1.03 to 1.66) per 1 SD increase in baseline levels of AGES score (Table 4.2, model 3). The HRs for incident fatal and non-fatal CVD per 1 SD increase in baseline CEL, CML and Ln-pentosidine were comparable: HR=1.24 (1.01 to 1.52), $H R=1.22$ (0.96 to 1.56) and $H R=1.29$ (1.03 to 1.60), respectively (Table 4.3, model 3). Similar results were found for the associations between the AGEs and incident all-cause mortality: $H R=1.22$ (1.00 to 1.49), $H R=1.17$ (0.91 to 1.50) and $H R=1.28$ (1.03 to 1.59), respectively (Table 4.2 and 4.4 for analyses for each AGE separately).

If we excluded from the analyses the CVD cases to which an unequivocal CVDrelated cause of death could not be ascribed, our results did not change: $H R=1.31$ (1.02 to 1.70) after adjustments for age, sex, duration of diabetes, HbA1c, casecontrol status, other risk factors and the use of medication.

The associations between AGEs and CVD and all-cause mortality were comparable between patients with normoalbuminuria and nephropathy at baseline: $H R=1.60$ (95\%Cl: 0.68 to 3.80 ) and $H R=1.35$ (1.05 to 1.73) for CVD, and $H R=1.32$ (0.48 to 3.63) and 1.37 (1.06 to 1.77) for all-cause mortality, respectively. It should be noted that the wider confidence intervals around the estimates in the normoalbuminuria group were most likely due to the relatively low number of events (21 CVD and 18 deaths in this group).

Adjustment for markers of renal dysfunction (model 4a), low-grade inflammation (model 4b), endothelial dysfunction (model 4c) and arterial stiffness (model 4d) did not attenuate the associations between the AGEs and the study end-points, despite the adverse associations between plasma AGEs and most of these pathophysiological mechanisms (Table 4.5 and 4.6 for the associations presented for each AGE separately). 


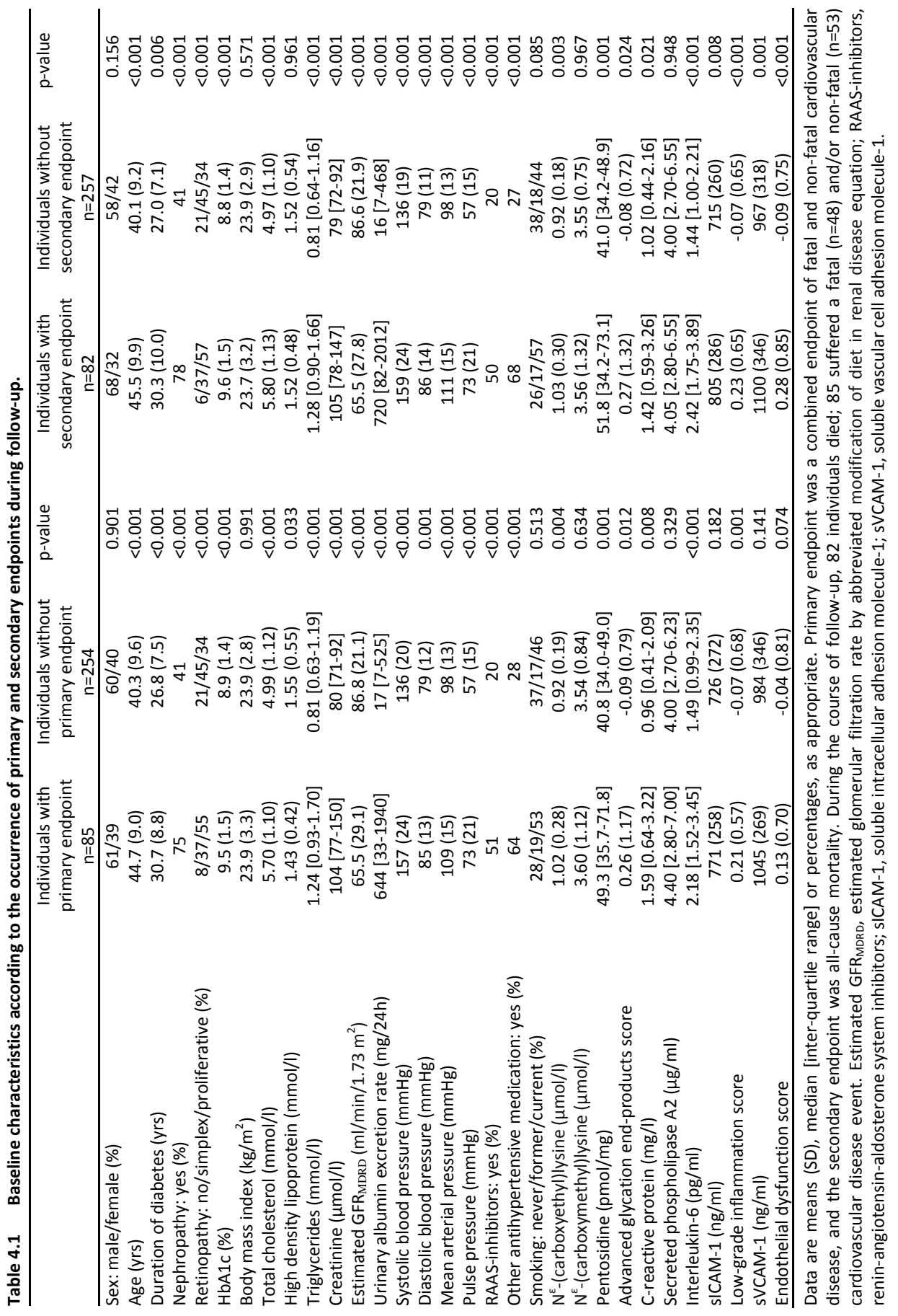


Table 4.2 Associations between baseline plasma AGEs and incident primary and secondary end points ( $n=339)$.

\begin{tabular}{|c|c|c|c|c|c|c|}
\hline \multirow[b]{2}{*}{ Model } & \multicolumn{3}{|c|}{ Primary endpoint (85 events) } & \multicolumn{3}{|c|}{ Secondary endpoint (82 events) } \\
\hline & $\mathrm{HR}$ & $95 \% \mathrm{Cl}$ & $\mathrm{p}$-value & $\mathrm{HR}$ & $95 \% \mathrm{Cl}$ & p-value \\
\hline 1 & 1.33 & $1.05 ; 1.69$ & 0.018 & 1.34 & $1.06 ; 1.69$ & 0.013 \\
\hline 2 & 1.36 & $1.08 ; 1.73$ & 0.011 & 1.34 & $1.06 ; 1.69$ & 0.013 \\
\hline $3 a$ & 1.35 & $1.07 ; 1.71$ & 0.013 & 1.36 & $1.07 ; 1.72$ & 0.011 \\
\hline $3 b$ & 1.31 & $1.03 ; 1.66$ & 0.026 & 1.25 & $0.99 ; 1.59$ & 0.060 \\
\hline 3 & 1.30 & $1.03 ; 1.66$ & 0.029 & 1.27 & $1.00 ; 1.62$ & 0.047 \\
\hline $4 a$ & 1.31 & $0.99 ; 1.73$ & 0.057 & 1.27 & $0.95 ; 1.68$ & 0.103 \\
\hline $4 b$ & 1.26 & $1.00 ; 1.61$ & 0.055 & 1.24 & $0.98 ; 1.58$ & 0.076 \\
\hline $4 c$ & 1.31 & $1.00 ; 1.62$ & 0.028 & 1.26 & $1.00 ; 1.59$ & 0.051 \\
\hline $4 d$ & 1.30 & $1.02 ; 1.66$ & 0.036 & 1.28 & $1.01 ; 1.64$ & 0.046 \\
\hline
\end{tabular}

Primary endpoint was a combined endpoint of fatal and non-fatal cardiovascular disease (CVD), and the secondary endpoint was all-cause mortality. During the course of follow-up, 82 individuals died; 85 suffered a fatal $(n=48)$ and/or non-fatal $(n=53)$ CVD event. HR, hazard ratio for primary or secondary endpoint per 1 SD increase in baseline AGEs score; AGEs, advanced glycation end products; $\mathrm{Cl}$, confidence interval. Model 1 is adjusted for age, sex, HbA1c, case-control status and duration of diabetes; Model 2: model $1+$ body mass index, mean arterial pressure, smoking status and total cholesterol; Model 3a: model $2+$ reninangiotensin-aldosterone system (RAAS) inhibitors; Model 3b: model 2 + other antihypertensive agents; Model 3: model 2 + RAAS inhibitors and other antihypertensive agents; Model 4a: model 3 + estimated glomerular filtration rate by abbreviated modification of diet in renal disease equation and Ln-urinary albumin excretion rate; Model 4b: model 3 + low-grade inflammation score; Model 4c: model $3+$ endothelial dysfunction score; Model $4 \mathrm{~d}$ : model $3+$ pulse pressure.

Table 4.3 Associations between baseline plasma AGEs and incident fatal and non-fatal cardiovascular disease ( $n=339 / 85$ events).

\begin{tabular}{|c|c|c|c|c|c|c|c|c|c|}
\hline \multirow[b]{2}{*}{ Model } & \multicolumn{3}{|c|}{ CEL } & \multicolumn{3}{|c|}{$\mathrm{CML}$} & \multicolumn{3}{|c|}{ Ln-pentosidine } \\
\hline & $\mathrm{HR}$ & $95 \% \mathrm{Cl}$ & $p$-value & $\mathrm{HR}$ & $95 \% \mathrm{Cl}$ & $p$-value & $\mathrm{HR}$ & $95 \% \mathrm{Cl}$ & p-value \\
\hline$\overline{1}$ & 1.31 & $1.07 ; 1.61$ & 0.009 & 1.12 & $0.88 ; 1.43$ & 0.347 & 1.35 & $1.09 ; 1.68$ & 0.006 \\
\hline 2 & 1.29 & $1.05 ; 1.58$ & 0.015 & 1.24 & $0.98 ; 1.57$ & 0.078 & 1.35 & $1.09 ; 1.67$ & 0.006 \\
\hline $3 a$ & 1.28 & $1.04 ; 1.57$ & 0.020 & 1.24 & $0.98 ; 1.57$ & 0.074 & 1.34 & $1.08 ; 1.66$ & 0.008 \\
\hline $3 b$ & 1.25 & $1.01 ; 1.53$ & 0.036 & 1.22 & $0.96 ; 1.56$ & 0.100 & 1.29 & $1.04 ; 1.61$ & 0.021 \\
\hline 3 & 1.24 & $1.01 ; 1.52$ & 0.041 & 1.22 & $0.96 ; 1.56$ & 0.098 & 1.29 & $1.03 ; 1.60$ & 0.024 \\
\hline $4 a$ & 1.21 & $0.95 ; 1.53$ & 0.118 & 1.23 & $0.96 ; 1.58$ & 0.108 & 1.30 & $1.00 ; 1.70$ & 0.048 \\
\hline $4 b$ & 1.21 & $0.98 ; 1.49$ & 0.075 & 1.19 & $0.94 ; 1.51$ & 0.152 & 1.25 & $1.01 ; 1.56$ & 0.043 \\
\hline $4 c$ & 1.24 & $1.01 ; 1.52$ & 0.041 & 1.23 & $0.97 ; 1.55$ & 0.095 & 1.29 & $1.04 ; 1.60$ & 0.023 \\
\hline $4 d$ & 1.24 & $1.00 ; 1.52$ & 0.047 & 1.24 & $0.97 ; 1.58$ & 0.088 & 1.27 & $1.01 ; 1.59$ & 0.042 \\
\hline $5 *$ & 1.12 & $0.75 ; 1.65$ & 0.587 & 0.93 & $0.60 ; 1.44$ & 0.736 & 1.24 & $0.87 ; 1.76$ & 0.237 \\
\hline
\end{tabular}

$\mathrm{HR}$, hazard ratio for fatal and non-fatal cardiovascular disease per 1 SD increase in baseline CEL, CML or Lnpentosidine levels; AGEs, advanced glycation end products; CEL, $\mathrm{N}^{\varepsilon}$-(carboxyethyl)lysine; CML, $\mathrm{N}^{\varepsilon}$-(carboxymethyl)lysine; $\mathrm{Cl}$, confidence interval. Model 1 is adjusted for age, sex, $\mathrm{HbA} 1 \mathrm{c}$, case-control status and duration of diabetes; Model 2: model $1+$ body mass index, mean arterial pressure, smoking status and total cholesterol; Model 3a: model 2 + renin-angiotensin-aldosterone system (RAAS) inhibitors; Model 3b: model $2+$ other antihypertensive agents; Model 3: model $2+$ RAAS inhibitors and other antihypertensive agents; Model 4a: model 3 + estimated glomerular filtration rate by abbreviated modification of diet in renal disease equation and Ln-urinary albumin excretion rate; Model 4b: model $3+$ low-grade inflammation score; Model 4c: model 3 + endothelial dysfunction score; Model 4d: model $3+$ pulse pressure; Model 5: model $3+\mathrm{CEL}, \mathrm{CML}$ and Ln-pentosidine. *Due to the high correlations $(r>0.7)$ between all three AGEs, this model may suffer from collinearity and may not be appropriate. 
Table 4.4 Associations between baseline plasma AGEs and incident all-cause mortality ( $n=339 / 82$ events).

\begin{tabular}{|c|c|c|c|c|c|c|c|c|c|}
\hline \multirow[b]{2}{*}{ Model } & \multicolumn{3}{|c|}{ CEL } & \multicolumn{3}{|c|}{ CML } & \multicolumn{3}{|c|}{ Ln-pentosidine } \\
\hline & $\mathrm{HR}$ & $95 \% \mathrm{Cl}$ & $p$-value & $\mathrm{HR}$ & $95 \% \mathrm{Cl}$ & p-value & $\mathrm{HR}$ & $95 \% \mathrm{Cl}$ & p-value \\
\hline 1 & 1.30 & $1.08 ; 1.58$ & 0.006 & 1.09 & $0.85 ; 1.40$ & 0.509 & 1.42 & $1.15 ; 1.76$ & 0.001 \\
\hline 2 & 1.27 & $1.04 ; 1.55$ & 0.017 & 1.21 & $0.95 ; 1.54$ & 0.133 & 1.35 & $1.10 ; 1.67$ & 0.005 \\
\hline $3 a$ & 1.29 & $1.05 ; 1.57$ & 0.014 & 1.21 & $0.95 ; 1.54$ & 0.128 & 1.37 & $1.11 ; 1.70$ & 0.004 \\
\hline $3 b$ & 1.20 & $0.99 ; 1.47$ & 0.067 & 1.16 & $0.91 ; 1.49$ & 0.234 & 1.26 & $1.01 ; 1.56$ & 0.037 \\
\hline 3 & 1.22 & $1.00 ; 1.49$ & 0.051 & 1.17 & $0.91 ; 1.50$ & 0.215 & 1.28 & $1.03 ; 1.59$ & 0.027 \\
\hline $4 a$ & 1.19 & $0.94 ; 1.50$ & 0.153 & 1.16 & $0.88 ; 1.51$ & 0.297 & 1.30 & $1.00 ; 1.70$ & 0.054 \\
\hline $4 b$ & 1.20 & $0.98 ; 1.48$ & 0.076 & 1.14 & $0.89 ; 1.46$ & 0.314 & 1.25 & $1.01 ; 1.56$ & 0.043 \\
\hline $4 c$ & 1.21 & $0.99 ; 1.48$ & 0.058 & 1.16 & $0.92 ; 1.48$ & 0.213 & 1.27 & $1.03 ; 1.58$ & 0.029 \\
\hline $4 d$ & 1.23 & $1.00 ; 1.51$ & 0.049 & 1.19 & $0.92 ; 1.54$ & 0.179 & 1.28 & $1.02 ; 1.60$ & 0.032 \\
\hline 5* & 1.18 & $0.79 ; 1.76$ & 0.413 & 0.80 & $0.50 ; 1.28$ & 0.346 & 1.29 & $0.91 ; 1.84$ & 0.159 \\
\hline
\end{tabular}

$\mathrm{HR}$, hazard ratio for all-cause mortality per $1 \mathrm{SD}$ increase in baseline CEL, CML or Ln-pentosidine levels; AGEs, advanced glycation end products; $\mathrm{CEL}, \mathrm{N}^{\varepsilon}$-(carboxyethyl)lysine; $\mathrm{CML}, \mathrm{N}^{\varepsilon}$-(carboxymethyl)lysine; $\mathrm{Cl}$, confidence interval. Model 1 is adjusted for age, sex, HbA1c, case-control status and duration of diabetes; Model 2: model 1 + body mass index, mean arterial pressure, smoking status and total cholesterol; Model 3a: model 2 + renin-angiotensin-aldosterone system (RAAS) inhibitors; Model 3b: model 2 + other antihypertensive agents; Model 3: model 2 + RAAS inhibitors and other antihypertensive agents; Model 4a: model 3 + estimated glomerular filtration rate by abbreviated modification of diet in renal disease equation and Ln-urinary albumin excretion rate; Model 4b: model 3 + low-grade inflammation score; Model 4c: model 3 + endothelial dysfunction score; Model 4d: model 3 + pulse pressure; Model 5: model $3+\mathrm{CEL}, \mathrm{CML}$, Ln-pentosidine. *Due to the high correlations ( $r>0.7)$ between all three AGEs, this model may suffer from collinearity and may not be appropriate.

Table 4.5 Associations between plasma AGEs and potential mechanisms linking AGEs to incident CVD and all-cause mortality ( $n=339)$.

\begin{tabular}{lcccc}
\hline Dependent variable & & \multicolumn{3}{c}{ All $\mathrm{n}=339$} \\
\cline { 3 - 5 } & Model & $\beta$ & $95 \% \mathrm{Cl}$ & $\mathrm{p}$-value \\
\hline Baseline eGFR & 1 & -0.32 & $-0.42 ; 0.23$ & $<0.001$ \\
Ln-urinary albumin excretion rate & 2 & -0.29 & $-0.39 ;-0.20$ & $<0.001$ \\
& 1 & -0.07 & $-0.12 ;-0.02$ & 0.008 \\
Inflammatory score & 2 & -0.04 & $-0.09 ; 0.00$ & 0.071 \\
Endothelial dysfunction score & 1 & 0.06 & $-0.02 ; 0.14$ & 0.123 \\
& 2 & 0.09 & $0.01 ; 0.17$ & 0.036 \\
Pulse pressure & 1 & 0.13 & $0.03 ; 0.22$ & 0.008 \\
& 2 & 0.13 & $0.03 ; 0.23$ & 0.009 \\
\hline
\end{tabular}

$\beta$, standardised regression coefficient: indicates change in dependent variable (in SD) per 1 SD increase in baseline AGEs score; AGEs, advanced glycation end products; CVD, cardiovascular disease; $\mathrm{Cl}$, confidence

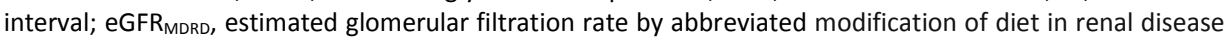
equation. Model 1, adjusted for age, sex, duration of diabetes, case-control status and HbA1c; Model 2, model 1 + body mass index, smoking status, mean arterial pressure, total cholesterol, use of reninangiotensin-aldosterone system inhibitors, other antihypertensive treatment and continuation of medication at baseline examination. 


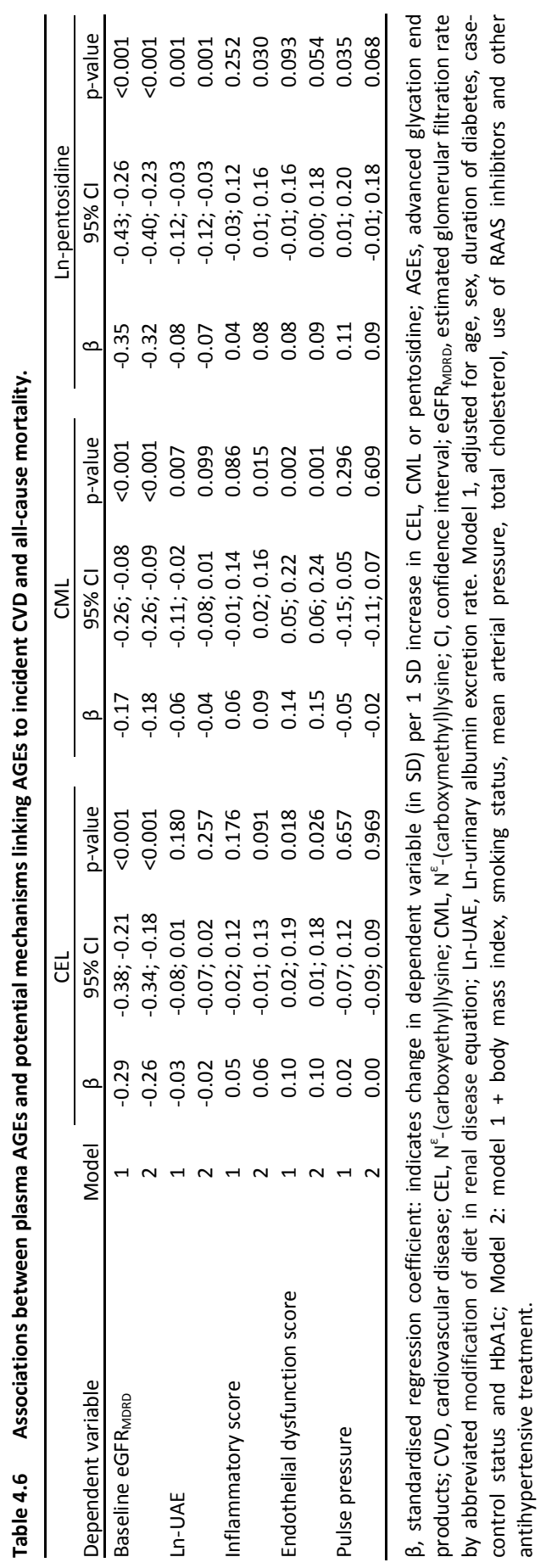


Because the two markers (Ln-UAE and eGFR) of renal dysfunction were interrelated (standardised $\beta=-0.52,95 \% \mathrm{Cl}:-0.61$ to -0.43 ) and because both markers individually were inversely associated with AGEs (Table 4.5), while Ln-UAE was positively and eGFR was inversely associated with incident CVD, adjustments for renal dysfunction were performed by adjustments for both baseline Ln-UAE and eGFR to ensure the most appropriate correction for renal dysfunction (model 4a).

\section{Additional analyses}

Patients were asked to stop their antihypertensive and diuretic treatment 8 days before the examination. However, $27 \%$ and $4 \%$ of patients in the nephropathy and normoalbuminuria groups, respectively, had taken antihypertensive medication on the day of examination. The associations between AGEs and study outcomes did not appreciably differ between those who did or did not withhold their medication at baseline examination, nor did they change after additional adjustment for medication withdrawal status (data not shown).

\section{Discussion}

The main findings of this study were that in patients with type 1 diabetes higher baseline plasma levels of AGEs are associated with incident fatal and non-fatal cardiovascular disease as well as all-cause mortality, independently of 'traditional' cardiovascular risk factors, but also of markers of renal and endothelial dysfunction, low-grade inflammation and arterial stiffness. AGEs may thus constitute a specific target for treatment in order to prevent the excess cardiovascular disease and mortality observed in patients with type 1 diabetes.

Our results are in agreement with studies that have shown positive associations between plasma levels of AGEs or Amadori products, specifically non-CML AGE (11), pentosidine (3) and Amadori-albumin (22), and microvascular complications, but these studies were limited by their cross-sectional designs $(3,11,22)$ and/or were confined to small study populations $(3,11)$. This is the first prospective study that has examined the associations between plasma CEL, CML and pentosidine and incident fatal and non-fatal cardiovascular disease as well as all-cause mortality in a large sample of patients with type 1 diabetes, and has also addressed the potential pathophysiological mechanisms that may explain the associations observed. Our findings are also in agreement with two previous studies which have related higher skin autofluorescence (23), as a potential marker for tissue AGEs accumulation, and AGEs levels in skin collagen (24) with incident coronary heart disease and microvascular complications in patients with type 1 diabetes, respectively. Whether and to what extent skin autofluorescence is associated with plasma AGEs levels still needs to be investigated. 
We investigated three out of many different AGEs, all of which were associated with incident fatal and non-fatal CVD to a similar extent. Based on their molecular characteristics one could hypothesise that each AGE could exert unfavorable effects on cellular functions through (partially) different pathways. However, CEL (as a putative marker of intracellular glycation), CML (as a potential ligand of RAGE), and pentosidine (as one of the cross-linking AGEs) were highly correlated with each other (correlation coefficients all $>0.7$ ) and, therefore, in mutually adjusted analyses, none was independently associated with study outcomes (Table 4.3 and 4.4, model 5). These findings suggest that the adverse effects of CEL, CML and pentosidine on cardiovascular risk in type 1 diabetes largely overlap. Further studies may be needed to unravel the specific effects, if any, of intracellular protein glycation, formation of cross-links in the extracellular matrix, and the AGE-RAGE axis on increased CVD risk attributable to AGEs in type 1 diabetes.

Although some minor differences were found in the adverse associations between each of the AGEs on the one hand and markers of renal and endothelial dysfunction, low-grade inflammation and pulse pressure on the other, overall, none of these pathophysiological mechanisms investigated explained the positive associations between the AGEs and incident fatal and non-fatal CVD as well as all-cause mortality. We cannot discard the possibility that the use of a selection of markers representing renal and endothelial dysfunction, low-grade inflammation and arterial stiffness may have led to an underestimation of their mediating effects in those associations, however. Furthermore, other mechanisms (e.g. oxidative stress) not investigated herein could also play a role in the link between AGEs and CVD. It is noteworthy that markers of renal dysfunction, specifically UAE (but not eGFR), and of arterial stiffness, i.e. pulse pressure, did not attenuate the associations between AGEs and incident fatal and non-fatal CVD as well as all-cause mortality, but were associated with incident fatal and non-fatal CVD independently of AGEs and other risk factors [HR=2.19 (1.17 to 4.10) and $H R=1.53$ (1.15 to 2.02), respectively]. These findings thus suggest that all these three mechanisms may need specific monitoring/treatment in order to decrease excess cardiovascular disease in diabetes.

There are limitations to our study. First, samples for analyses of AGEs and other biomarkers were taken at baseline only, which impedes evaluation of the impact of changes in these variables on cardiovascular outcome. Second, potential misclassification of non-specific mortality as CVD-related mortality may have introduced non-differential biases, in which case the estimates reported herein may have been underestimated. However, we cannot discard the possibility that our results may have been affected by possible differential underreporting of non-fatal CVD. Third, we measured plasma levels of three specific AGEs and it is not clear whether these are representative of the total pool of AGEs. In addition, AGEs accumulate in tissue and cellular concentrations of AGEs are higher than plasma AGEs levels (25). Further studies in which both plasma and tissue levels of AGEs are measured are needed to clarify the relation between the AGEs levels in these two 
compartments and their specific association to CVD. Fourth, we as most of other studies conducted in humans $(4-9,11-13)$ did not normalise the plasma AGEs levels for an amino acid concentration, which may not enable direct comparison (of absolute values) with some other studies $(3,5,10,12,14,15)$. Nevertheless, we do not think normalization for an amino acid concentration is likely to affect the associations between plasma AGEs and study endpoints in our present study, because in preliminary analyses (in a different cohort) we observed very strong correlations ( $r>0.9$ ) between normalised and non-normalised values of AGEs, and comparable associations of normalised and non-normalised plasma AGEs levels with outcome (data not shown).

In conclusion, higher plasma levels of AGEs at baseline are associated with incident fatal and non-fatal CVD as well as all-cause mortality in type 1 diabetes independent of other risk factors and may thus constitute a pathway which explains, at least in part, the increased CVD risk attributable to type I diabetes in these patients. 


\section{References}

1. Soedamah-Muthu SS, Fuller JH, Mulnier HE, Raleigh VS, Lawrenson RA, Colhoun HM. High risk of cardiovascular disease in patients with type 1 diabetes in the U.K.: a cohort study using the general practice research database. Diabetes Care 2006;29:798-804

2. Goldin A, Beckman JA, Schmidt AM, Creager MA. Advanced glycation end products: sparking the development of diabetic vascular injury. Circulation 2006;114:597-605

3. Salman AG, Mansour DE, Swelem AH, Al-Zawahary WM, Radwan AA. Pentosidine - a new biochemical marker in diabetic retinopathy. Ophthalmic Res 2009;42:96-98

4. Norlinah MI, Hamizah R, Md Isa SH, Wan Nazaimoon WM, Khalid BA. The effects of short-term, rapid glycemic control on the peroneal nerve function and serum VCAM-1 and AGE in type 2 diabetic patients in Malaysia. Indian J Med Sci 2009;63:131-138

5. Piarulli F, Sartore G, Ceriello A, Ragazzi E, Reitano R, Nollino L, Cosma C, Fedele D, Lapolla A. Relationship between glyco-oxidation, antioxidant status and microalbuminuria in type 2 diabetic patients. Diabetologia 2009;52:1419-1425

6. Semba RD, Ferrucci L, Sun K, Beck J, Dalal M, Varadhan R, Walston J, Guralnik JM, Fried LP. Advanced glycation end products and their circulating receptors predict cardiovascular disease mortality in older community-dwelling women. Aging Clin Exp Res 2009;21:182-190

7. Semba RD, Bandinelli S, Sun K, Guralnik JM, Ferrucci L. Plasma carboxymethyl-lysine, an advanced glycation end product, and all-cause and cardiovascular disease mortality in older communitydwelling adults. J Am Geriatr Soc 2009;57:1874-1880

8. Kilhovd BK, Juutilainen A, Lehto S, Ronnemaa T, Torjesen PA, Hanssen KF, Laakso M. Increased serum levels of methylglyoxal-derived hydroimidazolone-AGE are associated with increased cardiovascular disease mortality in nondiabetic women. Atherosclerosis 2009;205:590-594

9. Kilhovd BK, Juutilainen A, Lehto S, Ronnemaa T, Torjesen PA, Hanssen KF, Laakso M. Increased serum levels of advanced glycation endproducts predict total, cardiovascular and coronary mortality in women with type 2 diabetes: a population-based 18 year follow-up study. Diabetologia 2007;50: 1409-1417

10. Sugiyama S, Miyata T, Ueda Y, Tanaka H, Maeda K, Kawashima S, Van Ypersele de Strihou C, Kurokawa K. Plasma levels of pentosidine in diabetic patients: an advanced glycation end product. J Am Soc Nephrol 1998;9:1681-1688

11. Miura J, Yamagishi S, Uchigata Y, Takeuchi M, Yamamoto H, Makita Z, Iwamoto Y. Serum levels of non-carboxymethyllysine advanced glycation endproducts are correlated to severity of microvascular complications in patients with Type 1 diabetes. J Diabetes Complications 2003;17:16-21

12. Lapolla A, Piarulli F, Sartore G, Ceriello A, Ragazzi E, Reitano R, Baccarin L, Laverda B, Fedele D. Advanced glycation end products and antioxidant status in type 2 diabetic patients with and without peripheral artery disease. Diabetes Care 2007;30:670-676

13. Koyama Y, Takeishi $Y$, Arimoto T, Niizeki T, Shishido T, Takahashi H, Nozaki N, Hirono O, Tsunoda Y, Nitobe J, Watanabe T, Kubota I. High serum level of pentosidine, an advanced glycation end product (AGE), is a risk factor of patients with heart failure. J Card Fail 2007;13:199-206

14. Suliman ME, Heimburger O, Barany P, Anderstam B, Pecoits-Filho R, Rodriguez Ayala E, Qureshi AR, Fehrman-Ekholm I, Lindholm B, Stenvinkel P. Plasma pentosidine is associated with inflammation and malnutrition in end-stage renal disease patients starting on dialysis therapy. J Am Soc Nephrol 2003; $14: 1614-1622$

15. Kilhovd BK, Juutilainen A, Lehto S, Ronnemaa T, Torjesen PA, Birkeland KI, Berg TJ, Hanssen KF, Laakso $M$. High serum levels of advanced glycation end products predict increased coronary heart disease mortality in nondiabetic women but not in nondiabetic men: a population-based 18-year follow-up study. Arterioscler Thromb Vasc Biol 2005;25:815-820

16. Semba RD, Ferrucci L, Fink JC, Sun K, Beck J, Dalal M, Guralnik JM, Fried LP. Advanced glycation end products and their circulating receptors and level of kidney function in older community-dwelling women. Am J Kidney Dis. 2009;53:51-58 
17. Tarnow L, Cambien F, Rossing P, Nielsen FS, Hansen BV, Lecerf L, Poirier O, Danilov S, Parving HH. Lack of relationship between an insertion/deletion polymorphism in the angiotensin I-converting enzyme gene and diabetic nephropathy and proliferative retinopathy in IDDM patients. Diabetes 1995;44: 489-494

18. Teerlink T, Barto R, Ten Brink HJ, Schalkwijk CG. Measurement of Nepsilon-(carboxymethyl)lysine and Nepsilon-(carboxyethyl)lysine in human plasma protein by stable-isotope-dilution tandem mass spectrometry. Clin Chem 2004;50:1222-1228

19. Scheijen JL, van de Waarenburg MP, Stehouwer CD, Schalkwijk CG. Measurement of pentosidine in human plasma protein by a single-column high-performance liquid chromatography method with fluorescence detection. J Chromatogr B Analyt Technol Biomed Life Sci 2009;877:610-614

20. De Jager J, Kooy A, Lehert P, Bets D, Wulffele MG, Teerlink T, Scheffer PG, Schalkwijk CG, Donker AJ, Stehouwer CD. Effects of short-term treatment with metformin on markers of endothelial function and inflammatory activity in type 2 diabetes mellitus: a randomized, placebo-controlled trial. J Intern Med 2005;257:100-109

21. Stehouwer CD, Henry RM, Ferreira I. Arterial stiffness in diabetes and the metabolic syndrome: a pathway to cardiovascular disease. Diabetologia 2008;51:527-539

22. Schalkwijk CG, Chaturvedi N, Twaafhoven H, van Hinsbergh VW, Stehouwer CD. Amadori-albumin correlates with microvascular complications and precedes nephropathy in type 1 diabetic patients. Eur J Clin Invest 2002;32:500-506

23. Meerwaldt R, Lutgers HL, Links TP, Graaff R, Baynes JW, Gans RO, Smit AJ. Skin autofluorescence is a strong predictor of cardiac mortality in diabetes. Diabetes Care 2007;30:107-112

24. Genuth S, Sun W, Cleary P, Sell DR, Dahms W, Malone J, Sivitz W, Monnier VM. Glycation and carboxymethyllysine levels in skin collagen predict the risk of future 10-year progression of diabetic retinopathy and nephropathy in the diabetes control and complications trial and epidemiology of diabetes interventions and complications participants with type 1 diabetes. Diabetes 2005;54: 3103-3111

25. Wautier JL, Schmidt AM. Protein glycation: a firm link to endothelial cell dysfunction. Circ Res 2004;95:233-238 


\section{Chapter 5}

Serum high-mobility group box-1 levels are positively associated with micro- and macroalbuminuria, but not with cardiovascular disease in type 1 diabetes: the EURODIAB Prospective Complications Study

Johanna W Nin, Isabel Ferreira, Casper G Schalkwijk, Martin H Prins, Nish Chaturvedi, John H Fuller, Coen D Stehouwer, and the EURODIAB Prospective Complications Study Group

Eur J Endocrinol. 2012;166:325-332 


\section{Abstract}

\section{Background and objective}

High-mobility group box-1 (HMGB1) is a pro-inflammatory cytokine that may contribute to the pathogenesis of micro- and macrovascular complications commonly observed in diabetes. We investigated whether HMGB1 is associated with: (1) markers of low-grade inflammation (LGI) and endothelial dysfunction (ED), and pulse pressure (PP, a marker of arterial stiffness); (2) prevalent nephropathy, retinopathy, and cardiovascular disease (CVD) in type 1 diabetes; and (3) the potential mediating roles of LGI, ED, and PP therein.

\section{Methods}

Cross-sectional nested case-control study of 463 patients (226 women; mean age $40 \pm 10$ yrs) with type 1 diabetes from the EURODIAB Prospective Complications Study (PCS). We used linear and binary or multinomial logistic regression analyses adjusted for traditional risk factors.

Results

Serum Ln-HMGB1 levels were positively associated with LGI and ED [standardised $\beta=0.11$ (95\% Cl: 0.03; 0.19 ) and $\beta=0.11(0.03 ; 0.20)$, respectively], but not with PP. Higher Ln-HMGB1 (per unit) was associated with greater odds of micro- and macroalbuminuria: $O R=1.24(0.90 ; 1.71)$ and $O R=1.61(1.15 ; 2.25), p$ for trend $=0.004$, respectively, Further adjustments for LGI or ED did not attenuate these associations. No such associations were found between Ln-HMGB1 and estimated glomerular filtration rate (eGFR), retinopathy or CVD, however.

\section{Conclusions}

In type 1 diabetes higher serum HMGB1 levels are associated with greater prevalence and severity of albuminuria, though not with eGFR, retinopathy, and CVD. Prospective studies are needed to clarify the causal role of HMGB1, if any, in the pathogenesis of vascular complications in type 1 diabetes. 


\section{Introduction}

The pathophysiological mechanisms that could link hyperglycaemia to the development of micro- and macrovascular complications in patients with diabetes mellitus are still unclear. One of the proposed mechanisms involves advanced glycation end products (AGEs) and the receptor for advanced glycation end products (RAGE) (1-4). Besides AGEs, RAGE can also be activated by other ligands, such as highmobility group box-1 (HMGB1) (5).

HMGB1 is a multifunctional nuclear DNA-binding protein that facilitates gene transcription (6). Extracellular HMGB1 released from necrotic cells (7) as well as from immune cells upon inflammatory stimuli (8) functions as a pro-inflammatory cytokine, which elicits pro-inflammatory responses from macrophages (9) and endothelial cells (10). Extracellular HMGB1, however, can also initiate tissue repair (11) and promote angiogenesis in animal models (12). In addition, HMGB1 functions as a chemotactic agent for endothelial precursor cells (13) and smooth muscle cells (14). Extracellular effects of HMGB1 are mediated by its binding to RAGE, but also, at least in part, by its binding to the receptors of the toll like receptors family (15). The mechanisms behind the balance between the detrimental and the beneficial actions of HMGB1, and whether these actions might be receptor-specific are still unclear.

Owing mainly to its pro-inflammatory function, it has been suggested that HMGB1 may be involved in the development of vascular disease (16). In this line, higher serum HMGB1 levels have been reported in individuals with coronary heart disease $(17,18)$ or heart failure (19) compared with those without these diseases. Inflammation is involved in the development of diabetic nephropathy (20), and in this line, a recent study showed that HMGB1 may play a role in the development of diabetic nephropathy in rats (21).

Whether HMGB1 levels are associated with the presence and severity of nephropathy, retinopathy and cardiovascular disease (CVD) in patients with type 1 diabetes, and the potential roles of low-grade inflammation (LGI), endothelial dysfunction (ED), and arterial stiffness therein have never been investigated, however. We have therefore addressed these issues in a large group of patients with type 1 diabetes in the EURODIAB PCS.

\section{Methods}

\section{Subjects and study design}

We used data from the EURODIAB PCS, which is a follow-up of the EURODIAB IDDM complications study that has been described in detail elsewhere (22-24). Briefly, baseline investigations were performed between 1989 and 1991 on 3,250 patients with type 1 diabetes. All patients gave informed consent and the study was approved 
by the local Ethics Committees. Of the 3,250 included patients, 1,880 (57.8\%) returned for follow-up examination on average 7-9 years after the baseline examinations. At follow-up, a cross-sectional nested case-control study of markers of LGI and ED, and their associations with complications was performed in a subset of patients $(n=543)$. Cases were selected as those with greatest vascular complication burden as possible $(n=348)$ and controls were selected as those who were completely free of any complications (i.e. with no evidence of CVD, albuminuria and retinopathy) ( $n=195)$. The present cross-sectional nested case-control study $(2,25-31)$ includes 463 of the subjects in whom complete data on serum levels of HMGB1 and other covariates of interest were available.

\section{Biomarkers}

Serum HMGB1 levels were measured in duplicate with a commercially available ELISA kit (Shino-Test Corporation, Tokyo, Japan) and the intra- and inter-assay coefficients of variation were 2.7 and $7.6 \%$, respectively.

Soluble vascular cell adhesion molecule-1 (sVCAM-1) and soluble E-selectin (sE-selectin) were measured in duplicate by sandwich enzyme immunoassays (R\&D Systems, Oxon, U.K.). The intra- and inter-assay coefficients of variation for sVCAM-1 were $4.0 \%$ and $9.1 \%$, respectively, and for sE-selectin, $2.1 \%$ and $3.1 \%$, respectively $(2,26)$.

Total transforming growth factor $\beta 1$ (TGF- $\beta 1$ ) was measured by an ELISA development system (R\&D Systems, Oxon, U.K.) and the intra- and inter-assay coefficients of variations were 5.0 and $7.0 \%$, respectively (27). Plasma levels of C-reactive protein (CRP) were measured with a highly sensitive in-house ELISA and plasma levels of interleukin-6 (IL-6) and tumour necrosis factor- $\alpha$ (TNF- $\alpha$ ) were measured using commercially available ELISA kits (R\&D Systems, Oxon, U.K.). Intraand inter-assay coefficients of variation were 3.9 and $8.7 \%, 4.5$ and $9.0 \%, 7.3$ and $8.5 \%$, respectively $(2,26)$.

\section{Other risk factors}

Blood pressure was measured twice in a seated position with a random zero sphygmomanometer (Hawskley, Lancing, UK) and appropriate cuff size, after patients had rested for five minutes, and the mean of the two readings was used in the analyses (32). Mean arterial pressure (MAP) was calculated as [systolic blood pressure $+(2 *$ diastolic blood pressure $)] / 3$. PP was calculated by subtracting the diastolic from the systolic blood pressure, and used as a marker of arterial stiffness $(32,33)$. Smoking habits were ascertained by questionnaire and subjects were categorised into categories: 'non-', 'moderate', and 'heavy smokers', according to their levels of pack years smoked (none, and below or above the sex-specific median, respectively) (2). Weight and height were measured with indoor clothing without shoes and body mass index (BMI) was calculated. Fasting cholesterol and triglyceride levels were measured 
by enzymatic colorimetric tests (34). Glycated haemoglobin $\left(\mathrm{HbA}_{1 \mathrm{c}}\right)$ was measured by a latex enhanced turbidimetric immunoassay (Roche Products, Welwyn Garden City, UK). The reference range for this assay was $4.2-6.2 \%$.

\section{Main outcomes}

Albumin excretion rates were measured from duplicate 24-h urine collections and micro- and macroalbuminuria were defined as an albumin excretion rate between 20 and 200, and above $200 \mu \mathrm{g} / \mathrm{min}$, respectively (22). GFR was estimated with the Cockcroft-Gault formula (35) and with the short modified diet in renal disease equation (36). Retinopathy was assessed from retinal photographs according to the EURODIAB protocol. Accordingly, non-proliferative retinopathy was defined as the presence of one or more microaneurysms, haemorrhages, and/or hard exudates. Proliferative retinopathy was defined as any new vessels, fibrous proliferations, preretinal haemorrhage, vitreous haemorrhage, or photocoagulation scars (37). CVD was defined as a positive medical history of a cardiovascular event, including myocardial infarction, angina, coronary artery bypass graft and/or stroke, and/or ischaemic changes on a centrally Minnesota coded ECG (38).

\section{Statistical analyses}

All analyses were performed with the Statistical Package for Social Sciences (SPSS) version 15.0 for Windows (SPSS Inc, Chicago, Illinois, USA). Variables with a skewed distribution (i.e. HMGB1, triglycerides, CRP, IL-6, TNF- $\alpha$, and TGF- $\beta 1$ ) were $\log _{\text {e }}$ transformed prior to further analyses. Comparisons of characteristics between subjects with vs. without vascular complications were performed with Student's t- or Chi-Square tests, as appropriate. In these analyses, cases were all those subjects with any vascular complication $(n=289)$; controls were all those without any vascular complication ( $n=174)$.

Markers of low-grade inflammation (LGI) were comprised into an overall LGI score by averaging the z-scores of LnCRP, LnIL-6, LnTNF- $\alpha$ and LnTGF- $\beta 1$; likewise, markers of endothelial dysfunction (ED) were comprised into an overall ED score by averaging the z-scores of sVCAM-1 and sE-selectin $(2-4,26)$. A z-score represents the distance between an individual's biomarker score from the population's total mean in units of the population's standard deviation, and is thus a common transformation that enables the combination of several markers originally expressed in different units. The two scores thus obtained represent a more robust measure of the individuals' levels of $L G I$ and ED and have the advantage of reducing the influence of the biological variability expected when LGI or ED is characterised based on the levels of each biomarker separately, since these were only measured once.

Linear regression analyses were used to examine the extent to which Ln-HMGB1 was associated with each of the biomarkers of LGI and ED, as well as their overall scores, and PP. We reported standardised regression coefficients (95\% confidence 
interval) to allow comparison of the strength of the associations. These analyses were first adjusted for age, sex, $\mathrm{HbA1c}$, duration of DM, case-control status, BMI, total cholesterol, MAP and smoking; second, for the use of antihypertensive medication; and third for eGFR estimated with Cockcroft-Gault formula.

We used multinomial logistic regression analyses to examine the associations between Ln-HMGB1 and the presence and severity of albuminuria as well as retinopathy, and binary logistic regression analyses to investigate the associations between Ln-HMGB1 and prevalent CVD. These analyses were adjusted for conventional CVD risk factors, use of antihypertensive medication and eGFR as described above, to ascertain independence from these factors. We further adjusted these associations for LGI and ED scores, and PP to ascertain the extent to which these mechanisms could explain (i.e. mediate) a portion of the associations found, in which case the effect sizes (OR) would be appreciably attenuated.

\section{Results}

Table 5.1 shows the characteristics of the patients with any vascular complications vs. those without. Overall, individuals with vascular complications had a more adverse atherosclerotic risk profile as illustrated by more unfavourable levels of conventional risk factors, LGI, ED, PP, and eGFR,.

After adjustments for age, sex, $\mathrm{HbA1c}$, duration of diabetes, case-control status, $\mathrm{BMI}$, total cholesterol, MAP, and smoking, serum Ln-HMGB1 levels were positively associated with LGI and ED scores (standardised regression coefficient $\beta=0.11[95 \% \mathrm{Cl}$ : 0.03 to 0.19 ] and $\beta=0.11$ [0.03 to 0.20 ], respectively), but not PP (Table 5.2, Model 1). Further adjustments for antihypertensive medication and eGFR did not attenuate these positive associations (Table 5.2, models 2-3). Serum Ln-HMGB1 levels were not associated with eGFR however.

After adjustments for conventional risk factors, Ln-HMGB1 levels were associated with greater odds for micro- and macroalbuminuria: $O R=1.23$ (0.90 to 1.70$)$ and $\mathrm{OR}=1.61$ (1.15 to 2.26), $\mathrm{p}$ for trend=0.004, per unit higher Ln-HMGB1, respectively (Table 5.3, model 3; Figure 5.1). When albuminuria was analysed as a continuous outcome, each unit increase in Ln-MHGB1 was associated with $3.9 \mu \mathrm{g} / \mathrm{min}(95 \% \mathrm{Cl}: 0.3$ to 7.9) in albuminuria $(p=0.030)$. No such associations were found between LnHMGB1 levels and prevalent CVD [OR=0.86 (0.66 to 1.12)] or retinopathy [OR=0.94 (0.70 to 1.26$)$ and $O R=0.90(0.64$ to 1.26$)$ for prevalent non-proliferative and proliferative retinopathy, respectively], however.

Despite the positive associations between Ln-HMGB1 and LGI as well as ED, the associations between HMGB1 and micro- and macroalbuminuria were not appreciably attenuated when these were further adjusted for the LGI score (model 4 vs. model 3) or the ED score (model 5 vs. model 3). 
Table 5.1 Clinical characteristics of the study population.

\begin{tabular}{|c|c|c|c|}
\hline & \multicolumn{3}{|c|}{ All $(n=463)$} \\
\hline & \multicolumn{3}{|c|}{$\begin{array}{l}\text { Vascular complications No vascular complications } p \text {-value } \\
(n=289)\end{array}$} \\
\hline Age (years) & $41.8(10.4)$ & $35.9(8.1)$ & $<0.001$ \\
\hline $\operatorname{Sex}(m / f, \%)$ & $55 / 45$ & $45 / 55$ & 0.056 \\
\hline BMI $\left(\mathrm{kg} / \mathrm{m}^{2}\right)$ & $24.9(3.5)$ & $23.8(2.6)$ & $<0.001$ \\
\hline HbA1c (\%) & $9.0(1.5)$ & $7.8(1.3)$ & $<0.001$ \\
\hline Duration of diabetes (years) & $25.2(9.1)$ & $15.3(7.0)$ & $<0.001$ \\
\hline Total cholesterol (mmol/l) & $5.49(1.12)$ & $5.00(1.09)$ & $<0.001$ \\
\hline Triglycerides (mmol/l) & $1.14[0.85-1.58]$ & $0.86[0.67-1.10]$ & $<0.001$ \\
\hline Smoking (non/moderate/heavy) (\%) & $38.8 / 27.3 / 33.9$ & $51.2 / 31.0 / 17.8$ & 0.001 \\
\hline Diastolic blood pressure ( $\mathrm{mmHg}$ ) & $75(12)$ & $73(11)$ & 0.060 \\
\hline Systolic blood pressure (mmHg) & $126(22)$ & $114(14)$ & $<0.001$ \\
\hline Mean arterial pressure $(\mathrm{mmHg})$ & $92(13)$ & $87(11)$ & $<0.001$ \\
\hline Pulse pressure $(\mathrm{mmHg})$ & $51(19)$ & $41(11)$ & $<0.001$ \\
\hline Antihypertensive medication (\%) & 45.3 & 6.3 & $<0.001$ \\
\hline 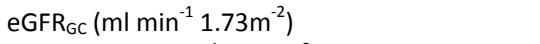 & $96.9(27.7)$ & $114.0(17.5)$ & $<0.001$ \\
\hline 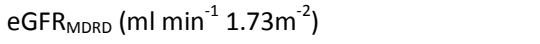 & $86.6(25.4)$ & $101.5(16.0)$ & $<0.001$ \\
\hline Albuminuria (normo-/micro-/macro-) (\%) & $38.1 / 23.5 / 38.4$ & - & - \\
\hline Retinopathy (no/background/proliferative) (\%) & $12.1 / 41.5 / 46.4$ & - & - \\
\hline Cardiovascular disease (\%) & 38.1 & - & - \\
\hline High-mobility group box-1 (ng/ml) & $1.26[0.78-2.57]$ & $1.45[0.89-2.75]$ & 0.406 \\
\hline $\mathrm{CRP}(\mathrm{mg} / \mathrm{l})$ & $1.29[0.46-2.75]$ & $0.71[0.35-1.88]$ & $<0.001$ \\
\hline IL-6 (pg/ml) & $2.12[1.34-3.94)]$ & $1.57[1.06-2.50]$ & $<0.001$ \\
\hline TNF- $\alpha(\mathrm{pg} / \mathrm{ml})$ & $3.18[2.39-4.47]$ & $2.22[1.68-2.85]$ & $<0.001$ \\
\hline TGF- $\beta 1$ (ng/ml) & $5.55[3.70-8.90]$ & $5.25[3.28-8.03]$ & 0.132 \\
\hline Inflammation score & $0.17(0.62)$ & $-0.28(0.54)$ & $<0.001$ \\
\hline sE-selectin (ng/ml) & $36(17)$ & $31(11)$ & $<0.001$ \\
\hline sVCAM-1(ng/ml) & 437 (149) & $380(104)$ & $<0.001$ \\
\hline Endothelial dysfunction score & $0.14(0.80)$ & $-0.24(0.49)$ & $<0.001$ \\
\hline
\end{tabular}

Data are means (standard deviation), median [inter-quartile range], or percentages, as appropriate.

BMI, body mass index; HbA1c, glycated haemoglobin; LDL, low-density lipoprotein; HDL, high-density lipoprotein; eGFR $\mathrm{CG}_{\mathrm{G}}$, estimated glomerular filtration rate by Cockcroft-Gault formula; eGFR $\mathrm{MDRD}_{\text {, estimated }}$ glomerular filtration rate by short modification of diet in renal disease equation; CRP, $C$ reactive protein; IL-6, interleukin-6; TNF- $\alpha$, tumor necrosis factor- $\alpha$; TGF- $\beta 1$, transforming growth factor $\beta 1$; sE-selectin, soluble E-selectin; sVCAM-1, soluble vascular cell adhesion molecule-1. 


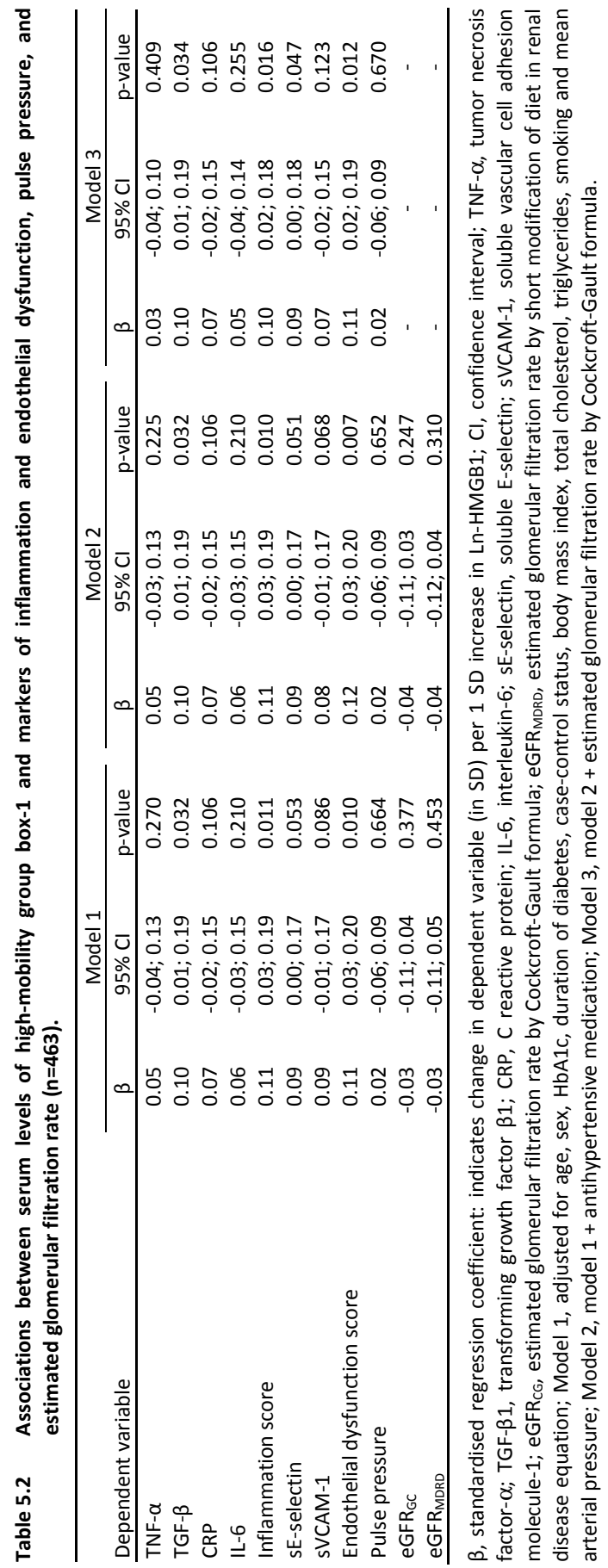




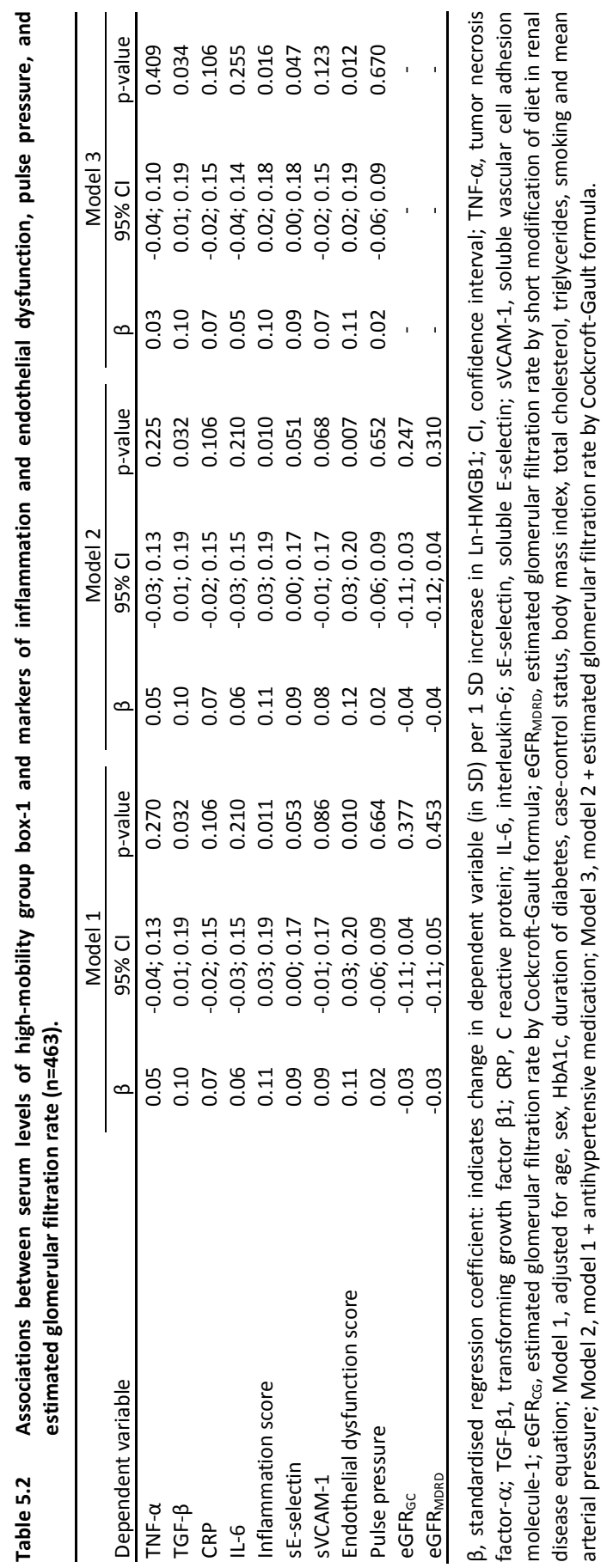




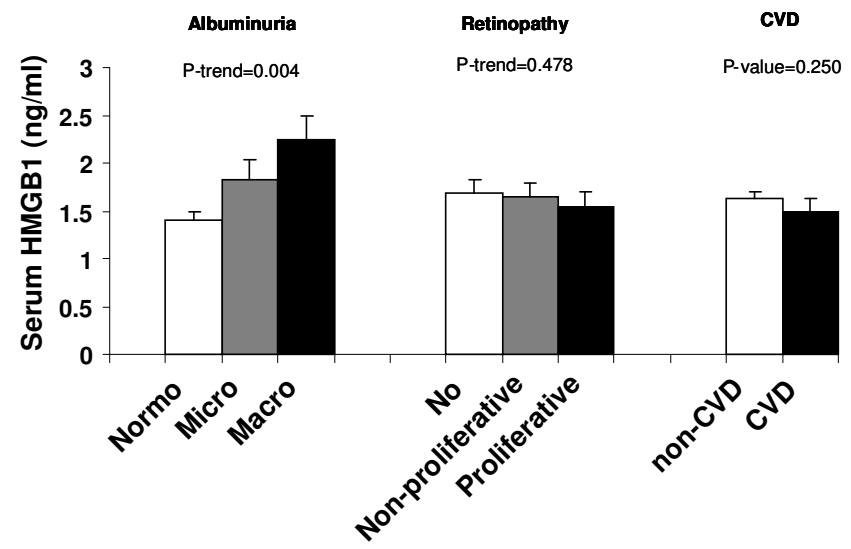

Figure 5.1 Serum high-mobility group box-1 levels according to the presence and severity of albuminuria and retinopathy, and the presence of cardiovascular disease.

Bars indicate geometric means + SE, which were adjusted for age, sex, HbA1c, duration of diabetes, case-control status, body mass index, total cholesterol, triglycerides, smoking, mean arterial pressure, antihypertensive medication, estimated glomerular filtration rate by Cockcroft-Gault formula, and presence of CVD, albuminuria and/or retinopathy as appropriate.

\section{Discussion}

The main finding of this study is that, among individuals with type 1 diabetes, serum HMGB1 levels are positively associated with the presence and severity of albuminuria, though not with eGFR, retinopathy, and CVD. In addition, HMGB1 levels were positively associated with markers of $L G I$ and ED, but these did not explain the association of HMGB1 with albuminuria. This is the first study to investigate the associations between HMGB1 and micro- and macrovascular complications as well as markers of LGI and ED in patients with type 1 diabetes.

The positive association between HMGB1 and albuminuria observed in the present study is supported by the findings in previous studies in rats, in which higher kidney HMGB1 levels were associated with the presence and severity of diabetic nephropathy (39). In addition, it has been reported that higher HMGB1 expression was found in the cytoplasm than in the nuclei of renal tissues in diabetic rats compared to mainly nucleic HMGB1 expression in renal tissues in control rats (21). The latter study has also reported higher RAGE expression and nucleic factor $\mathrm{KB}$ (NF-KB) activity suggesting a pathogenic role of HMGB1 in the development of renal injury in diabetic rats through RAGE and activation of NF-KB (21). However, we have measured serum HMGB1 only and it is unknown how serum levels relate to tissue levels. Extracellular HMGB1 may activate NF-kB and initiate and amplify the 
upregulation of pro-inflammatory cytokines and adhesion molecules by binding to RAGE $(5)$ or toll-like receptors $(15,16)$, and subsequently lead to increased risk for albuminuria.

Both HMGB1 (5) and AGEs (40) are shown to be ligands of RAGE. Ligation of RAGE leads via various intracellular signaling pathways to the activation of transcription factor nuclear factor $\mathrm{kB}$, which may alter the gene transcription and could lead to the upregulation of proinflammatory cytokines and adhesion molecules. These processes may underlie the pathogenesis of vascular complications in type 1 diabetes. Both serum HMGB1 and SRAGE (2) levels were positively associated with the presence and severity of albuminuria in patients with type 1 diabetes. However, in the present study we could not find an association between serum HMGB1 levels and the presence of CVD, while in our previous studies we have shown that both sRAGE (3), as a reflection of RAGE, and AGEs (4) were positively associated with incident CVD. This suggests that although HMGB1, AGEs, and (s)RAGE are interrelated they may not contribute to the same pathways that underlie the pathogenesis of micro- and macrovascular complications. This may, at least in part, be explained by the various different receptors for both HMGB1 (15) and AGEs (41), and by the fact that beside HMGB1 and AGEs, many other ligands exist for RAGE (42).

The adverse association between higher levels of HMGB1 and the presence and severity of albuminuria could not be explained by HMGB1-related low-grade inflammation and/or endothelial dysfunction. No association was found between HMGB1 and PP, and therefore, this marker of arterial stiffness could also not explain any association between HMGB1 and albuminuria. These findings suggest that HMGB1, LGI, ED and PP may all constitute different and independent pathways leading to albuminuria in type 1 diabetes. Indeed, this is supported by the observations that both higher LGI and ED scores were independently of serum HMGB1 levels associated with greater odds for micro- and macroalbuminuria: $O R=1.51$ ( 0.88 to 2.59) and $O R=1.86$ (1.10 to 3.18) per unit higher LGI score, and $O R=1.56$ (95\% Cl: 0.97 to 2.49) and $O R=2.08$ (1.33 to 3.27) per unit higher ED score, respectively. Although to a smaller extent, PP (per $10 \mathrm{mmHg}$ ) was also associated with greater odds for micro- [OR=1.09 (0.86 to 1.38) ] and macroalbuminuria [OR=1.20 (0.97 to 1.49)], independently of HMGB1 levels.

The lack of an association between serum levels of HMGB1 and CVD observed in the present study is in contrast to the positive associations that have been reported between serum levels of HMGB1 and coronary artery disease as well as heart failure in three previous studies, all of which were conducted among in patients with type 2 diabetes (17-19). In view of the strong associations observed between HMGB1 and LGI, ED as well as albuminuria, all of which are strong correlates of CVD, the lack of associations between HMGB1 and CVD as well as retinopathy are difficult to conciliate. We cannot discard the possibility that a type II error may have occurred and that we thus did not find an association between HMGB1 and prevalent CVD due to the play of chance. Further, preferably prospective, studies are needed to establish 
these associations more definitely. Indeed, the fact that we examined the associations in the context of a cross-sectional nested case-control study also is a limitation to our study, and any inferences about causality should thus be made with caution. Since there are no longitudinal data of this type in large groups of type 1 diabetes at this time, the present cross-sectional study may serve as a reasonable starting point to further explore these associations. In addition, we defined presence of CVD as a positive medical history of a cardiovascular event. We may have missed subclinical cardiovascular complications, which may lead to a dilution of the associations observed.

In conclusion, higher serum levels of HMGB1 are cross-sectionally associated with a higher prevalence of micro- and macroalbuminuria, but seemingly not with eGFR, retinopathy, and CVD, in patients with type 1 diabetes. Further prospective studies are needed to further clarify the causal role of HMGB1, if any, in the pathophysiology of micro- and macrovascular complications in type 1 diabetes. 


\section{References}

1. Brownlee M: Biochemistry and molecular cell biology of diabetic complications. Nature 2001;414: 813-820

2. Nin JW, Ferreira I, Schalkwijk CG, Prins MH, Chaturvedi N, Fuller JH, Stehouwer CD: Levels of soluble receptor for AGE are cross-sectionally associated with cardiovascular disease in type 1 diabetes, and this association is partially mediated by endothelial and renal dysfunction and by low-grade inflammation: the EURODIAB Prospective Complications Study. Diabetologia 2009;52:705-714

3. Nin JW, Jorsal A, Ferreira I, Schalkwijk CG, Prins MH, Parving HH, Tarnow L, Rossing P, Stehouwer CD: Higher plasma soluble Receptor for Advanced Glycation End Products (sRAGE) levels are associated with incident cardiovascular disease and all-cause mortality in type 1 diabetes: a 12-year follow-up study. Diabetes 2010;59:2027-2032

4. Nin JW, Jorsal A, Ferreira I, Schalkwijk CG, Prins MH, Parving HH, Tarnow L, Rossing P, Stehouwer CD: Higher plasma levels of advanced glycation end products are associated with incident cardiovascular disease and all-cause mortality in type 1 diabetes: a 12-year follow-up study. Diabetes Care 2011;34:442-447

5. Hori O, Brett J, Slattery T, Cao R, Zhang J, Chen JX, Nagashima M, Lundh ER, Vijay S, Nitecki D, et al.: The receptor for advanced glycation end products (RAGE) is a cellular binding site for amphoterin. Mediation of neurite outgrowth and co-expression of rage and amphoterin in the developing nervous system. J Biol Chem 1995;270:25752-25761

6. Bianchi ME, Agresti A: HMG proteins: dynamic players in gene regulation and differentiation. Curr Opin Genet Dev 2005;15:496-506

7. Scaffidi $P$, Misteli T, Bianchi ME: Release of chromatin protein HMGB1 by necrotic cells triggers inflammation. Nature 2002;418:191-195

8. Rendon-Mitchell B, Ochani M, Li J, Han J, Wang H, Yang H, Susarla S, Czura C, Mitchell RA, Chen G, Sama AE, Tracey KJ, Wang H: IFN-gamma induces high mobility group box 1 protein release partly through a TNF-dependent mechanism. J Immunol 2003;170:3890-3897

9. Li J, Kokkola R, Tabibzadeh S, Yang R, Ochani M, Qiang X, Harris HE, Czura CJ, Wang H, Ulloa L, Wang H, Warren HS, Moldawer LL, Fink MP, Andersson U, Tracey KJ, Yang H: Structural basis for the proinflammatory cytokine activity of high mobility group box 1. Mol Med 2003;9:37-45

10. Fiuza C, Bustin M, Talwar S, Tropea M, Gerstenberger E, Shelhamer JH, Suffredini AF: Inflammationpromoting activity of HMGB1 on human microvascular endothelial cells. Blood 2003;101:2652-2660

11. Straino S, Di Carlo A, Mangoni A, De Mori R, Guerra L, Maurelli R, Panacchia L, Di Giacomo F, Palumbo R, Di Campli C, Uccioli L, Biglioli P, Bianchi ME, Capogrossi MC, Germani A: High-mobility group box 1 protein in human and murine skin: involvement in wound healing. J Invest Dermatol 2008;128: 1545-1553

12. Biscetti F, Straface G, De Cristofaro R, Lancellotti S, Rizzo P, Arena V, Stigliano E, Pecorini G, Egashira K, De Angelis G, Ghirlanda G, Flex A: High-mobility group box-1 protein promotes angiogenesis after peripheral ischemia in diabetic mice through a VEGF-dependent mechanism. Diabetes 2010;59: 1496-1505

13. Chavakis E, Hain A, Vinci M, Carmona G, Bianchi ME, Vajkoczy P, Zeiher AM, Chavakis T, Dimmeler S: High-mobility group box 1 activates integrin-dependent homing of endothelial progenitor cells. Circ Res 2007;100:204-212

14. De Mori R, Straino S, Di Carlo A, Mangoni A, Pompilio G, Palumbo R, Bianchi ME, Capogrossi MC, Germani A: Multiple effects of high mobility group box protein 1 in skeletal muscle regeneration. Arterioscler Thromb Vasc Biol 2007;27:2377-2383

15. van Zoelen MA, Yang H, Florquin S, Meijers JC, Akira S, Arnold B, Nawroth PP, Bierhaus A, Tracey KJ, van der Poll T: Role of Toll-Like Receptors 2 and 4, and the Receptor for Advanced Glycation End Products (Rage) in Hmgb1 Induced Inflammation in Vivo. Shock 2009;31:280-284

16. Li W, Sama AE, Wang H: Role of HMGB1 in cardiovascular diseases. Curr Opin Pharmacol 2006;6: 130-135

17. Hu X, Jiang H, Bai Q, Zhou X, Xu C, Lu Z, Cui B, Wen H: Increased serum HMGB1 is related to the severity of coronary artery stenosis. Clin Chim Acta 2009;406:139-142 
18. Yan XX, Lu L, Peng WH, Wang L, Zhang Q, Zhang RY, Chen QJ, Shen WF: Increased serum HMGB1 level is associated with coronary artery disease in nondiabetic and type 2 diabetic patients. Atherosclerosis 2009;205:544-548

19. Wang L, Lu L, Zhang FR, Chen QJ, De Catherina R, Shen WF: Increased serum High-mobility group box-1 and cleaved receptor for advanced glycation endproducts levels and decreased endogenous secretory receptor for advanced glycation endproducts levels in diabetic and non-diabetic patients with heart failure. Eur J Heart Fail 2011;13:440-449

20. Rivero A, Mora C, Muros M, Garcia J, Herrera H, Navarro-Gonzalez JF: Pathogenic perspectives for the role of inflammation in diabetic nephropathy. Clin Sci (Lond) 2009;116:479-492

21. Kim J, Sohn E, Kim CS, Jo K, Kim JS: The role of high-mobility group box-1 protein in the development of diabetic nephropathy. Am J Nephrol 2011;33:524-529

22. Chaturvedi N, Bandinelli S, Mangili R, Penno G, Rottiers RE, Fuller JH: Microalbuminuria in type 1 diabetes: rates, risk factors and glycemic threshold. Kidney Int 2001;60:219-227

23. Chaturvedi N, Sjoelie AK, Porta M, Aldington SJ, Fuller JH, Songini M, Kohner EM: Markers of insulin resistance are strong risk factors for retinopathy incidence in type 1 diabetes. Diabetes Care 2001;24:284-289

24. Group TEICS: Microvascular and acute complications in IDDM patients: the EURODIAB IDDM Complications Study. Diabetologia 1994;37:278-285

25. Schram MT, Chaturvedi N, Schalkwijk C, Giorgino F, Ebeling P, Fuller JH, Stehouwer CD: Vascular risk factors and markers of endothelial function as determinants of inflammatory markers in type 1 diabetes: the EURODIAB Prospective Complications Study. Diabetes Care 2003;26:2165-2173

26. Schram MT, Chaturvedi N, Schalkwijk CG, Fuller JH, Stehouwer CD: Markers of inflammation are cross-sectionally associated with microvascular complications and cardiovascular disease in type 1 diabetes--the EURODIAB Prospective Complications Study. Diabetologia 2005;48:370-378

27. Chaturvedi N, Schalkwijk CG, Abrahamian H, Fuller JH, Stehouwer CD: Circulating and urinary transforming growth factor beta1, Amadori albumin, and complications of type 1 diabetes: the EURODIAB prospective complications study. Diabetes Care 2002;25:2320-2327

28. Gruden G, Bruno G, Chaturvedi N, Burt D, Schalkwijk C, Pinach S, Stehouwer CD, Witte DR, Fuller JH, Perin PC: Serum heat shock protein 27 and diabetes complications in the EURODIAB prospective complications study: a novel circulating marker for diabetic neuropathy. Diabetes 2008;57:1966-1970

29. Schalkwijk CG, Chaturvedi N, Schram MT, Fuller JH, Stehouwer CD: Adiponectin is inversely associated with renal function in type 1 diabetic patients. J Clin Endocrinol Metab 2006;91:129-135

30. Schram MT, Schalkwijk CG, Bootsma AH, Fuller JH, Chaturvedi N, Stehouwer CD: Advanced glycation end products are associated with pulse pressure in type 1 diabetes: the EURODIAB Prospective Complications Study. Hypertension 2005;46:232-237

31. Soedamah-Muthu SS, Chaturvedi N, Teerlink T, Idzior-Walus B, Fuller JH, Stehouwer CD: Plasma homocysteine and microvascular and macrovascular complications in type 1 diabetes: a crosssectional nested case-control study. J Intern Med 2005;258:450-459

32. Schram MT, Chaturvedi N, Fuller JH, Stehouwer CD: Pulse pressure is associated with age and cardiovascular disease in type 1 diabetes: the Eurodiab Prospective Complications Study. J Hypertens 2003;21:2035-2044

33. Stehouwer CD, Henry RM, Ferreira I: Arterial stiffness in diabetes and the metabolic syndrome: a pathway to cardiovascular disease. Diabetologia 2008;51:527-539

34. Fossati P, Prencipe L: Serum triglycerides determined colorimetrically with an enzyme that produces hydrogen peroxide. Clin Chem 1982;28:2077-2080

35. Cockcroft DW, Gault MH: Prediction of creatinine clearance from serum creatinine. Nephron 1976;16:31-41

36. Levey AS, Bosch JP, Lewis JB, Greene T, Rogers N, Roth D: A more accurate method to estimate glomerular filtration rate from serum creatinine: a new prediction equation. Modification of Diet in Renal Disease Study Group. Ann Intern Med 1999;130:461-470

37. Aldington SJ, Kohner EM, Meuer S, Klein R, Sjolie AK: Methodology for retinal photography and assessment of diabetic retinopathy: the EURODIAB IDDM complications study. Diabetologia 1995;38:437-444 
38. Koivisto VA, Stevens LK, Mattock M, Ebeling $P$, Muggeo $M$, Stephenson J, Idzior-Walus B: Cardiovascular disease and its risk factors in IDDM in Europe. EURODIAB IDDM Complications Study Group. Diabetes Care 1996;19:689-697

39. Li F, Yang N, Zhang L, Tan H, Huang B, Liang Y, Chen M, Yu X: Increased expression of toll-like receptor 2 in rat diabetic nephropathy. Am J Nephrol 2010;32:179-186

40. Kislinger T, Fu C, Huber B, Qu W, Taguchi A, Du Yan S, Hofmann M, Yan SF, Pischetsrieder M, Stern D, Schmidt AM: N(epsilon)-(carboxymethyl)lysine adducts of proteins are ligands for receptor for advanced glycation end products that activate cell signaling pathways and modulate gene expression. J Biol Chem 1999;274:31740-31749

41. Ohgami N, Nagai R, Ikemoto M, Arai H, Kuniyasu A, Horiuchi S, Nakayama H: Cd36, a member of the class b scavenger receptor family, as a receptor for advanced glycation end products. J Biol Chem 2001;276:3195-3202

42. Hofmann MA, Drury S, Fu C, Qu W, Taguchi A, Lu Y, Avila C, Kambham N, Bierhaus A, Nawroth P, Neurath MF, Slattery T, Beach D, McClary J, Nagashima M, Morser J, Stern D, Schmidt AM: RAGE mediates a novel proinflammatory axis: a central cell surface receptor for S100/calgranulin polypeptides. Cell 1999;97:889-901 


\section{Chapter 6}

Higher plasma high-mobility group box 1 levels are associated with incident cardiovascular disease and all-cause mortality in type 1 diabetes: a 12-yr follow-up study

Johanna W Nin, Isabel Ferreira, Casper G Schalkwijk, Anders Jorsal, Martin H Prins, Hans-Henrik Parving, Lise Tarnow, Peter Rossing, Coen D Stehouwer

Submitted 


\section{Abstract}

\section{Background and objective}

To investigate the associations of plasma levels of pro-inflammatory cytokine high-mobility group box 1 (HMGB1) with incident cardiovascular disease (CVD) and all-cause mortality in type 1 diabetes, and the extent to which any such associations could be explained by low-grade inflammation (LGI), endothelial and renal dysfunction, or pulse pressure (PP, a marker of arterial stiffness).

\section{Methods}

We prospectively followed 165 individuals with diabetic nephropathy and 168 individuals with persistent normoalbuminuria who were free of CVD at study entry and in whom levels of HMGB1 and other biomarkers were measured at baseline.

Results

Plasma levels of Ln-HMGB1 were not associated with markers of LGI, endothelial and renal dysfunction, and PP. During the course of follow-up [median: 12.3 years (7.8-12.5)], 80 individuals died; 82 suffered a fatal ( $n=46)$ and/or nonfatal $(n=53)$ CVD event. Incident fatal and nonfatal CVD and all-cause mortality increased with higher baseline plasma levels of $\mathrm{Ln}-\mathrm{HMGB} 1$ independently of other CVD risk factors: $\mathrm{HR}=1.55(95 \% \mathrm{Cl}$ : $0.94 ; 2.48)$ and $H R=1.86(1.18 ; 2.93)$, respectively. Further adjustments for LGI, endothelial and renal dysfunction, and PP did not attenuate these associations.

\section{Conclusions}

Plasma HMGB1 levels are positively associated with incident all-cause mortality in type 1 diabetes, independently of conventional cardiovascular risk factors and markers of several potential HMGB1-related pathophysiological mechanisms. To a lesser extent, higher plasma HMGB1 levels are also associated with incident fatal and nonfatal CVD in these patients. Thus, HMGB1 may explain, in part, the increased risk of CVD and mortality in type 1 diabetes. 


\section{Introduction}

The pathophysiological mechanisms that could link hyperglycaemia to the development of cardiovascular complications in patients with diabetes mellitus are still unclear. One of the proposed mechanisms involves advanced glycation end products (AGEs) and the receptor for advanced glycation end products (RAGE) (1). Besides AGEs, RAGE can also be activated by other ligands, which include highmobility group box 1 (HMGB1) (2).

HMGB1 is a multifunctional nuclear DNA-binding protein that facilitates gene transcription (3). Extracellular HMGB1 released from necrotic cells (4) as well as from immune cells upon inflammatory stimuli (5) functions as a pro-inflammatory cytokine, which elicits pro-inflammatory responses from macrophages and endothelial cells $(6,7)$. Extracellular effects of HMGB1 are mediated by its binding to RAGE, but also, at least in part, by its binding to the receptors of the toll-like receptors family (8). HMGB1-induced production of adhesion molecules and inflammatory cytokines could contribute to low-grade inflammation, endothelial and renal dysfunction, and arterial aging, all of which may partially explain the increased CVD in diabetes.

So far, three cross-sectional studies have investigated the associations between HMGB1 and cardiovascular outcomes in humans. These have reported higher levels of HMGB1 in patients with stable or unstable angina pectoris (9), with type 2 diabetes and coronary artery disease (10), and with heart failure (11) as compared with controls. In addition, one of these studies has also shown that individuals with heart failure at study entry who died during the follow-up of two years had higher levels of HMGB1 at baseline compared with the survivors (11).

Whether HMGB1 levels are associated with incident fatal and nonfatal CVD as well as all-cause mortality in individuals with type 1 diabetes, and the potential mediating roles of low-grade inflammation, endothelial and renal dysfunction, and pulse pressure (PP, as a marker of arterial stiffness) herein have never been investigated. We addressed these questions in a 12-year prospective follow-up study.

\section{Methods}

\section{Study population and design}

In 1993, 199 patients with type 1 diabetes and diabetic nephropathy defined according to clinical criteria [i.e. persistent macroalbuminuria (>300 mg/24 h) in at least two out of three previous consecutive 24-h urine collections, in the presence of diabetic retinopathy and the absence of other kidney or urinary tract disease] and 192 with persistent normoalbuminuria (i.e. urinary excretion rate $<30 \mathrm{mg} / 24 \mathrm{~h}$ ) were recruited from the outpatient clinic at Steno Diabetes Center for a prospective observational follow-up study. Details of the inclusion criteria and selection 
procedures have been described elsewhere (12). The study was approved by the local ethics committee, in accordance with the Helsinki Declaration, and all patients gave their informed written consent.

\section{Baseline investigations}

\section{Biomarkers}

Analyses of the biomarkers were done on frozen $\left(-80^{\circ} \mathrm{C}\right)$ samples and were performed at a central laboratory by C.G.S.

Plasma HMGB1 levels were measured in duplicate with a commercially available ELISA kit (Shino-Test Corporation, Tokyo, Japan) and the intra- and inter-assay coefficients of variation were $4.0 \%$ and $11.0 \%$, respectively.

High-sensitivity C-reactive protein (hsCRP) and secreted phospholipase A2 (sPLA2) were determined by enzyme-linked immunosorbent assays (ELISA) as described previously (13). Commercially available ELISA kits were used for measurements of plasma soluble vascular cell adhesion molecule-1 (sVCAM-1), soluble intercellular adhesion molecule-1 (sICAM-1) and interleukin-6 (IL-6) (Quantikine High Sensitivity; R\&D Systems, Oxon, U.K.). The intra- and inter-assay CVs of these immunoassays were $<8 \%$.

Protein-bound $\mathrm{N}^{\varepsilon}$-(carboxyethyl)lysine $(\mathrm{CEL})$ and $\mathrm{N}^{\varepsilon}$-(carboxymethyl)lysine (CML) were determined in plasma by stable-isotope dilution tandem mass spectrometry (14). Protein-bound pentosidine levels were determined in plasma by a single step reversed phase based high-performance liquid chromatography separation with fluorescent detection. The intra- and inter-assay CVs were $7.3 \%$ and $2.0 \%$ for CEL, $3.5 \%$ and $3.6 \%$ for $\mathrm{CML}$, and $2.7 \%$ and $2.8 \%$ for pentosidine, respectively.

\section{Other baseline assessments}

All investigations were performed in the morning after an overnight fast. No antihypertensive medication was ever prescribed in $24 \%$ of patients with nephropathy and $88 \%$ of the normoalbuminuric patients. All of the remaining patients were asked to stop their antihypertensive and diuretic treatment 8 days before the examination. Arterial blood pressure was measured twice with an appropriate cuff size following at least 10 minutes rest in the supine position. Mean arterial pressure (MAP) was calculated as [systolic blood pressure $+(2 *$ diastolic blood pressure $)] / 3$. PP was calculated by subtracting the diastolic from the systolic blood pressure, and used as a marker of arterial stiffness (15). Body mass index (BMI) was calculated by dividing weight by height squared. Urinary albumin excretion (UAE) was measured by an enzyme immunoassay from 24-h urine collections. Serum creatinine concentration was assessed by a kinetic Jaffé method. In all patients glomerular filtration rate (eGFR) was estimated according to the short Modification of Diet in Renal Disease equation (MDRD) (16). Patients were interviewed using the WHO cardiovascular questionnaire. 
Individuals were categorised into three groups according to their smoking status as never, former or current smokers.

\section{Follow-up and study endpoints}

All patients were followed up to the last visit at Steno Diabetes Center, until 1 September 2006 or until death $(n=82)$ or emigration $(n=3)$. All patients were traced through the national register during autumn 2006. If a patient had died before 1 September 2006, the date of death was recorded and information on the primary cause of death was obtained from the death certificate, which was reviewed by two independent observers. Additional available information from necropsy reports was also included. All deaths were classified as cardiovascular unless an unequivocal noncardiovascular cause was established. In all patients alive at the end of follow-up, nonfatal cardiovascular events were retrieved from their patient files from Steno Diabetes Center and/or other hospital records. The primary study outcome was a combined endpoint of fatal and non-fatal cardiovascular disease (i.e. myocardial infarction, percutaneous coronary intervention, coronary bypass grafting, amputation due to ischaemia, vascular surgery for peripheral atherosclerotic disease and stroke), and the secondary outcome was all-cause mortality.

\section{Statistical analyses}

All analyses were performed with the Statistical Package for Social Sciences (SPSS) version 15.0 for Windows (SPSS, Chicago, IL, USA).

Variables with a skewed distribution, i.e. HMGB1, triglycerides, CRP, IL-6, SPLA2, $\mathrm{UAE}$ and pentosidine, were $\log _{e}$ transformed prior to further analyses. Comparisons of baseline characteristics between groups were performed with Student's $t$ or $\chi^{2}$ tests, as appropriate.

We used linear regression analyses to investigate the cross-sectional associations between HMGB1 and markers of low-grade inflammation, endothelial and renal dysfunction, and arterial stiffness. Results of these analyses are expressed as standardised regression coefficients to allow comparison of the strength of the association between HMGB1 and each of these variables.

To investigate the associations between plasma HMGB1 and incident CVD as well as all-cause mortality, we used Cox proportional hazards regression models. These analyses were adjusted, first, for sex, age, duration of diabetes, case-control status and $\mathrm{HbA1c}$; second, for other cardiovascular risk factors (i.e. BMI, smoking status, total cholesterol and MAP); and third, for the use of renin-angiotensin-aldosterone system (RAAS) inhibitors, other antihypertensive treatment, and/or whether subjects did or did not withhold their medication prior to baseline examinations. This model was then further adjusted for markers of low-grade inflammation (expressed as a total score computed by averaging the z scores of Ln-IL-6, Ln-CRP, sICAM-1 and Ln-sPLA2), endothelial dysfunction (expressed as a total score computed by averaging the 
z scores of sVCAM-1 and sICAM-1), renal dysfunction (i.e. eGFR $R_{M D R D}$ and Ln-UAE), and arterial stiffness (i.e. PP); these markers were entered one at a time to ascertain the extent to which any such marker could attenuate (i.e. explain) the strength of the association between HMGB1 and study endpoints, which were given as hazard ratios (HR) with 95\% confidence intervals (Cls).

Finally, we investigated whether the associations listed above differed between patients with normoalbuminuria and those with nephropathy by adding interaction terms to our models, the significance of which was judged on the basis of a p-value $<0.1$ for the interaction term. We found no such interactions and therefore all results are presented for the two groups combined.

\section{Results}

Of the 391 patients included in this study, we excluded 17 (1 with nephropathy and 16 with normoalbuminura) in whom follow-up data were not obtained, 10 with missing data on baseline biomarkers levels ( 5 patients with nephropathy and 5 with normoalbuminuria), 7 with end stage renal failure and 24 with prior CVD at baseline (21 patients with nephropathy and 3 with normoalbuminuria). Results reported herein thus refer to 333 patients (165 with nephropathy and 168 with persistent normoalbuminuria at baseline).

During the course of follow-up [median: 12.3 years (inter-quartile range 7.8-12.5)], 80 individuals (24.0\%) died; $82(24.6 \%)$ suffered a fatal $(n=46)$ and/or non-fatal $(n=53)$ CVD event. Individuals with incident CVD events or who had died at follow-up had, at baseline, a more adverse atherosclerotic risk (Table 6.1).

Plasma Ln-HMGB1 levels were not associated with markers of low-grade inflammation, endothelial and renal dysfunction, advanced glycation endproducts, and arterial stiffness (Table 6.2).

After adjustment for age, sex, duration of diabetes, case-control status, HbA1c, $\mathrm{BMI}$, smoking status, total cholesterol, MAP, and the use of antihypertensive medication, the incidence of fatal and nonfatal CVD as well as all-cause mortality increased with higher baseline levels of HMGB1: $\mathrm{HR}=1.55(95 \% \mathrm{Cl}: 0.96$ to 2.51$)$ and $H R=1.86$ (1.18 to 2.93) per unit increase in Ln-HMGB1, respectively (Table 6.3, model 3; Figure 6.1 A-B).

Further adjustments for markers of low-grade inflammation (model 4), endothelial and renal dysfunction (models 5-6), and PP (model 7) did not appreciably attenuate the positive associations between Ln-HMGB1 and study endpoints (Table 6.3, models 4-7 vs. model 3). 


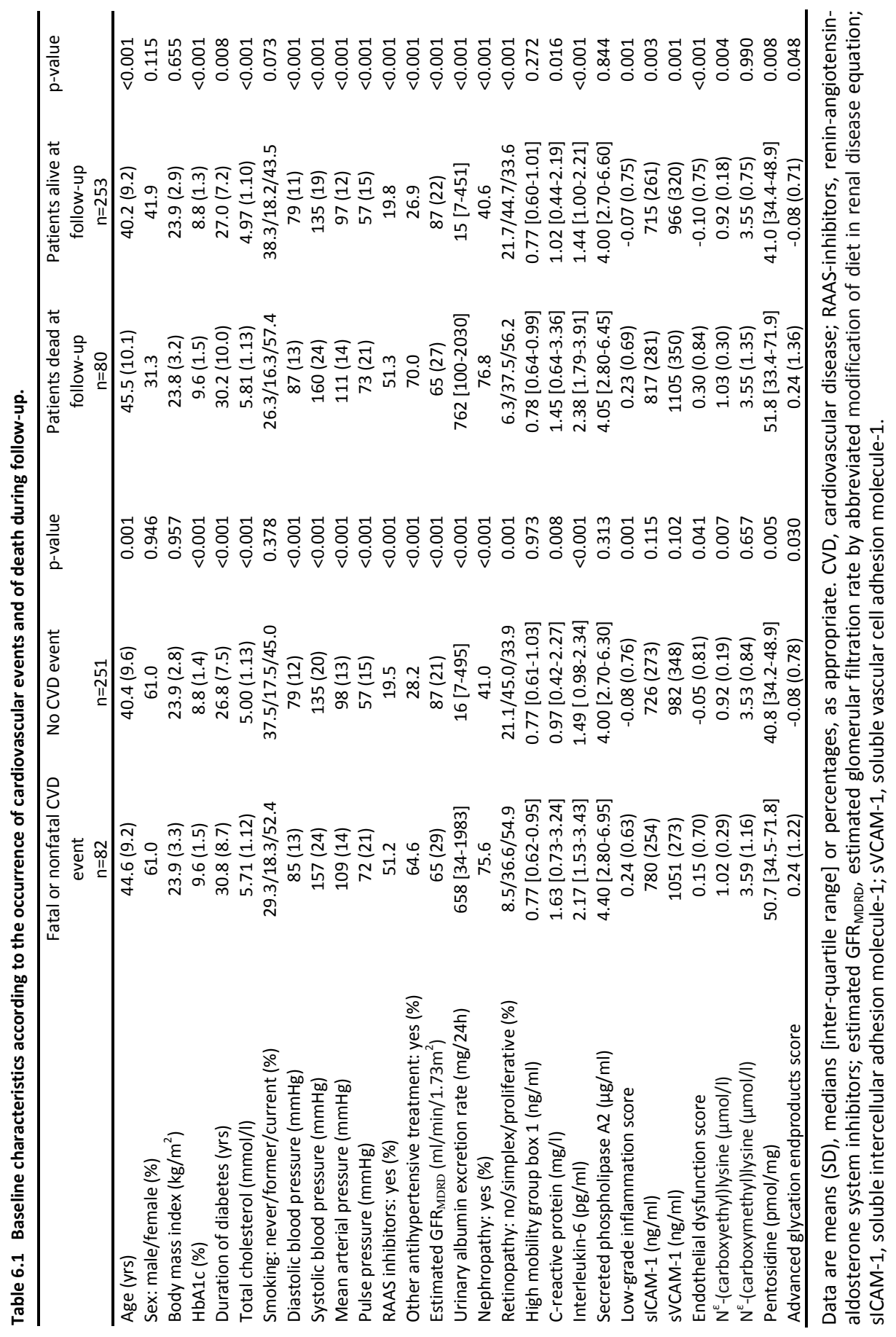


Table 6.2 Associations between plasma Ln-HMGB1 and markers of low-grade inflammation, endothelial and renal dysfunction, advanced glycation endproducts, and pulse pressure (n=333).

\begin{tabular}{lcccccc}
\hline & & Model 1 & & & Model 2 \\
Dependent variable & $\beta$ & $95 \% \mathrm{Cl}$ & $\mathrm{p}$-value & $\beta$ & \multicolumn{1}{c}{$95 \% \mathrm{Cl}$} & $\mathrm{p}$-value \\
\hline Ln C-reactive protein & 0.05 & $-0.06 ; 0.16$ & 0.354 & 0.06 & $-0.05 ; 0.17$ & 0.266 \\
Ln interleukin-6 & 0.11 & $0.00 ; 0.21$ & 0.049 & 0.08 & $-0.03 ; 0.19$ & 0.141 \\
Ln secreted phospholipase A2 & 0.04 & $-0.06 ; 0.14$ & 0.422 & 0.02 & $-0.08 ; 0.13$ & 0.668 \\
Low-grade inflammation score & 0.07 & $-0.01 ; 0.14$ & 0.097 & 0.05 & $-0.02 ; 0.13$ & 0.173 \\
Soluble vascular cell adhesion molecule-1 & -0.02 & $-0.13 ; 0.08$ & 0.677 & -0.02 & $-0.12 ; 0.09$ & 0.735 \\
Soluble intercellular adhesion molecule-1 & 0.15 & $0.04 ; 0.26$ & 0.007 & 0.10 & $-0.01 ; 0.20$ & 0.071 \\
Endothelial dysfunction score & 0.06 & $-0.02 ; 0.15$ & 0.134 & 0.04 & $-0.05 ; 0.12$ & 0.371 \\
& & & & & & \\
$N^{\varepsilon}$-(carboxyethyl)lysine & 0.08 & $-0.03 ; 0.18$ & 0.158 & 0.08 & $0.03 ; 0.18$ & 0.148 \\
$N^{\varepsilon}$-(carboxymethyl)lysine & 0.08 & $-0.03 ; 0.18$ & 0.138 & 0.08 & $-0.03 ; 0.18$ & 0.135 \\
Ln pentosidine & 0.00 & $-0.11 ; 0.10$ & 0.946 & 0.01 & $-0.09 ; 0.11$ & 0.878 \\
Advanced glycation endproducts score & 0.05 & $-0.05 ; 0.15$ & 0.300 & 0.05 & $-0.04 ; 0.15$ & 0.252 \\
Baseline eGFR & & & & & \\
Ln urinary albumin excretion rate & 0.03 & $-0.06 ; 0.12$ & 0.487 & 0.00 & $-0.08 ; 0.09$ & 0.938 \\
Pulse pressure & 0.01 & $-0.03 ; 0.05$ & 0.668 & 0.02 & $-0.03 ; 0.06$ & 0.434 \\
\hline
\end{tabular}

$\beta$, standardised regression coefficient: indicates change in dependent variable (in SD) per 1 SD increase in Ln-HMGB1. Model 1, adjusted for age, sex, duration of diabetes, case-control status and HbA1c; Model 2, model 1 plus additional adjustments for smoking status, mean arterial pressure, body mass index, total cholesterol, use of renin-angiotensin-aldosterone system inhibitors, other antihypertensive treatment, and continuation of medication at baseline examination.

Table 6.3 Associations between plasma Ln-HMGB1 and incident CVD events as well as all-cause mortality ( $n=333)$.

\begin{tabular}{|c|c|c|c|c|c|c|}
\hline \multirow[b]{2}{*}{ Model: adjustments } & \multicolumn{3}{|c|}{ Fatal and nonfatal CVD } & \multicolumn{3}{|c|}{ All-cause mortality } \\
\hline & $\mathrm{HR}$ & $95 \% \mathrm{Cl}$ & $\mathrm{p}$-value & $\mathrm{HR}$ & $95 \% \mathrm{Cl}$ & p-value \\
\hline $\begin{array}{l}\text { 1: age, sex, } \mathrm{HbA} 1 \mathrm{c} \text {, case-control status and } \\
\text { duration of diabetes }\end{array}$ & 1.37 & $0.86 ; 2.20$ & 0.186 & 1.65 & $1.06 ; 2.57$ & 0.028 \\
\hline $\begin{array}{l}\text { 2: model } 1+\mathrm{MAP}, \mathrm{BMI} \text {, smoking status and } \\
\text { total cholesterol }\end{array}$ & 1.47 & $0.91 ; 2.36$ & 0.113 & 1.72 & $1.08 ; 2.74$ & 0.022 \\
\hline 3a: model 2 + RAAS inhibitors agents & 1.49 & $0.93 ; 2.39$ & 0.098 & 1.73 & $1.08 ; 2.75$ & 0.021 \\
\hline 3b: model $2+$ other antihypertensive agents & 1.53 & $0.96 ; 2.43$ & 0.075 & 1.85 & $1.18 ; 2.91$ & 0.007 \\
\hline $\begin{array}{l}3 c \text { : model } 2+\text { continuation of medication } \\
\text { use at baseline examination }\end{array}$ & 1.53 & $0.94 ; 2.48$ & 0.087 & 1.69 & $1.07 ; 2.69$ & 0.026 \\
\hline 3: model $3 a, 3 b$ and $3 c$ & 1.55 & $0.96 ; 2.51$ & 0.073 & 1.86 & $1.18 ; 2.93$ & 0.008 \\
\hline 4: model $3+$ inflammatory score & 1.50 & $0.93 ; 2.43$ & 0.095 & 1.81 & $1.15 ; 2.87$ & 0.011 \\
\hline 5: model $3+$ endothelial dysfunction score & 1.55 & $0.96 ; 2.51$ & 0.073 & 1.81 & $1.14 ; 2.87$ & 0.012 \\
\hline 6: model $3+$ eGFR $_{\mathrm{MDRD}}$ and Ln-UAE & 1.54 & $0.96 ; 2.45$ & 0.071 & 1.80 & $1.14 ; 2.84$ & 0.011 \\
\hline 7: model $3+$ pulse pressure & 1.49 & $0.92 ; 2.42$ & 0.105 & 1.80 & $1.14 ; 2.85$ & 0.012 \\
\hline
\end{tabular}

$\mathrm{HR}$, hazard ratio for fatal and non-fatal CVD or all-cause mortality per each unit increase in Ln-HMGB1 levels at baseline; $\mathrm{Cl}$, confidence interval; $\mathrm{CVD}$, cardiovascular disease; MAP, mean arterial pressure; $\mathrm{BMI}$, body mass index; RAAS inhibitors, renin-angiotensin-aldosterone system inhibitors; eGFR, estimated glomerular filtration rate; UAE, urinary albumin excretion rate. 

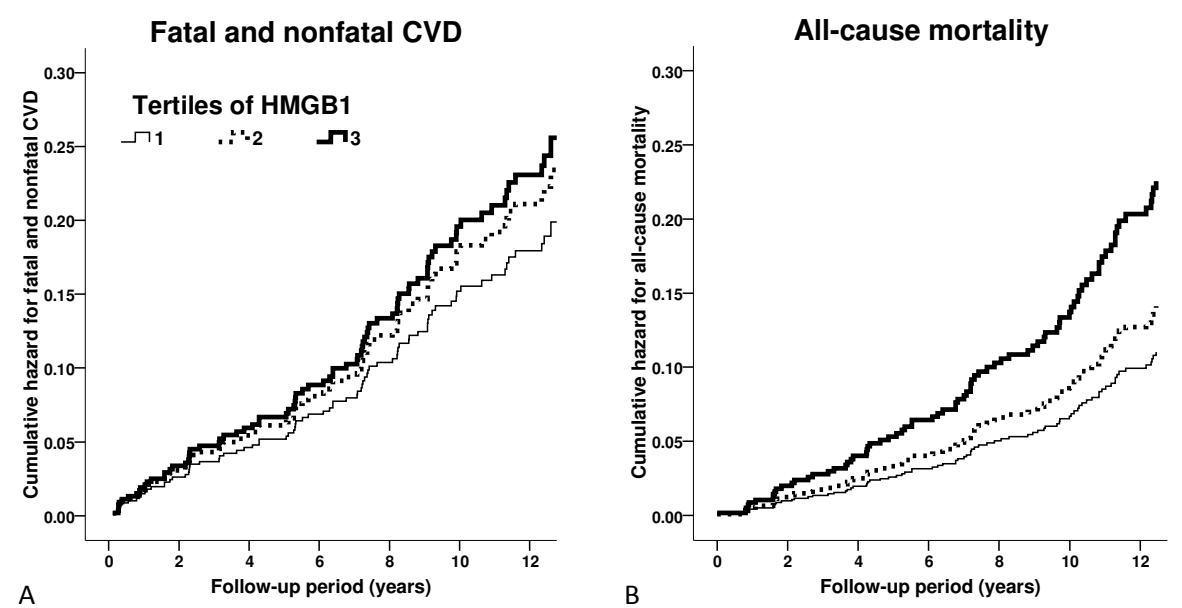

Figure 6.1 Cumulative hazard for fatal and non-fatal CVD (A) as well as all-cause mortality (B) across tertiles of plasma HMGB1. Data are adjusted for age, sex, case-control status, duration of diabetes, HbA1c, smoking status, mean arterial pressure, body mass index, total cholesterol, use of renin-angiotensin-aldosterone system inhibitors, other antihypertensive treatment, and continuation of medication at baseline examination. Compared with patients in the lowest tertile of $\mathrm{HMGB1}$, those in the middle and highest tertiles had increased risk for fatal and nonfatal CVD [HR=1.18 $(95 \% \mathrm{Cl} 0.68$ to 2.05$)$ and 1.29 (0.73 to 2.28$)$, respectively, $\mathrm{p}$ for trend $=0.337$ ] and all-cause mortality $[\mathrm{HR}=1.28(95 \% \mathrm{Cl} 0.70$ to 2.33$)$ and 2.05 (1.14 to 3.67), respectively, $P$ for trend $=0.018$.

\section{Discussion}

The main finding of this study was that, in patients with type 1 diabetes, higher levels of plasma HMGB1 are associated with all-cause mortality, independently of conventional cardiovascular risk factors, and markers of low-grade inflammation, endothelial and renal dysfunction, and pulse pressure. To a lesser extent, higher plasma HMGB1 levels were also positively associated with incident fatal and nonfatal CVD in these patients. This is the first prospective study that has investigated the associations between plasma HMGB1 and incident fatal and nonfatal CVD as well as all-cause mortality in a large sample of individuals with type 1 diabetes, and has also addressed potential mechanisms that could explain the associations observed.

Our findings are in agreement with three studies that have reported positive associations of HMGB1 with coronary artery disease $(9,10)$, heart failure $(11)$, and mortality related to heart diseases (11) in patients with and without type 2 diabetes, though these were limited by their cross-sectional study design (9-11) or a short follow-up period (11). In addition, at the molecular level, fatty streaks and fibrofatty lesions contain more macrophages with cytoplasmic and nucleic HMGB1 compared 
with normal intima (17), and HMGB1 is also expressed by activated vascular smooth muscle cells in more advanced atherosclerotic lesions (18). Furthermore, neutralising HMGB1 attenuated the development of atherosclerosis in an animal model (19).

Interestingly, in that same study neutralizing HMGB1 had only small effects on the expression of proinflammatory cytokines, which suggests that HMGB1 in atherosclerotic lesions may affect immune cell function rather than the expression of proinflammatory cytokines (19). In the present study, we did not find strong associations between HMGB1 and markers of low-grade inflammation, endothelial and renal dysfunction, and pulse pressure, although we cannot fully discard these potential associations due to the use of a selection of markers representing these processes.

Further adjustments for the markers of these pathophysiological mechanisms (i.e. low-grade inflammation, endothelial and renal dysfunction, and arterial stiffness) did not attenuate the positive associations observed between HMGB1 and outcomes. These findings suggest that these different pathophysiological mechanisms and HMGB1 may constitute distinct pathways leading to increased risk of CVD and mortality in these patients. Indeed, this is supported by the associations of eGFR $R_{M D R D}$, Ln-UAE, and pulse pressure with incident fatal and nonfatal CVD [HR=1.15 $(95 \% \mathrm{Cl}$ : 1.02 to 1.29 ) per $10 \mathrm{ml} / \mathrm{min} / 1.73 \mathrm{~m}^{2}$ decrease in eGFR $\mathrm{MDRD}, \mathrm{HR}=1.37$ (1.06 to 1.77) per 1 unit increase in $\mathrm{Ln}-\mathrm{UAE}$, and $\mathrm{HR}=1.24$ (1.05 to 1.45) per $10 \mathrm{mmHg}$ increase, respectively], independently of HMGB1.

Plasma levels of HMGB1 were not associated with plasma levels of $C M L$, while both HMGB1 (2) and CML (20) are ligands for RAGE, and both plasma levels of HMGB1 and CML were positively associated with incident CVD and all-cause mortality in patients with type 1 diabetes as shown in the present and in a previous study (14), respectively. Mutual adjustment for each other did not appreciably attenuate these positive associations (data not shown). These findings suggest that HMGB1-related and CML-related pathways leading to increased risk for CVD morbidity and mortality in type 1 diabetes do not overlap to an important extent, and may form specific targets for treatment in these patients.

The positive association between HMGB1 and incident all-cause mortality was stronger than that between HMGB1 and incident fatal and nonfatal CVD. In addition to diabetes $(10,21)$ and CVD $(9-11)$, HMGB1 is also associated with various diseases (e.g. inflammatory diseases and cancer) (22) commonly related with increased risk for mortality. This may explain, at least in part, the stronger association with incident allcause mortality than with incident fatal and nonfatal CVD. In addition, compared to fatal endpoints, nonfatal endpoints may have been more susceptible to misclassification bias, because of their dependency on the completeness and accuracy of patients' records and/or discharge letters. Most likely, if any misclassification occurred, we may have missed some cases (i.e. patients who were possibly considered as 'free from CVD' when in fact they were not), and in this case, such misclassification was likely to be random, because CVD status was ascribed without previous 
knowledge of subjects' plasma HMGB1 levels. These misclassifications, if present, may, if anything, lead to an underestimation of the strength of the association between HMGB1 and the combined study endpoint (incident fatal and nonfatal CVD).

There are limitations to our study. Samples for analyses of HMGB1 and other biomarkers were taken at baseline only, which impedes evaluation of the impact of changes in these variables on study outcomes. In addition, we measured plasma HMGB1 only and it is unknown how plasma levels relate to intracellular levels. Therefore, further studies are needed to elucidate both the interrelationship between extracellular and intracellular HMGB1 levels, and their associations with cardiovascular disease. Furthermore, in a recent study in patients with type 1 diabetes (EURODIAB nested case-control study) preliminary data showed that serum HMGB1 was not associated with prevalent CVD (23). The apparent discrepancy with the positive association between plasma HMGB1 and incident CVD observed in the present study suggests that measures obtained in serum and plasma may not represent the same pool of HMGB1. Further studies are needed to clarify both the interrelationship between serum and plasma levels of HMGB1, and their associations with cardiovascular disease.

In conclusion, higher plasma HMGB1 levels are associated with incident all-cause mortality in type 1 diabetes, independently of other conventional cardiovascular risk factors and markers of low-grade inflammation, endothelial and renal dysfunction, and arterial stiffness. To a lesser extent, higher plasma HMGB1 levels were also associated with higher incident fatal and nonfatal CVD in these patients. Altogether, HMGB1 may explain, in part, the risk of CVD and mortality in type 1 diabetes and may constitute a specific target for treatment in these patients. 


\section{References}

1. Brownlee M: Biochemistry and molecular cell biology of diabetic complications. Nature 2001;414: 813-820

2. Hori O, Brett J, Slattery T, Cao R, Zhang J, Chen JX, Nagashima M, Lundh ER, Vijay S, Nitecki D, et al.: The receptor for advanced glycation end products (RAGE) is a cellular binding site for amphoterin. Mediation of neurite outgrowth and co-expression of rage and amphoterin in the developing nervous system. J Biol Chem 1995;270:25752-25761

3. Bianchi ME, Agresti A: HMG proteins: dynamic players in gene regulation and differentiation. Curr Opin Genet Dev 2005;15:496-506

4. Scaffidi P, Misteli T, Bianchi ME: Release of chromatin protein HMGB1 by necrotic cells triggers inflammation. Nature 2002;418:191-195

5. Rendon-Mitchell B, Ochani M, Li J, Han J, Wang H, Yang H, Susarla S, Czura C, Mitchell RA, Chen G, Sama $A E$, Tracey KJ, Wang H: IFN-gamma induces high mobility group box 1 protein release partly through a TNF-dependent mechanism. J Immunol 2003;170:3890-3897

6. Li J, Kokkola R, Tabibzadeh S, Yang R, Ochani M, Qiang X, Harris HE, Czura CJ, Wang H, Ulloa L, Wang H, Warren HS, Moldawer LL, Fink MP, Andersson U, Tracey KJ, Yang H: Structural basis for the proinflammatory cytokine activity of high mobility group box 1. Mol Med 2003;9:37-45

7. Fiuza C, Bustin M, Talwar S, Tropea M, Gerstenberger E, Shelhamer JH, Suffredini AF: Inflammationpromoting activity of HMGB1 on human microvascular endothelial cells. Blood 2003;101:2652-2660

8. van Zoelen MA, Yang H, Florquin S, Meijers JC, Akira S, Arnold B, Nawroth PP, Bierhaus A, Tracey KJ, van der Poll T: Role of Toll-Like Receptors 2 and 4, and the Receptor for Advanced Glycation End Products (Rage) in Hmgb1 Induced Inflammation in Vivo. Shock 2009;31:280-284

9. Hu X, Jiang H, Bai $Q$, Zhou X, Xu C, Lu Z, Cui B, Wen H: Increased serum HMGB1 is related to the severity of coronary artery stenosis. Clin Chim Acta 2009;406:139-142

10. Yan XX, Lu L, Peng WH, Wang L, Zhang Q, Zhang RY, Chen QJ, Shen WF: Increased serum HMGB1 level is associated with coronary artery disease in nondiabetic and type 2 diabetic patients. Atherosclerosis 2009;205:544-548

11. Wang L, Lu L, Zhang FR, Chen QJ, De Catherina R, Shen WF: Increased serum High-mobility group box-1 and cleaved receptor for advanced glycation endproducts levels and decreased endogenous secretory receptor for advanced glycation endproducts levels in diabetic and non-diabetic patients with heart failure. Eur J Heart Fail 2011;13:440-449

12. Tarnow L, Cambien F, Rossing P, Nielsen FS, Hansen BV, Lecerf L, Poirier O, Danilov S, Parving HH: Lack of relationship between an insertion/deletion polymorphism in the angiotensin I-converting enzyme gene and diabetic nephropathy and proliferative retinopathy in IDDM patients. Diabetes 1995;44:489-494

13. De Jager J, Kooy A, Lehert P, Bets D, Wulffele MG, Teerlink T, Scheffer PG, Schalkwijk CG, Donker AJ, Stehouwer CD: Effects of short-term treatment with metformin on markers of endothelial function and inflammatory activity in type 2 diabetes mellitus: a randomized, placebo-controlled trial. J Intern Med 2005;257:100-109

14. Nin JW, Jorsal A, Ferreira I, Schalkwijk CG, Prins MH, Parving HH, Tarnow L, Rossing P, Stehouwer CD: Higher plasma levels of advanced glycation end products are associated with incident cardiovascular disease and all-cause mortality in type 1 diabetes: a 12-year follow-up study. Diabetes Care 2011;34:442-447

15. Stehouwer CD, Henry RM, Ferreira I: Arterial stiffness in diabetes and the metabolic syndrome: a pathway to cardiovascular disease. Diabetologia 2008;51:527-539

16. Levey AS, Bosch JP, Lewis JB, Greene T, Rogers N, Roth D: A more accurate method to estimate glomerular filtration rate from serum creatinine: a new prediction equation. Modification of Diet in Renal Disease Study Group. Ann Intern Med 1999;130:461-470

17. Kalinina N, Agrotis A, Antropova Y, DiVitto G, Kanellakis P, Kostolias G, llyinskaya O, Tararak E, Bobik A: Increased expression of the DNA-binding cytokine HMGB1 in human atherosclerotic lesions: role of activated macrophages and cytokines. Arterioscler Thromb Vasc Biol 2004;24:2320-2325 
18. Inoue K, Kawahara K, Biswas KK, Ando K, Mitsudo K, Nobuyoshi M, Maruyama I: HMGB1 expression by activated vascular smooth muscle cells in advanced human atherosclerosis plaques. Cardiovasc Pathol 2007;16:136-143

19. Kanellakis P, Agrotis A, Kyaw TS, Koulis C, Ahrens I, Mori S, Takahashi HK, Liu K, Peter K, Nishibori M, Bobik A: High-mobility group box protein 1 neutralization reduces development of diet-induced atherosclerosis in apolipoprotein e-deficient mice. Arterioscler Thromb Vasc Biol 2011;31:313-319

20. Kislinger T, Fu C, Huber B, Qu W, Taguchi A, Du Yan S, Hofmann M, Yan SF, Pischetsrieder M, Stern D, Schmidt AM: N(epsilon)-(carboxymethyl)lysine adducts of proteins are ligands for receptor for advanced glycation end products that activate cell signaling pathways and modulate gene expression. J Biol Chem 1999;274:31740-31749

21. Volz HC, Seidel C, Laohachewin D, Kaya Z, Muller OJ, Pleger ST, Lasitschka F, Bianchi ME, Remppis A, Bierhaus A, Katus HA, Andrassy M: HMGB1: the missing link between diabetes mellitus and heart failure. Basic Res Cardiol 105:805-820

22. Sims GP, Rowe DC, Rietdijk ST, Herbst R, Coyle AJ: HMGB1 and RAGE in inflammation and cancer. Annu Rev Immunol 2010;28:367-388

23. Ferreira I, Nin JW, Schalkwijk CG, Prins MH, Chaturvedi N, Fuller JH, Stehouwer CD: Higher serum hihg-mobility group box 1 levels are cross-sectionally associated with micro- and macroalbuminuria, but not with cardiovascular disease in type 1 diabetes: the EURODIAB PCS (Abstract). Diabetologia 2011;54:\$435 


\section{Chapter 7}

Pulse pressure partially explains the higher incidence of cardiovascular disease associated with advanced glycation endproducts and low-grade inflammation: a $12-y r$ prospective study in type 1 diabetes

Johanna W Nin, Isabel Ferreira, Casper G Schalkwijk, Anders Jorsal, Martin H Prins, Hans-Henrik Parving, Lise Tarnow, Peter Rossing, Coen D Stehouwer

Submitted 


\section{Abstract}

\section{Background and objective}

Accelerated arterial ageing, characterised by steeper increases in pulse pressure (PP) with age, increases cardiovascular disease (CVD) risk in type 1 diabetes. Advanced glycation endproducts (AGEs) and low-grade inflammation (LGI) may underlie these increases in PP and CVD risk. We have therefore investigated the extent to which PP mediates the associations of AGEs and LGI with incident CVD in 339 patients with type 1 diabetes.

\section{Methods}

Brachial PP, AGEs (e.g. pentosidine), and LGI markers (e.g. C-reactive protein, CRP) were measured at baseline. Incident CVD ( $\mathrm{n}=85)$ was ascertained over a median of 12.3 years. We used multivariable linear and Cox-regression models, and the $\alpha \beta$ product-of-coefficients method to ascertain the mediated effect.

\section{Results}

Both Ln-pentosidine and Ln-CRP (per SD) were independently associated with higher PP [2.4 $\mathrm{mmHg}(95 \% \mathrm{Cl}$ : 0.6-4.2) and $2.6 \mathrm{mmHg}$ (1.1-4.2)] and incident CVD [HR=1.32 (1.01-1.72) and HR=1.40 (1.08-1.82), respectively]. Further adjustment for PP significantly attenuated the associations of the cross-link AGE, pentosidine, and CRP, a marker of LGI, with CVD by $18 \%$ and $14 \%$, respectively, and may, thus, partially explain these associations. In addition, we categorised individuals into 4 groups: low-CRP/low-PP ( $n=93 / 10$ events, referent), high-CRP/low-PP ( $n=76 / 12$ events), low-CRP/high-PP ( $n=77 / 23$ events) and high-CRP/highPP ( $n=93 / 40$ events). Compared with the reference group, the risk factor-adjusted risk estimates were higher for both patients with high-CRP/low-PP [HR=1.18 (0.50-2.80)] and low-CRP/high-PP [HR=1.48 (0.633.50)], but considerably higher for those with high-CRP/high-PP [HR=2.63 (1.17-5.91)].

\section{Conclusions}

In type 1 diabetes, arterial stiffness, as expressed by PP, may explain a portion, albeit small, of the higher CVD risk associated with pentosidine. Cross-link breakers may, thus, offer a means to reduce arterial stiffening and related CVD in these patients. In addition, PP and CRP were interrelated and explained a portion of the associations with incident CVD in a mutual fashion. Notably, both CRP and PP remained independently associated with higher incidence of CVD, and in combination may increase even further the risk of CVD. This suggests that both LGI and arterial stiffness may need to be monitored and targeted separately in order to interrupt this vicious cycle and thereby deter the related cardiovascular sequelae often affecting these patients. 


\section{Introduction}

Patients with type 1 diabetes are characterised by accelerated arterial ageing, as illustrated by steeper increases in pulse pressure (PP) with age as compared with their peers without diabetes (1). Such increases in PP reflect arterial stiffening (2) and are associated with higher incident CVD in these patients $(3,4)$. The mechanisms underlying the increases in PP in diabetes are not clear, but advanced glycation endproducts (AGEs) (5) and low-grade inflammation (LGI) may play a role (2).

AGEs are formed by a nonenzymatic reaction between reducing sugars and proteins. These stable compounds accumulate with ageing and may contribute to ageand diabetes-associated arterial stiffening through the formation of collagen crosslinking, which alters the structure and function of the extracellular matrix (5). A causal underlying role of LGI in the development of arterial stiffness has been suggested by studies linking higher levels of C-reactive protein (CRP) (6) and inflammation-sensitive proteins in plasma (7) to the incidence of isolated systolic hypertension (6) or subsequent increases in PP (7). The premise of elevated CRP antedating the onset of hypertension has also been confirmed by prospective studies among initially normotensive individuals (8-11). Indeed, inflammation may influence arterial stiffening by affecting vascular smooth muscle cell tone due to reduced availability of nitric oxide and increased activity of vasoconstrictors such as endothelin-1, and by affecting the composition of the extracellular matrix (12). In addition, inflammation may increase the production of reactive oxygen species (13), which in turn triggers inflammatory processes leading to the proliferation of smooth muscle cells, the influx of leucocytes, and the production of pro-inflammatory cytokines (14). However, others have suggested that increases in PP per se may be a driving force behind increases in inflammation (reverse causation), and thereby in CVD risk (15-17). It is thus not clear whether elevated LGI leads to increases in PP or whether elevated PP imposes biomechanical stimuli to endothelial cells promoting a cascade of mechanisms associated with inflammation that then lead to higher levels of CRP (reverse causation) $(12,14,18,19)$. Another possibility is that CRP and PP act in concert and further boost each other's deleterious impact on CVD (self-enforcing/bidirectional causation).

We have recently shown that AGEs (20) and LGI (21) were associated with higher incident fatal and non-fatal CVD in type 1 diabetes. Given that both these mechanisms may enhance PP, and thereby increase CVD risk, elevated PP may thus constitute a mechanism through which LGI and AGEs are associated with increased CVD risk in these patients (Hypothesis one, Figure 7.1A - PP as a mediator). Alternatively (reverse causation), or in addition (bi-directional causation), LGI may (also) be consequent to increased PP and thus mediate the association between PP and incident CVD (Hypothesis 2, Figure 7.1B). In the present study we investigated these hypotheses in a 12-yr prospective cohort study of type 1 diabetes and incident CVD and all-cause mortality. The hypotheses were tested with the use of Mediation Analyses, a data 
analysis technique that helps identify whether a variable is likely to be in the causal pathway relating determinant to outcome variables, by quantifying and ascertaining the significance of any such mediation effect $(22,23)$.

A

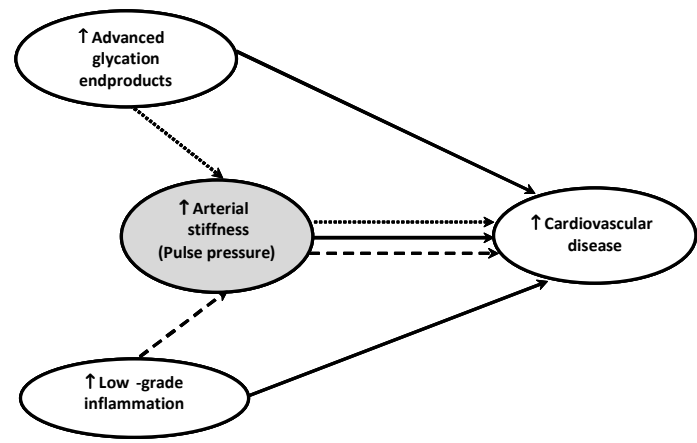

B

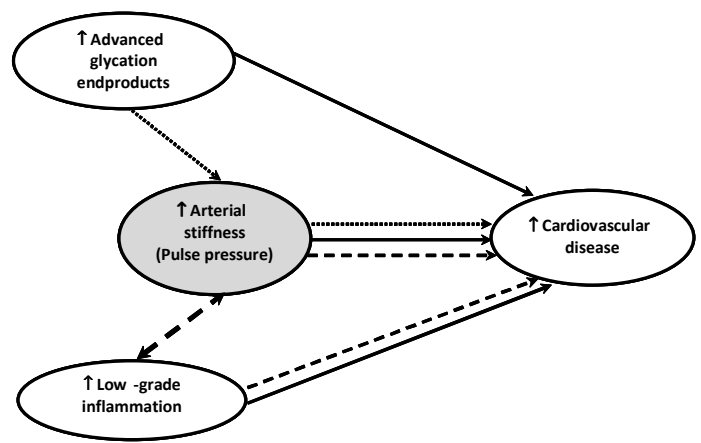

Figure 7.1 Hypotheses tested in the present study. Panel A) Hypothesis 1 - the associations of low-grade inflammation (LGI) and advanced glycation endproducts (AGEs) with incident cardiovascular disease (CVD) are, in part, mediated by arterial stiffness (as expressed by pulse pressure - PP); Panel B) Hypothesis 2 - LGI (also) mediates the association between PP and incident CVD, and in combination, LGI and PP may self-enforce their impact on CVD risk; Dotted and dashed lines indicate indirect/mediated 'effects' and the uninterrupted lines indicate direct or independent 'effects'.

\section{Methods}

\section{Study population and design}

In 1993, 391 patients with type 1 diabetes were enrolled in this $12-y r$ prospective observational study on CVD and mortality, as described in detail elsewhere $(20,21,24,25)$. Briefly, 199 patients with type 1 diabetes and nephropathy and 192 with normoalbuminuria were recruited from the outpatient clinic at the Steno 
Diabetes Center. Normoalbuminuria was defined as urinary excretion rate (UAE) $<30 \mathrm{mg} / 24 \mathrm{~h}$, and diabetic nephropathy was defined according to the following clinical criteria: UAE $>300 \mathrm{mg} / 24 \mathrm{~h}$ in at least two out of three previous consecutive 24-h urine collections, presence of diabetic retinopathy (assessed by fundus photography after pupillary dilatation), and no clinical or laboratory evidence of kidney or renal tract disease other than diabetic glomerulosclerosis. The study was approved by the local ethics committee and all patients gave their informed written consent.

\section{Baseline investigations}

All investigations were performed in the morning after an overnight fast. No antihypertensive medication was ever prescribed in $24 \%$ of patients with nephropathy and $88 \%$ of the normoalbuminuric patients. All of the remaining patients were asked to stop their antihypertensive treatment 8 days before the examination, but $27 \%$ and $4 \%$ of patients in, respectively, the nephropathy and normoalbuminuria groups, did not comply with this recommendation.

\section{Blood pressure}

Systolic (SBP) and diastolic blood pressure (DBP) were measured twice and averaged, on the right arm, after at least 10 minutes of rest in the supine position. The measurements were performed with a Hawksley random zero sphygmomanometer (Hawksley \& Sons Ltd, lancing, Sussex, UK) and appropriate cuff size. DBP was recorded at the disappearance of Korotkoff sounds (phase V). MAP was calculated as $[(2 * D B P)+S P)] / 3$. PP was calculated by subtracting DBP from SBP.

\section{Biomarkers of AGES, LGI, and endothelial dysfunction}

Analyses of the biomarkers were done on frozen $\left(-80^{\circ} \mathrm{C}\right)$ samples in our central laboratory (by C.G.S).

Plasma levels of protein-bound $\mathrm{N}^{\varepsilon}$-(carboxyethyl)lysine (CEL) and $\mathrm{N}^{\varepsilon}$ (carboxymethyl)lysine (CML) were determined, as markers of non-crosslinking AGEs, by stable-isotope dilution tandem mass spectrometry, and of protein-bound pentosidine, as a marker of cross-linking AGEs, were determined by a single step reversed phase based high-performance liquid chromatography (HPLC) separation with fluorescent detection (20). The intra- and inter-assay coefficients of variation (CVs) were $7.3 \%$ and $2.0 \%$ for CEL, $3.5 \%$ and $3.6 \%$ for $\mathrm{CML}$, and $2.7 \%$ and $2.8 \%$ for pentosidine, respectively.

We measured CRP, interleukin-6 (IL-6), and secreted phospholipase A2 (sPLA2) as markers of low-grade inflammation, soluble vascular cell adhesion molecule-1 (sVCAM-1) as a marker of endothelial dysfunction, and soluble intercellular adhesion molecule-1 (sICAM-1) as a marker of both LGI and endothelial dysfunction. Highsensitivity CRP was determined by in house enzyme-linked immunosorbent assays (ELISA) (26). Commercially available ELISA kits were used for the measurement of IL-6, 
sPLA2, sICAM-1, and sVCAM-1 (Quantikine High Sensitivity; R\&D Systems, Oxon, U.K.) (21). The intra- and inter-assay CVs of these immunoassays were all $<8 \%$.

\section{Other risk factors}

Measures of body mass index (BMI), glycated haemoglobin (HbA1c), total cholesterol, 24-h UAE rate, estimated glomerular filtration rate (eGFR) and smoking status (never, former or current) were described in detail before $(20,21,25)$.

\section{Follow-up and study end-points}

All patients were followed up to the last visit at Steno Diabetes Center, until 1 September 2006 or until death $(n=82)$ or emigration $(n=3)$. All patients were traced through the national register during autumn 2006. If a patient had died before 1 September 2006, the date of death was recorded and information on the primary cause of death was obtained from the death certificate, which was reviewed by two independent observers. Additional information available from necropsy reports was also included. All deaths were classified as cardiovascular unless an unequivocal noncardiovascular cause was established. In all patients alive at the end of follow-up, nonfatal cardiovascular events were retrieved from their patient files at the Steno Diabetes Center and/or other hospitals.

The primary study outcome was a combined end-point of fatal and non-fatal CVD (i.e. myocardial infarction, percutaneous coronary intervention, coronary bypass grafting, amputation due to ischaemia, vascular surgery for peripheral atherosclerotic disease and stroke). The study's secondary end-point was all-cause mortality.

\section{Statistical analyses}

All analyses were performed with the Statistical Package for Social Sciences (SPSS) version 15.0 for Windows (SPSS, Chicago, IL, USA) or R version 2.13.0 (The R Foundation for Statistical Computing 2011). Variables with a skewed distribution, i.e. CRP, IL-6, SPLA2, pentosidine, and UAE, were $\log _{e}$ transformed (Ln) prior to further analyses. Comparisons of baseline characteristics between groups were performed with Student's $t$ or $\chi^{2}$ tests, as appropriate.

\section{Mediation analyses}

The mediating role (i.e. extent and significance) of a variable/pathobiological mechanism hypothesised to be in the pathway between a given determinant and outcome was ascertained by quantitative appreciation of the attenuation in the strength of the association between determinant and outcome after adjustment for the potential mediator $(22,23)$.

Accordingly, we used ' $\alpha \beta$ product of coefficients' method to investigate the mediating role of PP in the associations of AGEs and markers of LGI (main 
determinants) with incident CVD or all-cause mortality (outcomes) (23). These analyses entail a series of steps to retrieve four coefficients (i.e. $\alpha, \beta, \tau$, and $\tau^{\prime}$ ) reflecting the associations of interest (Figure 7.2). First, we used multivariable linear regression analyses to ascertain which of the AGEs and markers of LGI considered were associated with PP ( $\alpha$ paths). Second, we used Cox proportional hazards analyses to investigate the associations between PP (the potential mediator) and incident CVD or all-cause mortality, when adjusted for the AGEs and markers of LGI identified in the previous step ( $\beta$ path). Finally, Cox proportional hazards analyses were used to ascertain the relationships between AGEs or markers of LGI and incident CVD or mortality before ( $\tau_{1}$ and $\tau_{2}$, respectively) and after adjustment for PP (i.e. $\tau_{1}{ }^{\prime}$ and $\tau_{2}{ }^{\prime}$, respectively). Given that the $\alpha$ and the $\beta$ (as well as $\tau$ and $\tau^{\prime}$ ) coefficients and respective standard errors (SEs) were obtained by, respectively, ordinary least squares regression and maximum likelihood, they were first scaled to enable comparability across different estimation models, as described in detail elsewhere $(23,27)$. The scaled coefficients and SEs were then entered into the RMediation package written for use in the $\mathrm{R}$ statistical software to calculate the $\alpha \beta$ product and respective $95 \%$ confidence interval $(\mathrm{Cl})(28)$. The $\alpha \beta$ product indicates the magnitude of attenuation from $\tau$ (Figure 7.2A) to $\tau^{\prime}$ (Figure 7.2B, i.e. the mediated effect, which is significant if 0 is not included in the $\mathrm{Cl}$. Note that this specific software uses bootstrapping procedures to estimate asymmetric Cls to properly reflect the distribution of the $\alpha \beta$ product, which is often skewed $(22,29)$. The proportion mediated (in \%) was estimated by dividing the mediated effect $(\alpha \beta)$ by the total relationship of AGEs or markers of LGI with incident CVD (or all-cause mortality) as $\alpha_{1} \beta / \alpha_{1} \beta+\tau_{1}{ }^{\prime}$ or $\alpha_{2} \beta$ $/ \alpha_{2} \beta+\tau_{2}{ }^{\prime}$, respectively.

A

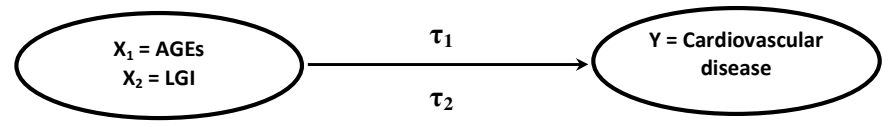

B

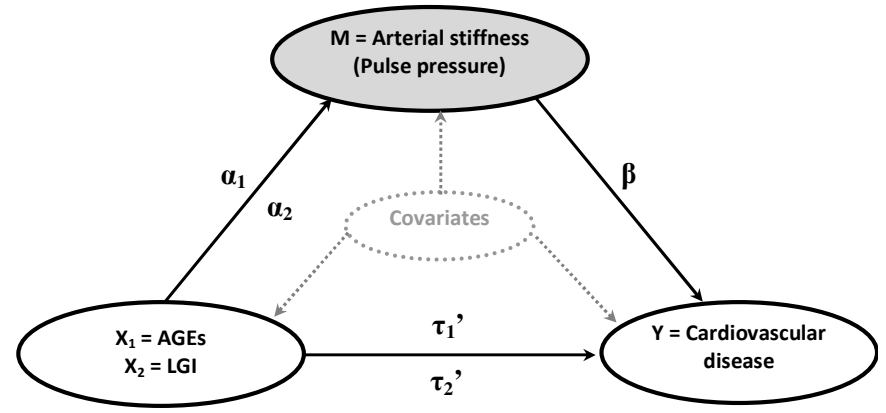

Figure 7.2 Illustration of the steps involved in mediation analyses models applied to the present study. $X$, study main determinants; $M$, potential mediator; $Y$, study outcome; LGI, low-grade inflammation; AGEs, advanced glycation endproducts. 
All analyses described above were adjusted for sex, age, duration of diabetes, $\mathrm{HbA1c}$, presence of nephropathy, BMI, smoking status, total cholesterol, use of antihypertensive medication, whether or not patients withheld medication at the baseline examination, endothelial dysfunction markers (sVCAM-1 and sICAM-1, if appropriate), eGFR, and Ln-UAE (models 1). We also included: mutual adjustment for AGEs or markers of LGI to ascertain independence of these two mechanisms (models 2); and adjustment for MAP (steady load) to establish that associations could be attributed to arterial stiffness (PP) independently of residual contribution from peripheral resistance (models 3) (30). All effect estimates were expressed per SD of the main determinants to enable comparisons of the strength of associations between them. To investigate whether the associations listed above differed between patients with normoalbuminuria vs. with nephropathy, or between individuals who did vs. did not withhold medication at the baseline examination, we added interaction terms to our models. We did not find any significant interactions ( $p$-values for interaction terms all>0.1). All results were therefore presented for the whole study population.

\section{Joint effects of CRP and PP on incident CVD}

To evaluate whether CRP and PP exerted synergistic effects on incident CVD, we constructed cumulative hazard curves after categorizing individuals into 4 groups: low-CRP/low-PP, high-CRP/low-PP, low-CRP/high-PP and high-CRP/high-PP, with high and low defined as $\geq$ or $<$ the median levels of CRP and PP. The observed effect estimates (HR) for the high-CRP-high-PP group were then compared with those that could be expected by combination of the independent effects of high-CRP with high$\mathrm{PP}$, assuming either an additive or a multiplicative interaction between CRP and PP (31).

\section{Results}

Of the 391 patients included in this study, we excluded 17 in whom it was not possible to obtain sufficient follow-up data, 4 with missing data on baseline biomarkers levels, 7 with end stage renal failure and 24 with prior CVD. Results reported herein thus refer to 339 patients.

During the course of follow-up (median: 12.3 years [inter-quartile range 7.6-12.5]), 82 individuals (24.2\%) died; 85 (25.1\%) suffered a fatal $(n=48)$ and/or non-fatal $(n=53)$ CVD event. Comparisons of the baseline characteristics between individuals with vs. without incident CVD events are shown in Table 7.1. 
Table 7.1 Baseline characteristics according to the occurrence of cardiovascular disease events during follow-up.

\begin{tabular}{|c|c|c|c|}
\hline & $\begin{array}{l}\text { Fatal or non-fatal CVD } \\
\qquad(\mathrm{n}=85)\end{array}$ & $\begin{array}{l}\text { No CVD } \\
(n=254)\end{array}$ & $P$-value \\
\hline Sex: male/female (\%) & $61 / 39$ & $60 / 40$ & 0.901 \\
\hline Age (yrs) & $44.7(9.0)$ & $40.3(9.6)$ & $<0.001$ \\
\hline Duration of diabetes (yrs) & $30.7(8.8)$ & $26.8(7.5)$ & $<0.001$ \\
\hline Nephropathy: yes (\%) & 75 & 41 & $<0.001$ \\
\hline Retinopathy: no/simplex/proliferative (\%) & $8 / 37 / 55$ & $21 / 45 / 34$ & $<0.001$ \\
\hline HbA1c (\%) & $9.5(1.5)$ & $8.9(1.4)$ & $<0.001$ \\
\hline Body mass index $\left(\mathrm{kg} / \mathrm{m}^{2}\right)$ & $23.9(3.3)$ & $23.9(2.8)$ & 0.991 \\
\hline Total cholesterol (mmol/l) & $5.70(1.10)$ & $4.99(1.12)$ & $<0.001$ \\
\hline Urinary albumin excretion rate $(\mathrm{mg} / 24 \mathrm{~h})$ & $644[33-1940]$ & $17[7-525]$ & $<0.001$ \\
\hline 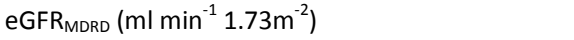 & $65.5(29.1)$ & $86.8(21.1)$ & $<0.001$ \\
\hline Antihypertensive medication (\%) & 66 & 31 & $<0.001$ \\
\hline Smoking: never/former/current (\%) & $28 / 19 / 53$ & $37 / 17 / 46$ & 0.513 \\
\hline Pentosidine (pmol/mg) & $49.3[35.7-71.8]$ & $40.8[34.0-49.0]$ & 0.001 \\
\hline $\mathrm{N} \varepsilon$-(carboxyethyl)lysine $(\mu \mathrm{mol} / \mathrm{l})$ & $1.02(0.28)$ & $0.92(0.19)$ & 0.004 \\
\hline $\mathrm{N} \varepsilon$-(carboxymethyl)lysine ( $\mu \mathrm{mol} / \mathrm{l})$ & $3.60(1.12)$ & $3.54(0.84)$ & 0.634 \\
\hline C-reactive protein (mg/l) & $1.59[0.64-3.22]$ & $0.96[0.41-2.09]$ & 0.008 \\
\hline Interleukin-6 (pg/ml) & $2.18[1.52-3.45]$ & $1.49[0.99-2.35]$ & $<0.001$ \\
\hline Secreted phospholipase A2 $(\mu \mathrm{g} / \mathrm{ml})$ & $4.40[2.80-7.00]$ & $4.00[2.70-6.23]$ & 0.329 \\
\hline Soluble intercellular adhesion molecule-1 (ng/ml) & $771(258)$ & $726(272)$ & 0.182 \\
\hline Soluble vascular cell adhesion molecule- 1 ( $\mathrm{ng} / \mathrm{ml})$ & 1045 (269) & $984(346)$ & 0.141 \\
\hline Systolic blood pressure (mmHg) & $157(24)$ & $136(20)$ & $<0.001$ \\
\hline Diastolic blood pressure (mmHg) & $85(13)$ & $79(12)$ & 0.001 \\
\hline Mean arterial pressure (mmHg) & $109(15)$ & $98(13)$ & $<0.001$ \\
\hline Pulse pressure $(\mathrm{mmHg})$ & $73(21)$ & $57(15)$ & $<0.001$ \\
\hline
\end{tabular}

Data are means $(\mathrm{SD})$, median [inter-quartile range] or percentages, as appropriate. eGFR $\mathrm{MDRD}_{\text {, estimated }}$ glomerular filtration rate by short modification of diet in renal disease equation.

\section{Associations of AGEs and markers of LGI with PP ( $\alpha_{1}$ and $\alpha_{2}$ paths)}

In analyses adjusted for age, sex, duration of diabetes, use of antihypertensive medication, and other risk factors, pentosidine and CRP, but not the other AGEs or markers of LGI were significantly associated with PP (Table 7.2, model 1). These associations did not materially change when we included mutual adjustments between CRP and pentosidine (model 2) and further adjustment for MAP (model 3). In this fully adjusted model, $\mathrm{PP}$ was $2.6 \mathrm{mmHg}$ (equivalent to $0.15 \mathrm{SD}$ ) and $2.4 \mathrm{mmHg}$ (equivalent to $0.13 \mathrm{SD}$ ) higher per each SD increase in Ln-pentosidine and Ln-CRP, respectively.

\section{Associations of PP with incident CVD and all-cause mortality (B path)}

After adjustments for conventional risk factors (Table 7.3, model 1), both pentosidine and CRP (model 2), and MAP (model 3), PP (per SD) was independently associated with higher incident CVD: $\mathrm{HR}=1.40$ (95\% Cl: 1.04-1.88). The association of PP with allcause mortality was weaker $[\mathrm{HR}=1.36(1.00-1.85)]$ and borderline not significant. 


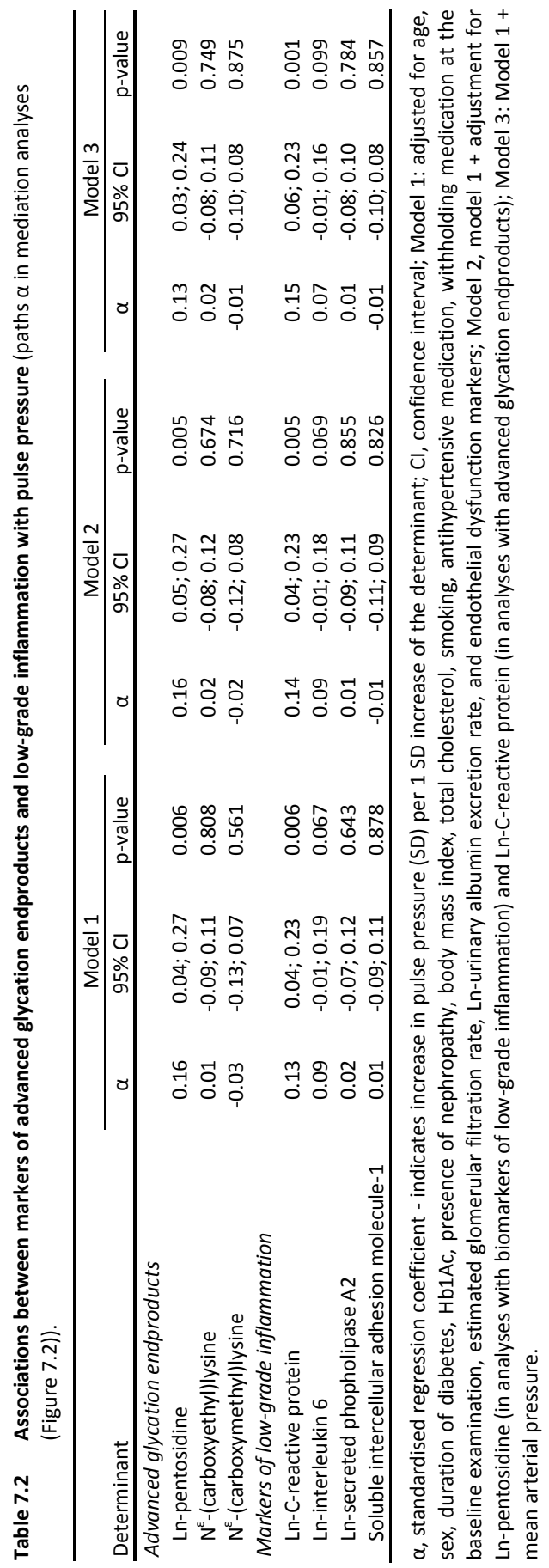


Associations between pentosidine and CRP with incident CVD and mortality ( $\tau_{1}$ and $\tau_{2}$ paths) and the mediating role of PP herein ( $\tau_{1}{ }^{\prime}$ and $\tau_{2}{ }^{\prime}$ paths)

In analyses adjusted for conventional risk factors (Table 7.3, model 1), one another (model 2), and MAP (model 3), pentosidine and CRP were both independently and significantly associated with higher incident CVD: $H R=1.32$ (1.01-1.72) and $H R=1.40$ (1.08-1.82) per SD higher Ln-pentosidine and Ln-CRP, respectively. After further adjustment for PP the association between pentosidine and incident CVD was attenuated to $\mathrm{HR}=1.23(0.93-1.63)$ and was no longer statistically significant; the association between CRP and incident CVD was attenuated to HR=1.35 (1.08-1.82), but remained statistically significant (model 4).

Mediation analyses showed that the magnitude of the mediated effects by PP amounted to $\sim 18 \%$ in the pentosidine $\rightarrow$ CVD association and to $\sim 14 \%$ in the $\mathrm{CRP} \rightarrow \mathrm{CVD}$ association, and both were statistically significant (Table 7.4).

In analyses with the study's secondary end-point, adjustment for PP attenuated the increased risk for all-cause mortality associated with pentosidine from $H R=1.31$ $(1.00-1.71)$ to $1.26(0.96-1.66)$ and the increased risk associated with CRP from $\mathrm{HR}=1.31$ (0.99-1.73) to $1.26(0.95-1.67) \quad$ (Table 7.3). The magnitude of these attenuations was similar to those observed in analyses with incident CVD and amounted to $\sim 15 \%$ and $\sim 16 \%$, respectively, but did not reach statistical significance (Table 7.4).

\section{Joint effects of CRP and PP on incident CVD}

The cumulative hazard curves after categorizing individuals into 4 groups: lowCRP/low-PP ( $n=93 / 10$ events, referent), high-CRP/low-PP ( $n=76 / 12$ events), lowCRP/high-PP ( $n=77 / 23$ events) and high-CRP/high-PP ( $n=93 / 40$ events), with high and low defined as $\geq$ or $<$ the median levels of CRP $(1.06 \mathrm{mg} / \mathrm{l})$ and PP $(58 \mathrm{~mm} \mathrm{Hg})$ are shown in Figure 7.3. Compared with the reference group, the risk factor-adjusted risk estimates were higher for both patients with high-CRP/low-PP [HR=1.18 (0.50-2.80)] and low-CRP/high-PP [HR=1.48 (0.63-3.50)], but considerably higher for those with high-CRP/high-PP [HR=2.63 (1.17-5.91)]. Albeit possibly underpowered due to stratification (see wider $\mathrm{Cls}$ around risk estimates), these analyses showed that the observed CVD risk for having both elevated CRP and elevated PP (2.63) was higher than could be expected from their independent effects considering either an additive [i.e. $1.18+1.48-1=1.66$ ] or a multiplicative model [i.e. $1.18 * 1.48=1.75$ ]. For the secondary end-point all-cause mortality, the risk factor-adjusted risk estimates were higher for patients with high-CRP/low-PP [HR=1.93 (0.74-5.07)] and low-CRP/high-PP [HR=1.59 (0.63-4.07)]. The risk for all-cause mortality when having both higher CRP and higher PP [HR=2.83 (1.14-7.05)] was higher than could be expected from their independent effects considered in an additive [i.e. $1.93+1.59-1=2.52$ ], but not in a multiplicative model [i.e. 1.93*1.59=3.07]. 


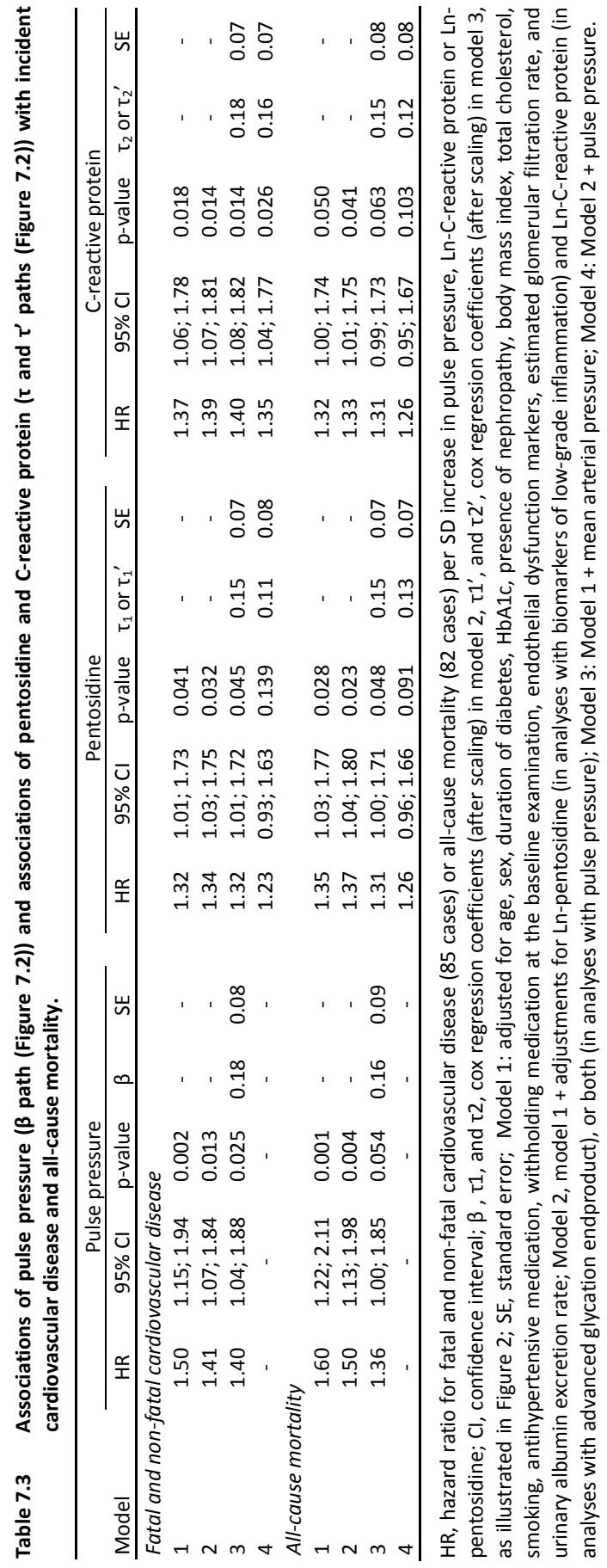




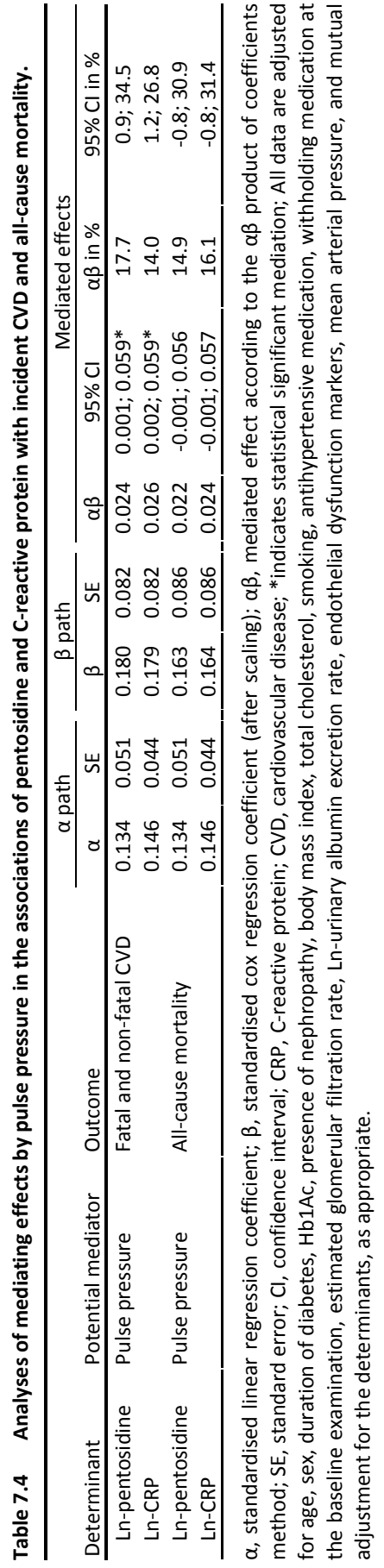




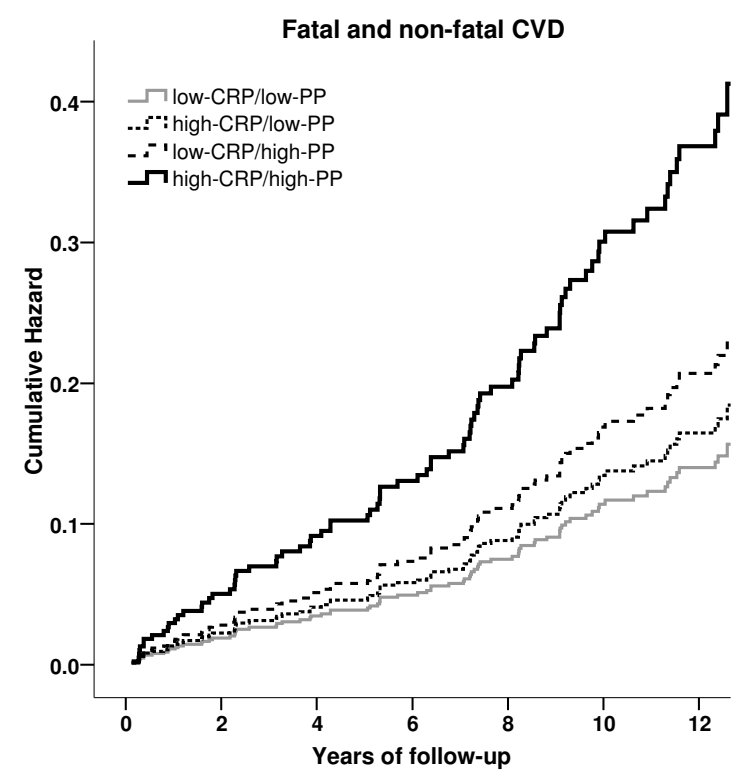

Figure 7.3 Cumulative hazard rates of fatal and non-fatal CVD in patients with type 1 diabetes according to their levels of C-reactive protein and pulse pressure. Data are adjusted for age, sex, duration of diabetes, Hb1Ac, presence of nephropathy, body mass index, total cholesterol, smoking, antihypertensive medication, withholding medication at the baseline examination, estimated glomerular filtration rate, Ln-urinary albumin excretion rate, endothelial dysfunction markers and pentosidine.

\section{Discussion}

Our study has three main findings. First, higher levels of plasma pentosidine and CRP were independently associated with higher PP as well as higher incident fatal and nonfatal CVD among patients with type 1 diabetes. Second, PP significantly explained a portion of the higher fatal CVD risk associated with elevated pentosidine and CRP. This does not exclude the possibility of reverse causation, as indeed CRP also explained a similar and significant portion of the higher incidence of CVD associated with PP. However, and as third main finding, the combination of elevated CRP with elevated PP increased CVD risk beyond what could be expected by their independent effects, suggesting that $\mathrm{LGI}$ and arterial stiffness are causally interrelated and self-enforcing features involved in the development of CVD in type 1 diabetes. This is the first study that has examined the interrelationships of AGEs, LGI, and arterial stiffness and their impact on CVD by testing, with empirical data and mediation analytical techniques, 
operative or mediating pathways. All in all, our findings support more closely our $2^{\text {nd }}$ initial hypothesis (Figure 7.1B).

We found a positive association between pentosidine, but not CEL nor CML, and PP. Pentosidine possibly contributes more directly to arterial stiffening by forming cross-links between molecules in the arterial wall. $(5,32)$ Reductions in arterial stiffness in animals treated with aminoguanidine, a potent inhibitor of AGEs formation and protein-to-protein cross-linking (33), or 4,5-dimethyl-3-phenacylthiazolium chloride (DPTC or ALT-711), an AGE cross-link breaker compound (34), have substantiated the concept of AGE cross-link-mediated increase in arterial stiffness. The beneficial effects of ALT-11 were also confirmed in a proof-of principle randomised controlled trial showing $\sim 15 \%$ improvements in arterial compliance accompanied by steeper decreases in PP in older individuals treated with ALT-711 as compared with placebotreated individuals (35). Our study extend these earlier findings and emphasise the clinical relevance of arterial stiffness resulting from cross-linking AGEs, by showing that pentosidine-related increases in PP may explain $\sim 18 \%$ of the increased CVD risk associated with this AGE in type 1 diabetes.

The lack of associations with the non-cross-linking AGEs examined in our study (i.e. CEL and CML) seem to emphasise further a predominant role of cross-linking AGEs in the process of accelerated arterial stiffening in diabetes. CEL, a putative marker for intracellular glycation, could alter cellular properties and lead to disturbances in vascular homeostatis $(36,37)$. CML, a potential ligand for the receptor for AGE (RAGE) (38), could induce receptor-mediated activation of transcription factor NF-KB, thereby leading to formation of endothelial adhesion molecules (36). In this line, we have previously shown, in this cohort, that higher plasma soluble RAGE (sRAGE) levels were positively associated with both PP and incident CVD [HR=1.90 (1.13-3.21)], and that a portion of the latter could indeed be due to sRAGE-related increases in PP [HR attenuated to $1.67(0.98-2.87)$ ] (25). Therefore, CEL and CML may affect arterial stiffness through indirect effects on vascular cell function, whereas pentosidine may have a more direct impact on arterial stiffness $(5,32)$. However, we have previously observed positive associations of CEL and CML with PP in another cohort of individuals with type 1 diabetes (EURODIAB) (39). The reasons for the discrepancy with the present study are not completely clear, but could in part be attributed to a relatively high portion of individuals with prevalent CVD in that study, whereas the present one excluded individuals with prior CVD. Indeed, in that study CEL and CML were positively associated with PP mainly in the individuals with prevalent vascular complications (39).

The association observed between CRP and PP is in line with previous studies (1517), as well as with studies showing significant associations of predominantly CRP (and less so, if anything, of other LGI markers, e.g. IL-6) with more direct estimates of arterial stiffness (e.g. carotid distensibility and central pulse wave velocity) $(40,41)$. We now extend these findings by showing that the mediating effects by PP in the $\mathrm{CRP} \rightarrow \mathrm{CVD}$ association (or, conversely, the mediating effects by CRP in the PP $\rightarrow$ CVD 
association) were significant (albeit small in magnitude). We do not think that the mediation effects simply reflect confounding between CRP and PP given the abundant mechanistic evidence linking the two (either way) provided by prospective $(6,7,17,40)$ and experimental studies [reviewed in $(12,14)$ ]. Instead, the association between CRP and PP may be causal and bidirectional and thus conciliate previous evidence focusing exclusively on one of the possible directions. Indeed, and in support of this, when in combination, higher levels of CRP and PP increased CVD risk to a greater extent than could be expected by their independent joint effects (Figure 3). Notably, self-enforcing effects of CRP and BP on incident CVD have been reported before (42). Altogether, the findings suggest a biological interaction (31) between inflammation and arterial stiffness underlying cardiovascular sequelae in type 1 diabetes.

Both upregulation of SPLA2 (43) and of CRP (44) are downstream effects of IL-6. The lack of associations of IL- 6 and SPLA2 with PP may be explained by the fact that IL-6 has many downstream effects, including anti-inflammatory effects (45), and these may not all be specifically associated with arterial stiffening. sPLA2 is an enzyme that catalyzes the hydrolysis of glycerophospholipids at the sn-2 position, which generates pro-atherogenic oxidised lipids (46) that are more specifically related to atherosclerosis than arterial stiffening. In addition, the diurnal variation of IL-6 and sICAM-1 may be greater than that of CRP (47), which may partially explain the lack of associations with PP.

Despite being statistically significant, the magnitude of the mediation effects by PP (i.e. arterial stiffening) in the associations between pentosidine and CRP with incident CVD was small, which leaves much room for other mechanisms (e.g. atherosclerosis) to explain these associations. However, we may have underestimated the 'true' magnitude of mediation by PP. First, PP was calculated on the basis of two BP readings, which could be affected by measurement error. In addition, we used brachial, not central, PP as an estimate of arterial stiffness. In a recent meta-analysis, both central and brachial PP $(10 \mathrm{mmHg})$ were significantly associated with incident CVD and mortality [HR=1.32 (1.22-1.42) and HR=1.19 (1.10-1.28), respectively] (48). Although central PP had only marginal added value in CVD risk prediction (48), the magnitude of the risk estimates was higher for the central than the brachial PP. A recent study in type 1 diabetes (the FinnDiane Study) (4) has shown that both brachial (10 $\mathrm{mmHg}$ ) [risk-factors adjusted $\mathrm{HR}=1.22(1.10-1.34)$ as estimated in the whole study population: events $/ n=178 / 4,321$ ] and central PP [risk-factors adjusted $H R=1.29$ (1.021.62), but estimated in a sub-population only: events $/ n=35 / 408]$, were associated with incident CVD, though the latter association was no longer significant after adjustment for previous CVD. Nevertheless, and despite the need to move beyond brachial PP to better understand etiology and fine tune stiffness-related risk estimation, it remains that brachial PP is an easily accessible measure and current clinical practice and decision making still relies on brachial BP recordings $(2,49)$. Furthermore, given the evidence for an accelerated increase in brachial PP in type 1 
diabetes (1), the central-to-brachial PP amplification phenomenon may be less influential in these individuals.

Other limitations to our study are that AGEs, markers of LGI, and PP were only measured at baseline, impeding evaluation of the impact of changes in these variables on each other and on CVD. Therefore, although our data supports the view of a bidirectional and self-enforcing association between CRP and PP, we cannot establish definite causation between the two. Also, although we adjusted our analyses for a large set of covariates, we cannot fully exclude the possibility of residual confounding (50). Finally, this study was confined to individuals with type 1 diabetes and, therefore, extrapolations of its key findings to the general and/or other at-risk populations need caution.

In conclusion, in type 1 diabetes, arterial stiffness, as expressed by PP, may explain a portion, albeit small, of the higher CVD risk associated with pentosidine. Cross-link breakers may, thus, offer a means to reduce arterial stiffening and related CVD in these patients. In addition, PP and CRP were interrelated and explained a portion of the associations with incident CVD in a mutual fashion. Notably, both CRP and PP remained independently associated with higher incidence of CVD, and in combination may increase even further the risk of CVD. This suggests that both LGI and arterial stiffness may need to be monitored and targeted separately in order to interrupt this vicious cycle and thereby deter the related cardiovascular sequelae often affecting these patients. 


\section{References}

1. Ronnback M, Fagerudd J, Forsblom C, Pettersson-Fernholm K, Reunanen A, Groop PH: Altered agerelated blood pressure pattern in type 1 diabetes. Circulation 2004;110:1076-1082

2. Stehouwer CD, Henry RM, Ferreira I: Arterial stiffness in diabetes and the metabolic syndrome: a pathway to cardiovascular disease. Diabetologia 2008;51:527-539

3. Schram MT, Chaturvedi N, Fuller JH, Stehouwer CD: Pulse pressure is associated with age and cardiovascular disease in type 1 diabetes: the Eurodiab Prospective Complications Study. J Hypertens 2003;21:2035-2044

4. Gordin D, Waden J, Forsblom C, Thorn L, Rosengard-Barlund M, Tolonen N, Saraheimo M, Harjutsalo V, Groop PH: Pulse Pressure Predicts Incident Cardiovascular Disease but Not Diabetic Nephropathy in Patients With Type 1 Diabetes (The FinnDiane Study). Diabetes Care 2011;34:886-891

5. Aronson D: Cross-linking of glycated collagen in the pathogenesis of arterial and myocardial stiffening of aging and diabetes. J Hypertens 2003;21:3-12

6. Mattace-Raso FU, Verwoert GC, Hofman A, Witteman JC: Inflammation and incident-isolated systolic hypertension in older adults: the Rotterdam study. J Hypertens 2010;28:892-895

7. Engstrom G, Janzon L, Berglund G, Lind P, Stavenow L, Hedblad B, Lindgarde F: Blood pressure increase and incidence of hypertension in relation to inflammation-sensitive plasma proteins. Arterioscler Thromb Vasc Biol 2002;22:2054-2058

8. Wang TJ, Gona P, Larson MG, Levy D, Benjamin EJ, Tofler GH, Jacques PF, Meigs JB, Rifai N, Selhub J, Robins SJ, Newton-Cheh C, Vasan RS: Multiple biomarkers and the risk of incident hypertension. Hypertension 2007;49:432-438

9. Sesso HD, Wang L, Buring JE, Ridker PM, Gaziano JM: Comparison of interleukin-6 and C-reactive protein for the risk of developing hypertension in women. Hypertension 2007;49:304-310

10. Niskanen L, Laaksonen DE, Nyyssonen K, Punnonen K, Valkonen VP, Fuentes R, Tuomainen TP, Salonen R, Salonen JT: Inflammation, abdominal obesity, and smoking as predictors of hypertension. Hypertension 2004;44:859-865

11. Sesso HD, Buring JE, Rifai N, Blake GJ, Gaziano JM, Ridker PM: C-reactive protein and the risk of developing hypertension. JAMA 2003;290:2945-2951

12. Schillaci G, Pirro M: C-reactive protein in hypertension: clinical significance and predictive value. Nutr Metab Cardiovasc Dis 2006;16:500-508

13. Napoli C, de Nigris F, Palinski W: Multiple role of reactive oxygen species in the arterial wall. J Cell Biochem 2001;82:674-682

14. Savoia C, Schiffrin EL: Inflammation in hypertension. Curr Opin Nephrol Hypertens 2006;15:152-158

15. Abramson JL, Weintraub WS, Vaccarino V: Association between pulse pressure and C-reactive protein among apparently healthy US adults. Hypertension 2002;39:197-202

16. Schillaci G, Pirro M, Gemelli F, Pasqualini L, Vaudo G, Marchesi S, Siepi D, Bagaglia F, Mannarino E: Increased C-reactive protein concentrations in never-treated hypertension: the role of systolic and pulse pressures. J Hypertens 2003;21:1841-1846

17. Amar J, Ruidavets JB, Peyrieux JC, Mallion JM, Ferrieres J, Safar ME, Chamontin B: C-reactive protein elevation predicts pulse pressure reduction in hypertensive subjects. Hypertension 2005;46:151-155

18. Virdis A, Ghiadoni L, Plantinga Y, Taddei S, Salvetti A: C-reactive protein and hypertension: is there a causal relationship? Curr Pharm Des 2007;13:1693-1698

19. Avolio A: Pulse pressure and inflammatory markers. J Hypertens 2004;22:247-249

20. Nin JW, Jorsal A, Ferreira I, Schalkwijk CG, Prins MH, Parving HH, Tarnow L, Rossing P, Stehouwer CD: Higher plasma levels of advanced glycation end products are associated with incident cardiovascular disease and all-cause mortality in type 1 diabetes: a 12-year follow-up study. Diabetes Care 2011;34: 442-447

21. Astrup AS, Tarnow L, Pietraszek L, Schalkwijk CG, Stehouwer CD, Parving HH, Rossing P: Markers of endothelial dysfunction and inflammation in type 1 diabetic patients with or without diabetic nephropathy followed for 10 years: association with mortality and decline of glomerular filtration rate. Diabetes Care 2008;31:1170-1176

22. Hayes AF: Beyond Baron and Kenny: Statistical Mediation Analysis in the New Millennium. Communication Monographs 2009;76:408-420 
23. MacKinnon DP: Introduction to Statistical Mediation Analysis. Taylor \& Francis Group 2008;

24. Tarnow L, Cambien F, Rossing P, Nielsen FS, Hansen BV, Lecerf L, Poirier O, Danilov S, Boelskifte S, Borch-Johnsen K: Insertion/deletion polymorphism in the angiotensin-I-converting enzyme gene is associated with coronary heart disease in IDDM patients with diabetic nephropathy. Diabetologia 1995;38:798-803

25. Nin JW, Jorsal A, Ferreira I, Schalkwijk CG, Prins MH, Parving HH, Tarnow L, Rossing P, Stehouwer CD: Higher plasma soluble Receptor for Advanced Glycation End Products (sRAGE) levels are associated with incident cardiovascular disease and all-cause mortality in type 1 diabetes: a 12-year follow-up study. Diabetes 2010;59:2027-2032

26. De Jager J, Kooy A, Lehert P, Bets D, Wulffele MG, Teerlink T, Scheffer PG, Schalkwijk CG, Donker AJ, Stehouwer CD: Effects of short-term treatment with metformin on markers of endothelial function and inflammatory activity in type 2 diabetes mellitus: a randomized, placebo-controlled trial. J Intern Med 2005;257:100-109

27. Tein JY, Mackinnon DP: Estimating Mediated Effects with Survival Data. In H. Yanai, A. O. Rikkyo, K. Shigemasu, Y. Kano, \& J. J. Meulman (Eds.) New Developments on Psychometrics 2003:SpringerVerlag Tokyo Inc. 405-412

28. Tofighi D, Mackinnon DP: RMediation: An R package for mediation analysis confidence intervals. Behav Res Methods 2011;

29. Preacher KJ, Hayes AF: Asymptotic and resampling strategies for assessing and comparing indirect effects in multiple mediator models. Behav Res Methods 2008;40:879-891

30. Franklin SS, Lopez VA, Wong ND, Mitchell GF, Larson MG, Vasan RS, Levy D: Single versus combined blood pressure components and risk for cardiovascular disease: the Framingham Heart Study. Circulation 2009;119:243-250

31. Rothman K, Greenland S, Lash T: Modern Epidemiology. Lippincott Williams \& Wilkins 2008;

32. Brownlee M: Advanced protein glycosylation in diabetes and aging. Annu Rev Med 1995;46:223-234

33. Huijberts MS, Wolffenbuttel BH, Boudier HA, Crijns FR, Kruseman AC, Poitevin P, Levy BI: Aminoguanidine treatment increases elasticity and decreases fluid filtration of large arteries from diabetic rats. J Clin Invest 1993;92:1407-1411

34. Vaitkevicius PV, Lane M, Spurgeon H, Ingram DK, Roth GS, Egan JJ, Vasan S, Wagle DR, Ulrich P, Brines M, Wuerth JP, Cerami A, Lakatta EG: A cross-link breaker has sustained effects on arterial and ventricular properties in older rhesus monkeys. Proc Natl Acad Sci U S A 2001;98:1171-1175

35. Kass DA, Shapiro EP, Kawaguchi M, Capriotti AR, Scuteri A, deGroof RC, Lakatta EG: Improved arterial compliance by a novel advanced glycation end-product crosslink breaker. Circulation 2001;104: 1464-1470

36. Goldin A, Beckman JA, Schmidt AM, Creager MA: Advanced glycation end products: sparking the development of diabetic vascular injury. Circulation 2006;114:597-605

37. Giardino I, Edelstein D, Brownlee M: Nonenzymatic glycosylation in vitro and in bovine endothelial cells alters basic fibroblast growth factor activity. A model for intracellular glycosylation in diabetes. J Clin Invest 1994;94:110-117

38. Kislinger T, Fu C, Huber B, Qu W, Taguchi A, Du Yan S, Hofmann M, Yan SF, Pischetsrieder M, Stern D, Schmidt AM: N(epsilon)-(carboxymethyl)lysine adducts of proteins are ligands for receptor for advanced glycation end products that activate cell signaling pathways and modulate gene expression. J Biol Chem 1999;274:31740-31749

39. Schram MT, Schalkwijk CG, Bootsma AH, Fuller JH, Chaturvedi N, Stehouwer CD: Advanced glycation end products are associated with pulse pressure in type 1 diabetes: the EURODIAB Prospective Complications Study. Hypertension 2005;46:232-237

40. van Bussel BC, Schouten FS, Henry RM, Schalkwijk CG, de Boer MR, Ferreira I, Smulders YM, Twisk JW, Stehouwer CD: Endothelial dysfunction and low-grade inflammation are associated with greater arterial stiffness in healthy adults over a 6-year period - The Amsterdam Growth and Health Longitudinal Study. Hypertension 2011;58:588-95

41. Yasmin, McEniery CM, Wallace S, Mackenzie IS, Cockcroft JR, Wilkinson IB: C-reactive protein is associated with arterial stiffness in apparently healthy individuals. Arterioscler Thromb Vasc Biol 2004;24:969-974

42. Blake GJ, Rifai N, Buring JE, Ridker PM: Blood pressure, C-reactive protein, and risk of future cardiovascular events. Circulation 2003;108:2993-2999 
43. Crowl RM, Stoller TJ, Conroy RR, Stoner CR: Induction of phospholipase A2 gene expression in human hepatoma cells by mediators of the acute phase response. J Biol Chem 1991;266:2647-2651

44. Volanakis JE: Human C-reactive protein: expression, structure, and function. Mol Immunol 2001;38:189-197

45. Steensberg A, Fischer CP, Keller C, Moller K, Pedersen BK: IL-6 enhances plasma IL-1ra, IL-10, and cortisol in humans. Am J Physiol Endocrinol Metab 2003;285:E433-437

46. Mallat Z, Lambeau G, Tedgui A: Lipoprotein-associated and secreted phospholipases A in cardiovascular disease: roles as biological effectors and biomarkers. Circulation 2010;122:2183-2200

47. Meier-Ewert HK, Ridker PM, Rifai N, Price N, Dinges DF, Mullington JM: Absence of diurnal variation of C-reactive protein concentrations in healthy human subjects. Clin Chem 2001;47:426-430

48. Vlachopoulos C, Aznaouridis K, O'Rourke MF, Safar ME, Baou K, Stefanadis C: Prediction of cardiovascular events and all-cause mortality with central haemodynamics: a systematic review and meta-analysis. Eur Heart J 2010;31:1865-1871

49. Williams B, Lacy PS: Central haemodynamics and clinical outcomes: going beyond brachial blood pressure? Eur Heart J 2010;31:1819-1822

50. Davey Smith G, Lawlor DA, Harbord R, Timpson N, Rumley A, Lowe GD, Day IN, Ebrahim S: Association of $\mathrm{C}$-reactive protein with blood pressure and hypertension: life course confounding and mendelian randomization tests of causality. Arterioscler Thromb Vasc Biol 2005;25:1051-1056 
Chapter 8

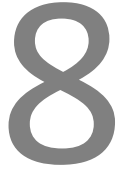

Summary and General discussion 
Chapter 8 


\section{Summary}

The increasing prevalence of type 1 diabetes and its related vascular complications pose a tremendous burden for patients and our society (1), but the cellular and molecular mechanisms underlying the development of these vascular complications are still not fully elucidated. For the prevention and/or treatment of these diabetesrelated complications, we need a better understanding of these underlying mechanisms. Several potential mechanisms have been proposed to unravel the link between diabetes and the increased risk of cardiovascular disease (CVD) in these patients. We focused on the potential roles of advanced glycation endproducts (AGEs) and their receptor (RAGE), high-mobility group box-1 (HMGB1), endothelial and renal dysfunction, low-grade inflammation (LGI), and arterial stiffness (i.e. pulse pressure, PP).

\section{Present findings}

In the EURODIAB PCS nested case-control study we showed that higher levels of SRAGE, as a reflection of higher levels of RAGE, are cross-sectionally associated with greater prevalence of CVD in patients with type 1 diabetes (Chapter 2). This positive association could be attenuated by $\sim 50 \%$ by endothelial and renal dysfunction and LGI, which suggests that these mechanisms may constitute pathways that link sRAGE, as a reflection of RAGE, to greater prevalence of CVD in type 1 diabetes. Positive trends were found between higher levels of sRAGE and the presence and across the levels of severity of albuminuria and retinopathy, though these were not independent of traditional risk factors. To gain more insight into the temporal relationship between sRAGE and vascular complications in type 1 diabetes, we investigated the associations between plasma SRAGE and incident fatal and non-fatal CVD as well as all-cause mortality in a 12 year follow-up study (Chapter 3). Incident fatal and non-fatal CVD as well as all-cause mortality doubled per unit higher Ln-sRAGE at baseline. Renal dysfunction, estimated by glomerular filtration rate, could explain in part (up to $25 \%$ ) the positive association between plasma sRAGE and incident fatal and non-fatal CVD. In addition, we showed that higher levels of sRAGE at baseline were associated with steeper decline in glomerular filtration rate in the course of follow-up (Chapter 3 ), which supports the hypothesis that renal dysfunction is an intermediate in the association between SRAGE and cardiovascular disease in these patients.

We measured three AGEs (i.e. CEL, CML, and pentosidine) that could exert unfavourable effects on cellular functions through (partially) different pathways, and together, these may thus reflect a wide range of the potential adverse effects of AGEs. In a 12 year follow-up study in patients with type 1 diabetes, we observed $~ 30 \%$ increase in incident fatal and non-fatal CVD as well as all-cause mortality per 1 unit higher AGEs score (calculated by averaging the z-scores of CEL, CML, and pentosidine) independently of other risk factors (Chapter 4). 
To further explore the ligand-RAGE axis, we also investigated the associations between HMGB1, a pro-inflammatory cytokine but also a ligand of RAGE, and the prevalence and incidence of vascular complications in type 1 diabetes. We showed positive cross-sectional associations between serum levels of HMGB1 and the presence and severity of albuminuria, but not with prevalent retinopathy and CVD (Chapter 5). This suggests that serum HMGB1 is involved differently in pathways that lead to micro- and macrovascular complications, which could, at least in part, be explained by the fact that HMGB1 is a ligand for different receptors with distinct functions. However, we cannot neglect the possibility that the lack of association between serum HMGB1 and prevalent CVD was due to the play of chance. In addition, in a prospective study in patients with type 1 diabetes we observed that higher levels of plasma HMGB1 are associated with higher incidence of all-cause mortality (Chapter 6), and, to a lesser extent, also with higher incident fatal and non-fatal CVD. These associations were independent of conventional cardiovascular risk factors and of several potential HMGB1 related pathophysiological mechanisms.

In an attempt to disentangle the associations between LGI (i.e. C-reactive protein, CRP), cross-linking AGEs (i.e. pentosidine), and arterial stiffness as well as their associations with incident fatal and non-fatal CVD (Chapter 7), we showed that in type 1 diabetes, arterial stiffness, as expressed by PP, partially explains the higher risk for CVD associated with higher levels of pentosidine (marker of cross-linking AGEs). Crosslink breakers may, thus, offer a means to reduce arterial stiffening and related CVD in these patients. In addition, PP and CRP were interrelated and explained a portion of the associations with incident CVD in a mutual fashion. Notably, both CRP and PP remained independently associated with higher incidence of CVD, and the combination of elevated CRP with elevated PP increased CVD risk beyond what could be expected from their independent effects, suggesting that LGI and arterial stiffness are causally interrelated and self-enforcing features involved in the development of CVD in type 1 diabetes. Both LGI and arterial stiffness may thus need to be monitored and targeted separately in order to interrupt this vicious cycle and thereby deter the related cardiovascular sequelae often affecting these patients. 


\section{General discussion}

\section{Study population}

We used a European multi-centre nested case-control study and a Danish prospective cohort study in individuals with type 1 diabetes. In the cross-sectional nested casecontrol study cases were selected as those with the greatest vascular complication burden as possible and controls were selected as those who were completely free of any vascular complication. This selection allowed us to compare individuals with single or multiple complications with individuals free of complications as efficiently as possible. Cases and controls were unmatched, so that the impact of variables of interest could still be assessed and analyses were performed with adjustments for potential confounders.

The Danish prospective cohort study with a 12 year follow-up gave us the opportunity to look at the temporal relationships between determinants of interest and clinical outcomes. This study consisted of 391 patients with type 1 diabetes who were enrolled in a prospective observational study on cardiovascular complications and mortality. In 1993, 199 patients with type 1 diabetes and nephropathy and 192 with normoalbuminuria (i.e. urinary excretion rate $<30 \mathrm{mg} / 24 \mathrm{~h}$ ) were recruited from the outpatient clinic at Steno Diabetes Center (Gentofte, Denmark). Diabetic nephropathy was defined according to the following clinical criteria: persistent macroalbuminuria $>300 \mathrm{mg} / 24 \mathrm{~h}$ in at least two out of three previous consecutive 24$\mathrm{h}$ urine collections, presence of diabetic retinopathy (assessed by fundus photography after pupillary dilatation), and no clinical or laboratory evidence of kidney or renal tract disease other than diabetic glomerulosclerosis.

Both studies included patients with type 1 diabetes only. Therefore, extrapolations to other populations (e.g. patients with type 2 diabetes) need some caution. In addition, because we did not include a control group in our studies, we cannot address the question as to whether the AGE-RAGE axis-related higher prevalence and incidence of vascular complications could explain the excess risk for cardiovascular complications observed in type 1 diabetes.

In aetiological research we try to investigate (confirm or exclude) the relation between a determinant and a certain disease outcome, in which the effects of factors that may obscure such relationship are taken into account. Although the individuals included in our studies were well characterised and we minimised the influence of confounding in the associations observed by adjustments for many possible confounders, interference by factors we did not measure cannot be ruled out. In addition, in all our studies we included individuals in whom full data on variables of interest were available. Selection bias may occur if individuals included in the analyses would differ considerably from the ones excluded from the analyses. However, no such differences with regard to our main determinants or our main outcome 
measures were observed between individuals excluded and those included in our studies.

\section{Main determinants}

\section{Soluble receptor for advanced glycation endproducts (RAGE)}

Different cell types including human endothelial cells express RAGE. In addition to cellbound RAGE, soluble forms of RAGE (sRAGE) appear extracellularly. These soluble forms result from alternative splicing (2) or from proteolytical cleavage of the membrane-bound RAGE (Figure 1.3), which is most probably shed into the circulation by the sheddase, a disintegrin and metalloprotease 10 (3). The functional role of these soluble forms of RAGE in the circulation remains unclear, but they may reflect the activity of the ligand-RAGE axis. The positive associations observed between SRAGE and prevalence and incidence of CVD reported in Chapter 2 and 3, respectively, are in line with a large Finnish cohort study (4), but not all previous studies (5-7), among patients with type 1 diabetes. The reasons for these contradictory findings are not clear, but may be explained by the fact that different pools of soluble RAGE were measured and investigated across studies, namely, the total pool of sRAGE by the Quantikine sRAGE ELISA kit (R\&D systems, Minneapolis, USA) in the Finnish (4) and in our studies, or specifically the splice variant esRAGE by the B-Bridge International esRAGE ELISA kit (Daiichi Fine Chemicals, Takaoka, Japan) in the others (5-7). The inconclusive findings from the studies so far may thus be due to differences in measured variants of soluble RAGE, each of which might have a different function. The differences in the clinical settings or ethnicity might also contribute to the discrepancies in these studies.

The naturally occurring form of sRAGE, as well as artificially produced SRAGE, can potentially bind to a ligand thereby acting as a decoy, which prevents ligand-RAGE interaction and activation $(8,9)$. This could thus explain any inverse association observed between sRAGE/esRAGE and vascular complications. However, although SRAGE has been an interesting subject of investigation under this suspected decoy function, it is very unlikely that SRAGE can act as such (i.e. by capturing and eliminating AGEs and/or other ligands) because the levels of circulating sRAGE are at least 1000 times lower than needed for efficient binding and elimination of AGEs and other ligands. In addition, a recent 4-year prospective multi-centre study in patients with type 2 diabetes has reported both SRAGE and esRAGE to be positively associated with higher risk of coronary heart disease (10).

\section{Advanced glycation endproducts (AGES)}

We included three different AGEs in our analyses. Based on their characteristics each of them may represent a different part of the mechanisms through which AGEs could exert their potential adverse effects in the development of vascular complications in 
type 1 diabetes. CEL (as a putative marker of intracellular glycation), CML (as a potential ligand of RAGE), and pentosidine (as one of the cross-linking AGEs), together, may thus reflect a wide range of the potential unfavourable effects of AGEs.

In our study (Chapter 4) we did not normalise CEL, CML and pentosidine for an amino acid, e.g. lysine, and this may not enable direct comparison (of absolute values) with other studies that have done so (and did not report the values for the AGEs and the amino acid, separately). This would be an important limitation if such lack of normalisation would affect our findings. In order to address this, we have examined data from the EURODIAB study, in which plasma CML, CEL, and lysine concentrations were available (11). When we examine the correlations between CEL and CML with or without normalisation for lysine $(39.7 \pm 4.4 \mathrm{mM})$, we found that CEL $(1.21 \pm 0.47 \mu \mathrm{M})$ and CEL/lysine $(31 \pm 11 \mu \mathrm{M} / \mathrm{M})$ as well as CML $(2.26 \pm 0.79 \mu \mathrm{M})$ and CML/Lysine (57 $\pm 18 \mu \mathrm{M} / \mathrm{M})$ were highly correlated: correlation coefficients were 0.95 and 0.94 , respectively. Moreover, in the EURODIAB study the associations between plasma CEL as well as CML and the presence of CVD did not differ between normalised and nonnormalised values. Given these strong correlations between normalised and nonnormalised values of AGEs, and their comparable associations with the presence of CVD, normalisation for an amino acid concentration is unlikely to affect the associations between plasma AGEs and study endpoints in our prospective study (Chapter 4).

\section{High-mobility group box-1 (HMGB1)}

HMGB1 was discovered as an intranuclear protein involved in the DNA organisation and regulation of transcription (12). Recently, extracellular HMGB1, released by necrotic cells (13) and inflammatory cells upon activation (14), has been suggested to function as a pro-inflammatory cytokine (15), at least in part, through ligation of RAGE (16) or toll-like receptors (17).

We have measured HMGB1 levels in serum in the cross-sectional study and in plasma in the prospective study. In the cross-sectional study we did not find a positive association between serum HMGB1 and prevalent CVD (Chapter 5) in contrary to the positive association observed in the prospective study between plasma HMGB1 levels and incident CVD (Chapter 6). The lack of association between serum HMGB1 and prevalent CVD may be due to the play of chance or residual confounding by, for example, lipid lowering drugs. However, the apparent discrepancy could also imply that serum HMGB1 and plasma HMGB1 do not represent the same pool of HMGB1 in these patients. This might be explained by the platelet activation and coagulation cascade initiated in the vacuum container during the usual process to obtain serum samples from the blood samples. Activated platelets release several pro-inflammatory cytokines, and platelet activation markers are positively associated with serum HMGB1 levels in patients with disseminated intravascular coagulation associated with haematologic malignancies (18). In addition, it has been reported that part of the HMGB-1 present in the cytoplasma of resting platelets could be transported to the 
platelet surface upon platelet activation (19). This process may vary per blood sample according to the platelet count and, therefore, serum HMGB-1 levels may not reflect adequately the extracellular HMGB-1 levels in the subjects.

\section{Circulating levels vs. tissue levels of biomarkers}

In our studies we have measured circulating levels of sRAGE, AGEs, and HMGB1 only, and it is not clear whether these are representative of the total pool of these biomarkers. Indeed, AGEs accumulate in tissue and cellular concentrations of AGEs are higher than plasma AGEs levels (23). The extents to which the circulating levels of RAGE and HMGB1 relate to their tissue levels are unknown. Further studies in which both circulating and tissue levels of these biomarkers are measured are needed to clarify the relation between the biomarkers levels in the two compartments and their specific associations to vascular complications.

\section{Low-grade inflammation and endothelial dysfunction}

We used biomarkers to represent LGI and endothelial dysfunction, though we do not exactly know whether this is the most adequate method to represent these pathophysiological mechanisms, because both mechanisms comprise many aspects.

In addition, the levels of the markers of $L G I$ and endothelial dysfunction investigated were only measured once, which might have diluted the associations we found. However, we combined the z-scores of the different markers of LGI and endothelial dysfunction into averaged scores to overcome biological variability of a single biomarker. A z-score represents the distance between an individual's biomarker score from the population's total mean in units of the population's standard deviation, and is thus a common transformation that enables the combination of several markers originally expressed in different units. We assumed that every biomarker measured reflects (part of) the process of LGI or endothelial dysfunction. We have weighted them equally, however, it is unclear which marker may be more important than the others.

\section{Arterial stiffness (i.e. pulse pressure)}

Brachial PP was calculated on the basis of two blood pressure readings, which could be affected by measurement error. In addition, we used brachial, not central, PP as an estimate of arterial stiffness. In a recent meta-analysis, both central and brachial PP (10 $\mathrm{mmHg}$ ) were significantly associated with incident CVD and mortality [HR=1.32 (1.22-1.42) and $H R=1.19$ (1.10-1.28), respectively] (20). Although central PP had only marginal added value in CVD risk prediction, the magnitude of the risk estimates was higher for the central than the brachial PP. A recent study in type 1 diabetes (the FinnDiane Study) has shown that both brachial $(10 \mathrm{mmHg})$ [risk-factors adjusted $H R=1.22$ (1.10-1.34) as estimated in the whole study population: events/n=178/4,321] and central PP [risk-factors adjusted $H R=1.29(1.02-1.62)$, but estimated in a sub- 
population only: events/n=35/408], were associated with incident CVD, though the latter association was no longer significant after adjustment for previous CVD (21). Nevertheless, and despite the need to move beyond brachial PP to better understand aetiology and fine tune stiffness-related risk estimation, it remains that brachial PP is an easily accessible measure and current clinical practice and decision making still relies on brachial blood pressure recordings. Furthermore, given the evidence for accelerated arterial aging in type 1 diabetes (22), the central-to-brachial PP amplification phenomenon may be less influential in these individuals.

\section{Outcomes}

In the EURODIAB study prevalent CVD was defined as a positive medical history of a cardiovascular event including myocardial infarction, angina, coronary artery bypass graft and/or stroke, and/or ischaemic changes on a centrally Minnesota-coded ECG. This non-fatal outcome may be susceptible to misclassifications, because of its dependency on the completeness and accuracy of patients' records and/or discharge letters. Albumin excretion rates (UAEs) were measured from duplicate $24 \mathrm{~h}$ urine collections, which are considered the gold standard for measuring albuminuria. However, these collections are cumbersome and inadequate collections may impair its reliability. Retinopathy was assessed from retinal photo-graphs according to the EURODIAB protocol (2-field $45^{\circ}$ retinal photography) (24). This method compared favourably with the gold standard 7 -field $30^{\circ}$ retinal photography. The 2 -field $45^{\circ}$ proved to be acceptably repeatable and accurate (24).

In the Danish prospective cohort study all patients were traced through the national register, which is a reliable source for mortality dates. The date of death was recorded and information on the primary cause of death was obtained from the death certificate, which was reviewed by two independent observers. Additional available information from necropsy reports was also included. In all patients alive at the end of follow-up non-fatal cardiovascular events were retrieved from their patient files from Steno Diabetes Center and/or other hospital records. The primary study outcome was a combined end-point of fatal and non-fatal CVD (i.e. myocardial infarction, percutaneous coronary intervention, coronary bypass grafting, amputation due to ischaemia, vascular surgery for peripheral atherosclerotic disease and stroke), and the secondary outcome was all-cause mortality. All deaths were classified as cardiovascular unless an unequivocal non-cardiovascular cause was established. Potential misclassification of non-specific mortality as CVD-related mortality may have introduced non-differential biases, in which case the estimates reported herein may have been underestimated.

Although the secondary end-point in this study (all-cause mortality) was quite valid, our primary end-point including non-fatal end-points may have been more susceptible to misclassification bias, because of its dependency on the completeness and accuracy of patients' records and/or discharge letters. Most likely, we may have 
missed some cases (i.e. patients who were possibly considered as 'free from CVD' when in fact they were not), but then such misclassification was likely to be random because CVD status was ascribed without prior knowledge of subjects' biomarkers levels. Again, these misclassifications, if present, may, if anything, have led to an underestimation of the strength of the associations between our main determinants and the combined main study end-point (fatal and non-fatal CVD).

\section{Clinical relevance}

The increasing prevalence of type 1 diabetes and its related vascular complications pose a tremendous burden for patients and our society, while the pathophysiological mechanisms underlying the development of these vascular complications are still to be elucidated. Results from animal studies suggested that the AGE-RAGE axis $(9,23,25,26)$ and HMGB-1 (27) may play a role in the development of vascular complications in diabetes. Whether these animal models could adequately reflect the human clinical situation is unclear. Beside the differences between species, we also cannot neglect the differences in settings (28). Namely, in experimental animal studies the animal model is carefully selected to investigate one specific determinant, while in a human clinical setting we are confronted with patients with several comorbidities and various circumstances. Translational observational/descriptive studies in humans are often limited by ethical and financial issues. Ideally, we would like to test our hypotheses at relevant sites where the pathophysiological processes take place. However, mostly we are restricted to investigate markers, such as circulating levels, of the determinants of interest. Despite of this limitation, the findings observed in our studies have additional value to the existing knowledge from animal studies and bring us a step closer to revealing the relevance of the pathophysiological mechanisms investigated to the higher risk for vascular complications in type 1 diabetes. In addition, we have tried not to look only for putative associations between determinants and outcomes, but also to provide insights into the underlying pathways. Furthermore, though the intention of our studies was to investigate aetiological hypotheses, circulating levels of biomarkers investigated may have predictive qualities and could form easy accessible clinical tools, in contrast to the more difficultly obtainable tissue levels of these biomarkers.

We showed that sRAGE, AGEs, HMGB1, and markers of LGI and arterial stiffness were, independently of traditional risk factors, associated with greater prevalence and/or higher incidence of vascular complications in patients with type 1 diabetes. These risk factors could constitute new targets in the prevention and/or treatment of vascular complications in type 1 diabetes. In addition, we showed that the individual mechanisms are related to each other, as illustrated in Figure 8.1. Higher incident CVD associated with higher levels of plasma sRAGE may, in part, be explained by SRAGEassociated renal dysfunction. In addition, increased arterial stiffness may constitute a mechanism through which cross-linking AGEs could lead to higher risk for CVD, and 
therefore, targeting cross-linking AGEs may offer a means to reduce related arterial stiffening and CVD in type 1 diabetes. Furthermore, both CRP and PP were independently associated with higher incidence of CVD, and the combination of elevated CRP with elevated PP increased CVD risk beyond what could be expected by their independent effects, suggesting that LGI and arterial stiffness exert selfenforcing effects on CVD in type 1 diabetes. This suggests that both LGI and arterial stiffness may need to be monitored and targeted separately in order to interrupt this vicious cycle and thereby deter the related cardiovascular sequelae often affecting these patients.

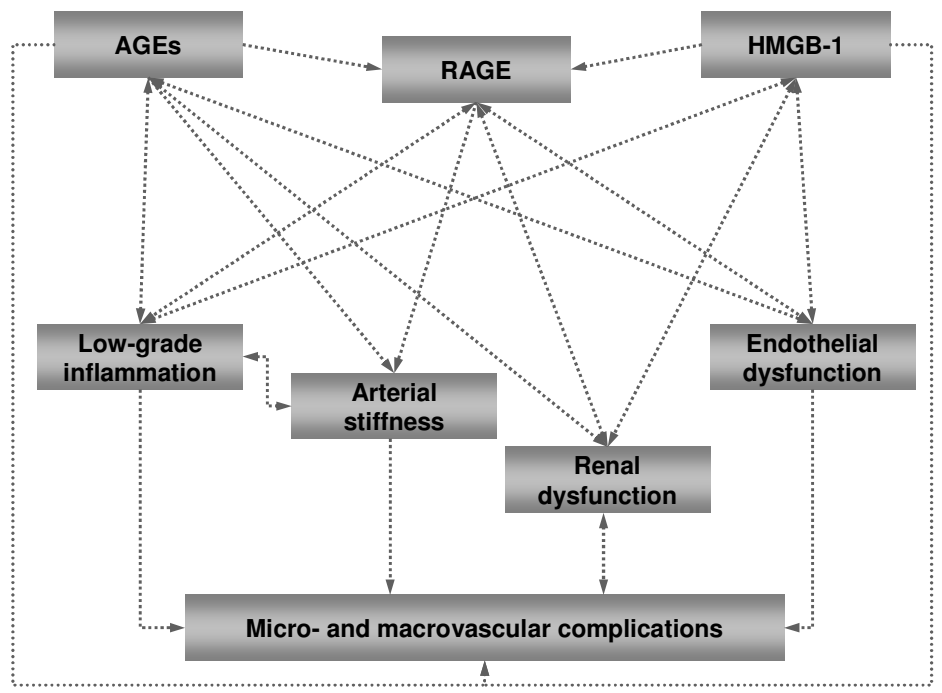

Figure 8.1. Present findings.

\section{Future research}

Although markers of the AGE-RAGE axis, LGI and arterial stiffness were associated with greater prevalence and/or higher incidence of vascular complications in patients with type 1 diabetes, longitudinal studies are needed to elucidate further the temporal relationship between these risk factors and clinical outcome. In addition, for our mediation analyses we had data at one time point only on the determinants and potential mediators and, thus, we cannot exclude the possibility of reverse causation as illustrated by the bi-directional arrows in Figure 8.1 between our main determinants (i.e. AGEs, SRAGE, and HMGB1) and our potential mediators (i.e. LGI, endothelial and renal dysfunction, and arterial stiffness). For more sophisticated 
mediation analyses, in which potential reverse causation analyses could be better addressed we would need data on both determinants and potential mediators at different time points during follow-up. No longitudinal data of the associations observed exist in large groups of type 1 diabetes at the time, thus these studies may serve as a reasonable starting point to further explore these associations.

In addition, studies in which both circulating and tissue levels of these biomarkers are measured are needed to clarify the relation between the biomarkers levels in the two compartments and their specific relevance to vascular complications.

Furthermore, it remains to be proven whether targeting and lowering the levels of these risk factors could also result in a more favourable clinical outcome. To enable such intervention studies we would also need drugs that are able to decrease levels and/or activity of the AGE-RAGE axis, LGI, and arterial stiffness. 


\section{References}

1. Rijksinstituut voor Volksgezondheid en Milieu (RIVM). Diabetes in Nederland. Omvang, risicofactoren en gevolgen, nu en in de toekomst., 2007

2. Yonekura H, Yamamoto Y, Sakurai S, Petrova RG, Abedin MJ, Li H, Yasui K, Takeuchi M, Makita Z, Takasawa S, Okamoto H, Watanabe T, Yamamoto $H$. Novel splice variants of the receptor for advanced glycation end-products expressed in human vascular endothelial cells and pericytes, and their putative roles in diabetes-induced vascular injury. Biochem J 2003;370:1097-1109

3. Raucci A, Cugusi S, Antonelli A, Barabino SM, Monti L, Bierhaus A, Reiss K, Saftig P, Bianchi ME. A soluble form of the receptor for advanced glycation endproducts (RAGE) is produced by proteolytic cleavage of the membrane-bound form by the sheddase a disintegrin and metalloprotease 10 (ADAM10). Faseb J 2008;22:3716-3727

4. Thomas MC, Soderlund J, Lehto M, Makinen VP, Moran JL, Cooper ME, Forsblom C, Groop PH. Soluble receptor for AGE (RAGE) is a novel independent predictor of all-cause and cardiovascular mortality in type 1 diabetes. Diabetologia 2011;54:2669-2677

5. Katakami N, Matsuhisa M, Kaneto H, Matsuoka TA, Sakamoto K, Nakatani Y, Ohtoshi K, HayaishiOkano R, Kosugi K, Hori M, Yamasaki Y. Decreased endogenous secretory advanced glycation end product receptor in type 1 diabetic patients: its possible association with diabetic vascular complications. Diabetes Care 2005;28:2716-2721

6. Katakami N, Matsuhisa M, Kaneto H, Matsuoka TA, Sakamoto K, Yasuda T, Umayahara Y, Kosugi K, Yamasaki Y. Serum endogenous secretory RAGE level is an independent risk factor for the progression of carotid atherosclerosis in type 1 diabetes. Atherosclerosis 2009;204:288-292, 2009

7. Katakami N, Matsuhisa M, Kaneto H, Matsuoka TA, Sakamoto K, Yasuda T, Yamasaki Y. Endogenous secretory RAGE but not soluble RAGE is associated with carotid atherosclerosis in type 1 diabetes patients. Diab Vasc Dis Res 2008;5:190-197

8. Bucciarelli LG, Wendt T, Qu W, Lu Y, Lalla E, Rong LL, Goova MT, Moser B, Kislinger T, Lee DC, Kashyap Y, Stern DM, Schmidt AM. RAGE blockade stabilizes established atherosclerosis in diabetic apolipoprotein E-null mice. Circulation 2002;106:2827-2835

9. Wendt TM, Tanji N, Guo J, Kislinger TR, Qu W, Lu Y, Bucciarelli LG, Rong LL, Moser B, Markowitz GS, Stein G, Bierhaus A, Liliensiek B, Arnold B, Nawroth PP, Stern DM, D'Agati VD, Schmidt AM. RAGE drives the development of glomerulosclerosis and implicates podocyte activation in the pathogenesis of diabetic nephropathy. Am J Pathol 2003;162:1123-1137

10. Colhoun HM, Betteridge DJ, Durrington P, Hitman G, Neil A, Livingstone S, Charlton-Menys V, Bao W, Demicco DA, Preston GM, Deshmukh H, Tan K, Fuller JH. Total Soluble and Endogenous Secretory Receptor for Advanced Glycation End Products as Predictive Biomarkers of Coronary Heart Disease Risk in Patients With Type 2 Diabetes: An Analysis From the CARDS Trial. Diabetes 2011;60:2379-2385

11. Schram MT, Schalkwijk CG, Bootsma AH, Fuller JH, Chaturvedi N, Stehouwer CD. Advanced glycation end products are associated with pulse pressure in type 1 diabetes: the EURODIAB Prospective Complications Study. Hypertension 2005;46:232-237

12. Bianchi ME, Agresti A. HMG proteins: dynamic players in gene regulation and differentiation. Curr Opin Genet Dev 2005;15:496-506

13. Scaffidi P, Misteli T, Bianchi ME. Release of chromatin protein HMGB1 by necrotic cells triggers inflammation. Nature 2002;418:191-195

14. Rendon-Mitchell B, Ochani M, Li J, Han J, Wang H, Yang H, Susarla S, Czura C, Mitchell RA, Chen G, Sama AE, Tracey KJ, Wang H. IFN-gamma induces high mobility group box 1 protein release partly through a TNF-dependent mechanism. J Immunol 2003;170:3890-3897

15. Li J, Kokkola R, Tabibzadeh S, Yang R, Ochani M, Qiang X, Harris HE, Czura CJ, Wang H, Ulloa L, Wang H, Warren HS, Moldawer LL, Fink MP, Andersson U, Tracey KJ, Yang H. Structural basis for the proinflammatory cytokine activity of high mobility group box 1. Mol Med 2003;9:37-45

16. Hori O, Brett J, Slattery T, Cao R, Zhang J, Chen JX, Nagashima M, Lundh ER, Vijay S, Nitecki D, et al.. The receptor for advanced glycation end products (RAGE) is a cellular binding site for amphoterin. Mediation of neurite outgrowth and co-expression of rage and amphoterin in the developing nervous system. J Biol Chem 1995;270:25752-25761 
17. van Zoelen MA, Yang H, Florquin S, Meijers JC, Akira S, Arnold B, Nawroth PP, Bierhaus A, Tracey KJ, van der Poll T. Role of toll-like receptors 2 and 4, and the receptor for advanced glycation end products in high-mobility group box 1-induced inflammation in vivo. Shock 2009;31:280-284

18. Nomura S, Fujita S, Ozasa R, Nakanishi T, Miyaji M, Mori S, Ito T, Ishii K. The correlation between platelet activation markers and HMGB1 in patients with disseminated intravascular coagulation and hematologic malignancy. Platelets 2011;22:396-397

19. Rouhiainen A, Imai S, Rauvala H, Parkkinen J. Occurrence of amphoterin (HMG1) as an endogenous protein of human platelets that is exported to the cell surface upon platelet activation. Thromb Haemost 2000;84:1087-1094

20. Vlachopoulos C, Aznaouridis K, O'Rourke MF, Safar ME, Baou K, Stefanadis C. Prediction of cardiovascular events and all-cause mortality with central haemodynamics: a systematic review and meta-analysis. Eur Heart J 2010;31:1865-1871

21. Gordin D, Waden J, Forsblom C, Thorn L, Rosengard-Barlund M, Tolonen N, Saraheimo M, Harjutsalo V, Groop PH. Pulse pressure predicts incident cardiovascular disease but not diabetic nephropathy in patients with type 1 diabetes (The FinnDiane Study). Diabetes Care 2011;34:886-891

22. Ronnback M, Fagerudd J, Forsblom C, Pettersson-Fernholm K, Reunanen A, Groop PH. Altered agerelated blood pressure pattern in type 1 diabetes. Circulation 2004;110:1076-1082

23. Wautier JL, Schmidt AM. Protein glycation: a firm link to endothelial cell dysfunction. Circ Res 2004;95:233-238

24. Aldington SJ, Kohner EM, Meuer S, Klein R, Sjolie AK. Methodology for retinal photography and assessment of diabetic retinopathy: the EURODIAB IDDM complications study. Diabetologia 1995;38:437-444

25. Yonekura H, Yamamoto Y, Sakurai S, Watanabe T, Yamamoto H. Roles of the receptor for advanced glycation endproducts in diabetes-induced vascular injury. J Pharmacol Sci 2005;97:305-311

26. Bierhaus A, Humpert PM, Morcos M, Wendt T, Chavakis T, Arnold B, Stern DM, Nawroth PP. Understanding RAGE, the receptor for advanced glycation end products. J Mol Med 2005;83:876-886

27. Kim J, Sohn E, Kim CS, Jo K, Kim JS. The role of high-mobility group box-1 protein in the development of diabetic nephropathy. Am J Nephrol 2011;33:524-529

28. Marincola FM. The trouble with translational medicine. J Intern Med 2011;270:123-127 
Samenvatting 


\section{Samenvatting}

Type 1-diabetes is een chronische ziekte, die zich gewoonlijk presenteert in de kindertijd of in de adolescentie. Type 1-diabetes wordt gekenmerkt door hoge glucosewaardes (hyperglykemie) en ontstaat door (auto-immuun) vernietiging van de insuline-producerende beta-cellen geclusterd in de eilandjes van Langerhans van de alvleesklier, wat resulteert in veelal een absoluut tekort aan insuline die dagelijkse insuline toediening noodzaakt. Symptomen veroorzaakt door hyperglykemie zijn onder meer polyurie, polydipsie, gewichtsverlies, verandering van gezichtsvermogen en vermoeidheid. Het aantal nieuwe ziektegevallen (incidentie) van type 1-diabetes bij kinderen varieert wereldwijd van 0,1/100.000 per jaar in Zunyi, China tot 36,8/100.000 per jaar in Sardinië, Italië. In Nederland wordt de incidentie van type 1-diabetes geschat op 13/100.000 per jaar bij kinderen $\leq 14$ jaar. De incidentie van type 1-diabetes lijkt toe te nemen in alle leeftijdsgroepen, met name bij jongere kinderen, met een totale jaarlijkse stijging van $\sim 3,9 \%$ geschat op basis van 20 populatie-gebaseerde registers in 17 Europese landen in de periode 1989-2003. De redenen voor deze toenemende incidentie zijn onbekend, maar waarschijnlijk spelen omgevingsfactoren een rol hierin. Ondanks uitgebreid wetenschappelijk onderzoek, kan type 1-diabetes niet worden voorkomen of genezen met de huidige beschikbare behandelingen, zoals immunotherapie, stamceltherapie of transplantatie van eilandjes van Langerhans.

Wereldwijd zijn er 22 miljoen patiënten met type 1-diabetes en dit zal naar verwachting verdubbelen in de komende 20-30 jaar. In Nederland wordt het huidige voorkomen (prevalentie) van type 1-diabetes geschat op 100.000. De last van diabetes voor zowel patiënten als voor onze maatschappij wordt voornamelijk veroorzaakt door diabetes-gerelateerde korte en lange termijn complicaties, geïllustreerd door een 4-voudige toename in het risico op hart- en vaatziekten (HVZ) bij type 1-diabetes, en een $\sim 7$-voudige en $\sim 17$-voudige toename van het risico op sterfte aan HVZ bij respectievelijk mannen en vrouwen, die type 1-diabetes hadden en jonger dan 40 jaar waren, vergeleken met mensen zonder diabetes. Daarnaast leiden diabetesgerelateerde microvasculaire complicaties (bijvoorbeeld diabetische retinopathie en nefropathie) tot een vermindering van visus en nierfunctie, die een hogere morbiditeit met zich meebrengen bij patiënten met type 1-diabetes.

De toenemende prevalentie van type 1-diabetes en de bijbehorende vasculaire complicaties vormen een enorme last voor de patiënten en voor onze samenleving, maar de cellulaire en moleculaire mechanismen die ten grondslag liggen aan het ontstaan van deze vasculaire complicaties zijn nog steeds niet volledig opgehelderd. Voor de preventie en/of de behandeling van deze diabetes-gerelateerde complicaties, moeten we een beter begrip verkrijgen van de mogelijk onderliggende mechanismen. Verschillende mechanismen zijn geopperd om de link tussen diabetes en het verhoogde risico op HVZ bij deze patiënten te verklaren. We hebben ons gericht op de potentiële rol van geavanceerde glycerings eindproducten (AGEs) en hun receptor 
(RAGE), high-mobility group box-1 (HMGB1), endotheel- en nierfunctiestoornissen, laaggradige ontsteking, en arteriële stijfheid (gemeten als verhoogde polsdruk).

\section{Resultaten}

In de EURODIAB nested case-control studie hebben we geobserveerd dat hogere waardes van het in plasma circulerende RAGE (sRAGE), als een weerspiegeling van hogere waardes van RAGE, cross-sectioneel geassocieerd zijn met een hogere prevalentie van HVZ in patiënten met type 1-diabetes (hoofdstuk 2). De sterkte van deze associatie neemt met $\sim 50 \%$ af wanneer wij de rol van endotheel- en nierdisfunctie en laaggradige ontsteking in het model opnemen, hetgeen suggereert dat deze mechanismen mogelijk de link kunnen vormen tussen hogere waardes van SRAGE, als een reflectie van RAGE, en de hogere prevalentie van HVZ in patiënten met type 1-diabetes. Positieve trends werden ook gevonden tussen hogere waardes van SRAGE en de aanwezigheid als ook de mate van ernst van albuminurie en retinopathie, maar deze waren niet onafhankelijk van de traditionele risicofactoren van HVZ. Om meer inzicht te krijgen in de temporele relatie tussen SRAGE en vasculaire complicaties bij type 1-diabetes, onderzochten we de associatie tussen plasma sRAGE waardes en de incidentie van fatale en niet-fatale gevallen van HVZ evenals de totale sterftegevallen in een studie waarin we de patiënten 12 jaar hebben gevolgd (hoofdstuk 3). Incidentie van fatale en niet-fatale HVZ alsook totale mortaliteit verdubbelde ongeveer per eenheid hogere waarde van plasma SRAGE, welke is gemeten aan het begin van de studie. Nierdisfunctie, geschat door glomerulaire filtratiesnelheid, zou hierbij voor een deel (tot $\sim 25 \%$ ) de positieve associatie tussen plasma SRAGE en incidentie van fatale en niet-fatale HVZ kunnen verklaren. Daarnaast toonden we aan dat hogere waardes van plasma sRAGE gemeten bij aanvang van de studie geassocieerd waren met sterkere daling van de glomerulaire filtratiesnelheid gemeten in de loop van de studie (hoofdstuk 3), welke de hypothese ondersteunt dat nierfunctiestoornis een intermediaire rol kan spelen in de associatie tussen SRAGE en HVZ in deze patiënten.

We hebben drie AGEs ( $C E L, C M L$, en pentosidine) gemeten, die ongunstige effecten op de celfuncties zouden kunnen uitoefenen door (gedeeltelijk) verschillende mechanismen, en samen, zouden deze drie dus een breed scala van de mogelijke schadelijke effecten van AGEs kunnen weerspiegelen. In een 12 jaar follow-up studie in patiënten met type 1-diabetes, observeerden we een $\sim 30 \%$ toename in incidentie van fatale en niet-fatale HVZ alsook totale mortaliteit per 1 eenheid hogere AGEs score (berekend als het gemiddelde van de z-scores van CEL, CML, en pentosidine) en deze associatie was onafhankelijk van andere HVZ risicofactoren (hoofdstuk 4).

Om verder de rol van de RAGE-as te verhelderen, hebben we ook onderzoek gedaan naar HMGB1, een pro-inflammatoir cytokine die een rol speelt bij ontsteking als deel van ons afweersysteem, maar ook een substraat die zich aan RAGE kan binden en kan activeren. We onderzochten de associaties tussen HMGB1 en de prevalentie 
en incidentie van vasculaire complicaties bij type 1-diabetes. We observeerden een cross-sectionele associatie tussen hogere serumspiegels van HMGB1 en de aanwezigheid en de ernst van albuminurie, maar niet met retinopathie of HVZ (hoofdstuk 5). Dit suggereert dat serum HMGB1 op andere manieren betrokken kan zijn in de mechanismen die leiden tot micro- en macrovasculaire complicaties, welke ten dele verklaard zouden kunnen worden door het feit dat HMGB1 kan binden aan verschillende receptoren met verschillende functies. We kunnen echter niet voorbijgaan aan de mogelijkheid dat het ontbreken van een associatie tussen serum HMGB1 en prevalentie van HVZ te wijten was aan toeval. Aangezien wij in de prospectieve studie in patiënten met type 1-diabetes wel een associatie observeerden, waarbij hogere waardes van plasma HMGB1 geassocieerd waren met een hogere incidentie van totale mortaliteit (hoofdstuk 6 ) en, in een minder sterke mate, ook met hogere incidentie van fatale en niet-fatale HVZ. Deze associaties waren onafhankelijk van conventionele HVZ risicofactoren en verschillende potentiële HMGB1 gerelateerde pathofysiologische mechanismen.

In een poging om de associaties tussen laaggradige ontsteking (gerepresenteerd door C-reactive protein, CRP), cross-linking AGEs (gerepresenteerd door pentosidine), en arteriële stijfheid onderling alsmede hun associaties met de incidentie van fatale en niet-fatale HVZ op te helderen (hoofdstuk 7), observeerden we in patiënten met type 1-diabetes, dat arteriële stijfheid, gerepresenteerd door polsdruk, gedeeltelijk het hogere risico op HVZ gerelateerd aan hogere pentosidinewaardes (marker van cross-linking AGEs) kon verklaren. Cross-link brekers kunnen daardoor een middel vormen om arteriële verstijving en de daaraan gerelateerde HVZ in deze patiënten verminderen. Daarnaast gingen hogere polsdrukwaardes samen met hogere CRP waardes, waarbij ze wederzijds hun associatie met een hogere incidentie van HVZ deels konden verklaren. Belangrijk daarbij is dat zowel hogere waardes van polsdruk als CRP onafhankelijk van elkaar geassocieerd bleven met hogere incidentie van HVZ en de combinatie van hoge polsdruk met hoog CRP het risico op HVZ vergrootte boven het te verwachten risico van wanneer men hun afzonderlijk effecten bijelkaar zou optellen. Dit suggereert dat arteriële stijfheid en laaggradige ontsteking causaal samenhangen en tevens dat er elkaar onderling versterkende mechanismen betrokken zijn bij het ontstaan van HVZ in type 1-diabetes. Zowel arteriële stijfheid als laaggradige ontsteking dienen dus afzonderlijk gemonitord en behandeld te worden om deze vicieuze cirkel te onderbreken en daarmee de cardiovasculaire complicaties die vaak in deze patiënten optreden te verminderen.

In hoofdstuk 8 worden de belangrijkste bevindingen van dit proefschrift samengevat en bediscussieerd. Ondanks meerdere beperkingen, zijn de bevindingen in onze studies van additionele waarde boven de bestaande kennis vanuit voornamelijk dierproeven en brengen deze observaties ons een stap dichter bij het ophelderen van de relevantie van de onderzochte pathofysiologische mechanismen ter verklaring van het hogere risico op vasculaire complicaties geassocieerd met type 1-diabetes. Daarnaast hebben we geprobeerd niet uitsluitend de mogelijke associaties 
tussen determinanten en uitkomsten te benoemen, maar ook om inzicht te verschaffen in de potentiële onderliggende mechanismen als link tussen determinant en uitkomst. 
Dankwoord 


\section{Dankwoord}

En nu dan het allerlaatste stuk tekst van mijn boekje en tevens waarschijnlijk ook het meest gelezen stuk. Het begin van mijn promotietraject viel me zwaar, vooral door de sterke verandering in werkstructuur van patiëntenzorg naar computerwerk. Maar geleidelijk kon ik de nieuwe werksfeer waarderen en uiteindelijk heb ik een hele gezellige, maar vooral ook leerzame tijd gehad. Nu is dan het moment gekomen om de vele mensen die hieraan hebben bijgedragen te bedanken.

Dear Isabel, thank you for all your efforts taken to guide me through the wilderness of epidemiology and statistics. Without being corny, I have to say that I have learned a lot from you and without you this thesis would have been impossible for me to finish (at least not in time). In the past four years there have been hard times, times when I was close to tears, and for those moments I am grateful for your listening ear and your mental support. Hopefully there will be more opportunities in the future to work with/learn from you.

Uiteraard wil ik ook mijn promotores, Prof. dr. CDA Stehouwer en Prof. dr. CG Schalkwijk, bedanken voor hun bijdrage en steun. Beste Coen, ten eerste moet ik je bedanken voor de kans die je me hebt gegeven om meer inzicht te krijgen in wetenschappelijk onderzoek en vooral in epidemiologie. Zonder jouw overtuigende woorden was ik nooit aan epidemiologisch onderzoek begonnen. Na de afgelopen jaren kan ik zelfs zeggen dat ik epidemiologie best leuk ben gaan vinden. Daarnaast wil ik je graag bedanken voor alle nuttige opmerkingen die hebben geleid tot verdere diepgang van de papers. Als laatste wil ik ook mijn dank uiten voor je snelle reacties. Beste Casper, om te beginnen bedankt voor de mogelijkheid om in deze leuke onderzoeksgroep te mogen werken. Daarnaast bedankt voor je laagdrempeligheid voor vragen stellen, je ontvangst in de vorm van een glimlach, je enthousiaste opstelling én de geweldige BBQs.

Prof. dr. MH Prins. Beste Martin, helaas dat je uiteindelijk niet mijn promotor kon zijn. We hebben elkaar niet veel gesproken, maar ik ben je dankbaar voor je positieve houding en al je geboden hulp.

De beoordelingscommissie Prof. dr. CP van Schayck, Prof. dr. JM Dekker, Prof. dr. Buurman en Prof. dr. NC Schaper wil ik graag bedanken voor de tijd die jullie hebben besteed aan het beoordelen van mijn proefschrift. Dear Prof. dr. A. Bierhaus, thank you very much for willing to be a member of the committee.

Dear Prof. dr. Chaturvedi and Prof. dr. Fuller, thank you very much for the opportunity to use the data from the EURODIAB prospective complication study. I 
would also like to thank you for your support and thoughtful comments when reviewing the manuscripts that led to chapters 2 and 5.

Dear Prof. dr. P Rossing, Prof. dr. L Tarnow, Prof. dr. H-H Parving and Anders Jorsal, I am very pleased that I could use the data from the LEACE study. I would like to thank you for the fruitful collaboration between our departments. I would also like to thank you for your support and valuable comments during the review processes of the manuscripts that led to chapters 3, 4, 6 and 7.

Mijn paranimfen, mijn kamergenootjes en mijn collega's. Beste Lian en Roel, een groot deel van de gezelligheid is zeker aan jullie te danken! Maar de wederzijdse aanmoedigingen, steun en hulp hebben zeker ook bijgedragen aan het succesvolle wetenschappelijke deel van mijn promotietraject. Helemaal geweldig dat jullie ook tijdens de verdediging achter me willen staan! Toch wel een beetje jammer, dat we niet alledrie tegelijkertijd op één dag kunnen promoveren, maar ach... nu hebben we drie afzonderlijke gelegenheden om te feesten. Lieve Lian, nog even de laatste loodjes (en ja, die zijn behoorlijk zwaar), maar dat gaat jou zeker lukken! En misschien heb jij inmiddels ook een datum geprikt als dit boekje is gedrukt. Wie weet kunnen we in de toekomst weer samenwerken (danwel dat ik bij je aanklop om raad, denk je aan die chaise longue... ^^^). Beste Roel, bij jou komt het vast en zeker allemaal wel goed. Jouw gedrevenheid en doorzettingsvermogen zullen jou nog ver brengen. Uiteraard hartstikke leuk dat we nog wel even collega's zullen blijven.

Beste mede-AIOs (en ex-AIOs). Elisabeth, Hanneke, José, Katrien, Marcelle, Marjon, Rianne, Bas, Barry, Dennis, Martijn, Nick, Nordin, Olaf, Steven, Thomas en Yvo. Bedankt voor de nuttige discussies, alle gezelligheid en gekheid. Ik wens jullie allen nog veel succes met jullie verdere (wetenschappelijke) carrière.

Katrien, Petra, Olaf en Ronald, graag wil ik jullie ook uitdrukkelijk bedanken voor de geboden hulp bij de administratieve zaken rondom het boekje. Als ik het zelf allemaal had moeten uitzoeken in die laaste weken waren allerlei brieven en bestanden nooit op tijd op hun bestemming aangekomen.

En niet te vergeten, Jean, Marjo en Vicky, bedankt voor de vele metingen die jullie voor me hebben gedaan en de uitleg die jullie me hebben gegeven. Beste Jean, ik wil je ook graag bedanken voor de computer-technische ondersteuning van de afgelopen jaren en voor de mooie foto's van de bruiloft.

Ook alle andere collega's en ex-collega's Carla, Dany, Joséphine, Margee en Marleen wil ik graag bedanken voor hun bijdrage en prettige samenwerking. 
Verder wil ik ook familie, vrienden en kennissen bedanken, die hun interesse en belangstelling hebben getoond in mijn promotie-onderzoek.

Lieve papa en mama, ondanks dat jullie nooit hebben begrepen waarom ik promotie-onderzoek ben gaan doen of überhaupt waar het onderzoek over ging, hebben jullie me gesteund in mijn beslissing. En ja, nu is het boekje af, maar ben ik weer aan een andere opleiding begonnen. Het is altijd erg verwarrend voor jullie geweest, omdat ik altijd 'student' ben gebleven voor jullie opvattingen. Maar wees gerust, eens zal ik écht gaan werken ${ }^{\wedge} \_\wedge$ Beste Jan, bedankt voor je belangstelling in de afgelopen jaren en al die lekkere chocolaatjes. En voor 'de andere eeuwige student in onze familie', alles komt goed ${ }^{\wedge}{ }^{\wedge}$

En dan... als laatste... Lieve Paul, bedankt voor al je begrip die je hebt getoond voor mijn drukke leven, voor het niet beschikbaar zijn op minstens één dag van het weekeinde, voor het niet meegaan naar (familie)feestjes, voor het 'moeten' werken tijdens vakanties en zelfs tijdens onze huwelijksreis, voor het geen tijd hebben voor huishoudelijk werk en nog voor zo veel andere zaken. Nooit heb je geklaagd over mijn eeuwige excuus van werken. Je bent zelfs voor mij en mijn werk naar Roermond verhuisd en gelukkig heb jij je draai uiteindelijk kunnen vinden hier in Limburg. Naast alle leuke momenten hebben we ook moeilijke momenten samen gehad. Ik ben blij dat we elkaar hebben kunnen steunen tijdens die zwaardere tijden en dat we elkaar daardoor nog meer zijn gaan waarderen. Hopelijk gaat het me lukken in de toekomst wel meer tijd voor je vrij te maken.

Johanna 
Curriculum vitae 


\section{Curriculum vitae}

Johanna Wai Man Nin werd op 2 november 1980 geboren te Roermond. Na het bepalen van haar VWO diploma aan het Bisschoppelijk College Broekhin te Roermond begon ze aan haar studie Geneeskunde aan de Universiteit van Maastricht, waar zij in 2005 haar artsexamen (cum laude) behaalde. Van oktober 2005 tot september 2007 is zij werkzaam geweest als arts-assistent Interne Geneeskunde niet in opleiding bij het Reinier de Graaf Gasthuis te Delft. In september 2007 startte zij als PhD student met haar promotietraject bij de afdeling Interne Geneeskunde van Universiteit Maastricht onder de supervisie van promotores Prof. dr. C.D.A. Stehouwer en Prof. dr. C.G. Schalkwijk en copromotor Dr. I. Ferreira. Het project was een samenwerking tussen de twee onderzoeksinstituten CAPHRI en CARIM.

Sinds oktober 2011 is zij werkzaam als assistent in opleiding tot internist in het Maastricht University Medical Centre $\left(\mathrm{MUMC}^{+}\right)$met als opleider Prof. dr. C.D.A. Stehouwer en plaatsvervangend opleider Prof. dr. R.P. Koopmans. 
Abbreviations 


\section{Abbreviations}

\begin{tabular}{|c|c|}
\hline ADAM10 & A disintegrin and metalloprotease 10 \\
\hline AGEs & Advanced glycation endproducts \\
\hline$\beta$ & Regression coefficient \\
\hline BMI & Body mass index \\
\hline CEL & Ne-(carboxyethyl)lysine \\
\hline $\mathrm{Cl}$ & Confidence interval \\
\hline CML & $\mathrm{N} \varepsilon$-(carboxymethyl)lysine \\
\hline CRP & C-reactive protein \\
\hline CV & Coefficient of variation \\
\hline CVD & Cardiovascular disease \\
\hline DBP & Diastolic blood pressure \\
\hline ED & Endothelial dysfunction \\
\hline eGFR & Estimated glomerular filtration rate \\
\hline ELISA & Enzyme-linked immunosorbent assays \\
\hline esRAGE & Endogenous secretory RAGE \\
\hline ESRD & End-stage renal disease \\
\hline HDL & High density lipoprotein \\
\hline HMGB-1 & High mobility group box 1 \\
\hline HPLC & High performance liquid chromatography \\
\hline HR & Hazard ratio \\
\hline IHD & Ischaemic heart disease \\
\hline IL-6 & Interleukin 6 \\
\hline LDL & Low density lipoprotein \\
\hline LGI & Low-grade inflammation \\
\hline MAP & Mean arterial pressure \\
\hline MDRD & Modification of Diet in Renal Disease \\
\hline MS & Mass spectrometry \\
\hline NFkB & Nuclear factor-kB \\
\hline PAD & Peripheral arterial disease \\
\hline PP & Pulse pressure \\
\hline RAAS & Renin-angiotensin-aldosterone system \\
\hline RAGE & Receptor for AGEs \\
\hline SBP & Systolic blood pressure \\
\hline SD & Standard deviation \\
\hline SE & Standard error \\
\hline sICAM-1 & Soluble intercellular adhesion molecule-1 \\
\hline sPLA2 & Secreted phospholipase A2 \\
\hline sRAGE & Soluble RAGE \\
\hline sVCAM-1 & Soluble vascular cell adhesion molecule \\
\hline TGF- $\beta$ & Transforming growth factor- $\beta$ \\
\hline TLR & Toll-like receptor \\
\hline TNF-a & Tumour necrosis factor-a \\
\hline UAE & urinary albumin excretion \\
\hline
\end{tabular}


